\title{
Seismological Aspects of the 1976 Eruptions of Augustine Volcano, Alaska
}

\section{U.S. GEOLOGICAL SURVEY BULLETIN 1768}

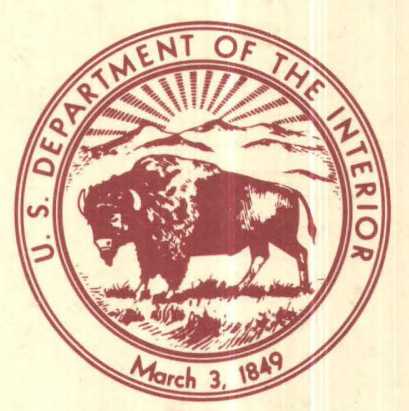


Seismological Aspects of the 1976 Eruptions of Augustine Volcano, Alaska

By JOHN W. REEDER and JOHN C. LAHR 


\title{
DEPARTMENT OF THE INTERIOR DONALD PAUL HODEL, Secretary
}

\author{
U.S. GEOLOGICAL SURVEY
}

Dallas L. Peck, Director

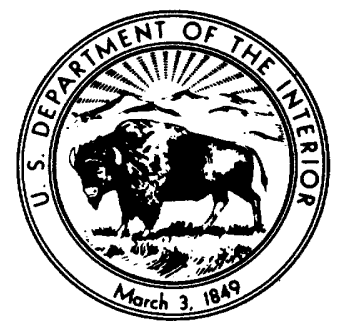

For sale by the

Books and Open-File Reports Section

U.S. Geological Survey

Federal Center, Box 25425

Denver, CO 80225

Library of Congress Cataloging-in-Publication Data

Reeder, John W.

Seismological aspects of the 1976 eruptions of Augustine volcano, Alaska.

U.S. Geological Survey Bulletin 1768

Bibliography

Supt. of Docs. No.: I 19.3:1768

1. Seismology-Alaska-Augustine volcano (Augustine Island). 2. Augustirie volcano (Augustine Island, Alaska). I.

Lahr, John C. II. Title. III. U.S. Geological Survey Bulletin 1768.

QE75.B9 No. 1768

[QE535.2.U6]

$557.3 \mathrm{~s}$

87-600041 [551.2'1'097983] 


\title{
CONTENTS
}

\author{
Abstract 1 \\ Introduction $\mathbf{1}$ \\ Seismic documentation 2 \\ Types of seismic signals $\mathbf{2}$ \\ Shallow earthquakes 3 \\ Volcanic tremor 6 \\ Large tremor (large-amplitude volcanic tremor) 7 \\ Small tremor (small-amplitude volcanic tremor) 8 \\ Some correlations and correlation problems between observed \\ eruptive activity and volcanic tremor $\mathbf{9}$ \\ Eruption-induced air-phase signals $\mathbf{1 1}$ \\ Seismic time sequence 12 \\ The January eruptive sequence 16 \\ The February eruptive sequence 21 \\ The April eruptive sequence $\mathbf{2 1}$ \\ Seismic data interpretations 21 \\ Source mechanisms for the eruptions $\mathbf{2 1}$ \\ Earthquake frequency-to-magnitude relationships 23 \\ Correlations between shallow earthquakes and explosive activity 27 \\ The air-phase mechanism 28 \\ Seismic-geologic correlation 29 \\ Conclusions $\mathbf{3 0}$ \\ References cited $\mathbf{3 0}$
}

\section{FIGURES}

1. Map showing the Cook Inlet segment of the regional USGS and NOAA seismograph network 2

2. Seismogram of a typical Augustine shallow earthquake on December 21, 1975 , with $\mathrm{M}_{\mathrm{L}}=1.6 \quad 4$

3. Seismograms of moderately shallow Augustine earthquakes on December $29,1975\left(M_{L}=2.2\right)$, and on November $21,1975\left(M_{L}=1.6\right) 4$

4. Plot of $\mathbf{S}$ minus $\mathbf{P}$ arrival-time intervals at seismic station CKK versus calculated hypocenter depths for some of the larger 1975-76 preeruption shallow Augustine earthquakes $\mathbf{5}$

5. Hypocenters for some of the larger 1976 very shallow ear thquakes of Augustine volcano 6

6. Distribution of hypocenters for the 21:26 u.t. January 22, 1976, very shallow Augustine ear thquake due to the arrival times at all stations being randomly varied 7

7. Seismogram of initial part of January 22, 1976, Augustine eruption 7

8. Seismogram of a January 23, 1976, Augustine eruption 8

9. Photograph of Alaska taken at 20:05:07 u.t. on January 23, 1976, by NOAA-4 satellite 9

10. Seismogram of a January 23, 1976, Augustine eruption 11

11. Seismogram and photographs related to February 8-9, 1976, eruptive activity of Augustine volcano 12

12. Seismogram and photograph related to a February 13,1976 , very shallow Augustine earthquake that was followed by small tremor and an eruptive cloud $\mathbf{1 4}$

13. Photographs of Augustine volcano taken by University of Washington Cloud and Aerosol Physies Group at 23:05:06 u.t. and 23:54:08 u.t. on February 8, 1976 
14. Photograph and seismogram related to February 13,1976 , eruptive activity at Augustine volcano $\mathbf{1 5}$

15. Vertical photograph of summit and northeast flank of Augustine volcano at 03:22 u.t. on April 13, 197616

16. Seismogram showing seismic activity and eruption-induced air-phase signals of Augustine volcano on January 24, $1976 \quad 17$

17. Graph showing commencement, duration, and approximate traveltime of Augustine eruption-induced air-phase disturbances as recorded at sesimic stations NNL, NKA, SKL, and PWA from 20:00 u.t. January 23 through January 24, 1976, with respect to large tremors at Augustine volcano as recorded by CKK $\mathbf{1 8}$

18-20. Histograms showing:

18. Sequence of Augustine events between November 1, 1975, and Apri1 30, $1976 \quad 19$

19. Daily shallow-earthquake radiated energy for Augustine volcano between November 1, 1975, and April 30, 197620

20. Sequence of Augustine events between 00:00 u.t. January 22 and 12:00 u.t. January 26, 197621

21. Graph showing Augustine January peak-to-peak amplitudes of large tremor and local magnitudes of very shallow ear thquakes during January 22-25, 197622

22. Histograms showing sequence of Augustine events between 12:00 u.t. February 6 and 13:00 u.t. February 14, $1976 \quad 24$

23. Graphs showing Augustine peak-to-peak amplitudes of large tremor and local magnitudes of shallow earthquakes during February 6-9, 197625

24. Histograms showing sequence of Augustine events between 00:00 u.t. April 13 and 00:00 u.t. April 19, $1976 \quad 25$

25. Graphs showing interval and cumulative frequency distributions of magnitudes for the Augustine 1975-76 shallow earthquakes 26

26-28. Plots showing:

26. Correlations between radiated energy of very shallow Augustine earthquakes and Augustine volcanic tremor duration between 08:30 u.t. January 23 and 03:30 u.t. January 24, 197627

27. Correlations between very shallow Augustine earthquake radiated energy, moderately shallow Augustine earthquake radiated energy, and Augustine volcanic tremor duration between February 7 and February 14, 197628

28. Correlations between very shallow Augustine earthquake radiated energy and Augustine small-tremor duration between 08:00 u.t. Apri1 16 and 16:00 u.t. April 18, 197628

29. Plots of radio soundings of the atmosphere at Kodiak, King Salmon, and Anchorage for 12:00 u.t. January 23, 00:00 u.t. January 24, and 00:00 u.t. January $25 \quad 29$

\section{TABLES}

1. Crustal model used for determining hypocenter locations for Augustine shallow earthquakes 6

2. Arrival times, durations, and amplitudes of Augustine volcanic tremors at CKK, during January 1976, including arrival times of eruption-induced infrasonics at Fairbanks $\mathbf{1 0}$

3. Arrival times and durations of Augustine eruption-induced air-phase seismic signals at NNL, NKA, SKL, and PWA, including maximum amplitudes of the air-phase seismic signals at PWA 24

Any use of trade names is for descriptive purposes only and does not imply endorsement by the U.S. Geological Survey 


\title{
Seismological Aspects of the 1976 Eruptions of Augustine Volcano, Alaska
}

\author{
By John W. Reeder ${ }^{1}$ and John C. Lahr
}

\section{Abstract}

Data from seismograph stations operated by the U.S. Geological Survey and the National Oceanic and Atmospheric Administration Palmer Observatory around Cook Inlet, Alaska, have proved useful in studying various aspects of the 1976 Augustine volcano eruptions that commenced on January 22. Shallow earthquakes, volcanic tremor, and eruption-induced air-phase disturbances all accompanied the Augustine 1976 eruptive activity. These related seismic events, including their seismic time sequences, revealed information on (a) the source mechanisms of the eruptions, (b) the earthquake frequency-to-magnitude relationships, (c) the relationships between shallow earthquakes and volcanic tremor, (d) the eruptioninduced air-phase mechanism, and (e) the seismicgeologic relationships.

The first eruption of Augustine volcano in 1976 began at about 18:00 on January 22 . This pyroclastic eruption commenced with no obvious seismic warning except for some minor shallow-earthquake activity that had occurred since May 1975. This eruption was followed by a very large swarm of shallow earthquakes with local magnitudes of 2.5 or less. The swarm reached a peak of 90 recognizable earthquakes per hour and lasted for $13.5 \mathrm{~h}$. A series of 12 large ventclearing pyroclastic eruptions followed. In general, each eruption generated a gradually increasing and then gradually decreasing seismic signal at the closest station, which was $82 \mathrm{~km}$ from Augustine volcano. Such signals, observed at distances of up to $321 \mathrm{~km}$, are believed to result directly from tremor that was caused by the transport of gases, magma, and (or) rock through the volcano.

Disturbances following seven of the last eight large January eruptions and traveling about $0.3 \mathrm{~km} / \mathrm{s}$ were recorded by seismograph stations to the northeast at distances of up to $321 \mathrm{~km}$. These signals are interpreted as atmospheric pressure disturbances that were generated by northeast-directed explosions from the volcano and that were then transmitted by favorable atmospheric conditions. This intepretation is supported by the destruction during the January eruptions of the northeast part of the crater wall.

\footnotetext{
${ }^{1}$ Alaska Division of Geological and Geophysical Surveys, Anchorage, Alaska 99510
}

These blasts were carried across the total length of Cook Inlet and were best recorded at seismograph stations not topographically shielded from Augustine volcano and situated on glacial deposits.

The next series of eruptions, which began on February 6 , was smaller and occurred over eight days during the final part of the vent-clearing stage and then during the principal part of the dome-building stage of the volcano. This series was accompanied but not preceded by increased seismic activity. The final eruptive activity, which commenced on April 13 and lasted about six days, was less explosive and appeared to be associated with minor dome growth. No eruption-induced air-phase disturbances were detected for any of the February or April eruptions.

\section{INTRODUCTION}

Augustine volcano, an andesitic calc-alkaline volcano located in the Cook Inlet of south-central Alaska, erupted explosively on January 22, 1976. This volcanic activity, consisting mainly of a series of explosive vent-clearing pyroclastic eruptions that were accompanied by shallow-earthquake swarms, lasted four days. Explosive eruptions began again on February 6, and these eruptions were also accompanied by shallow earthquake swarms and lasted eight days. This second phase of eruptive activity was initially vent clearing, but the later eruptions of this phase were definitely associated with the extrusion of a new lava dome (Johnston, 1978). The final eruptions, which were less explosive and appeared to be associated with minor dome growth, commenced on April 13 and lasted about six days. Augustine volcano has also erupted in $1883,1935,1963 / 64$, and most recently in 1986 (Kienle and others, 1986). These other eruptions were also principally pyroclastic eruptions.

Seismic stations operated by the regional National Oceanic and Atmospheric Administration (NOAA) and the U.S. Geological Survey (USGS) recorded the 1976 eruptive activity of Augustine volcano. In order to gain insight into the nature of this volcanic activity, seismograms from stations that recorded the eruptions were analyzed.

Acknowledgments.-Special thanks are extended to J.L. Stith, L.F. Radke, D.A. Johnston, D.J. Lalla, and Juergen Kienle, who, through their own research 
efforts, have given valuable insight into the 1976 volcanic activity of Augustine volcano. Thanks are also given to George Thompson, F.W. Klein, and Elliot Endo, who provided very helpful and constructive reviews of this report, and to C.H. Cramer, who helped with the initial identification of the air-phase seismic signals.

\section{SEISMIC DOCUMENTATION}

The 1976 eruptions of Augustine volcano were recorded by the Cook Inlet segment of a regional USGS and NOAA seismograph network. The stations in the Cook Inlet region are shown in figure 1 . Two of the USGS stations, CKK and BIG, which are located $82 \mathrm{~km}$ northwest and $103 \mathrm{~km}$ west, respectively, of Augustine volcano, recorded the eruptive activity. The USGS seismograph stations NNL, ILM, RDT, NKA, and SKL, which are located $142 \mathrm{~km}, 97 \mathrm{~km}, 146 \mathrm{~km}, 197 \mathrm{~km}$, and $221 \mathrm{~km}$, respectively, from Augustine volcano, recorded only the larger events. The NOAA seismograph stations $\mathrm{KDC}$ and $\mathrm{PWA}$, which are located $185 \mathrm{~km}$ south-southeast and $321 \mathrm{~km}$ northeast, respectively, of Augustine volcano, also recorded some of the larger volcanic activity. All of these stations were functional throughout the eruptions despite adverse weather conditions and the remoteness of the region.

The University of Alaska local seismograph network, consisting of five stations on Augustine Island and three stations near Augustine Island on the mainland, went out of operation before the main

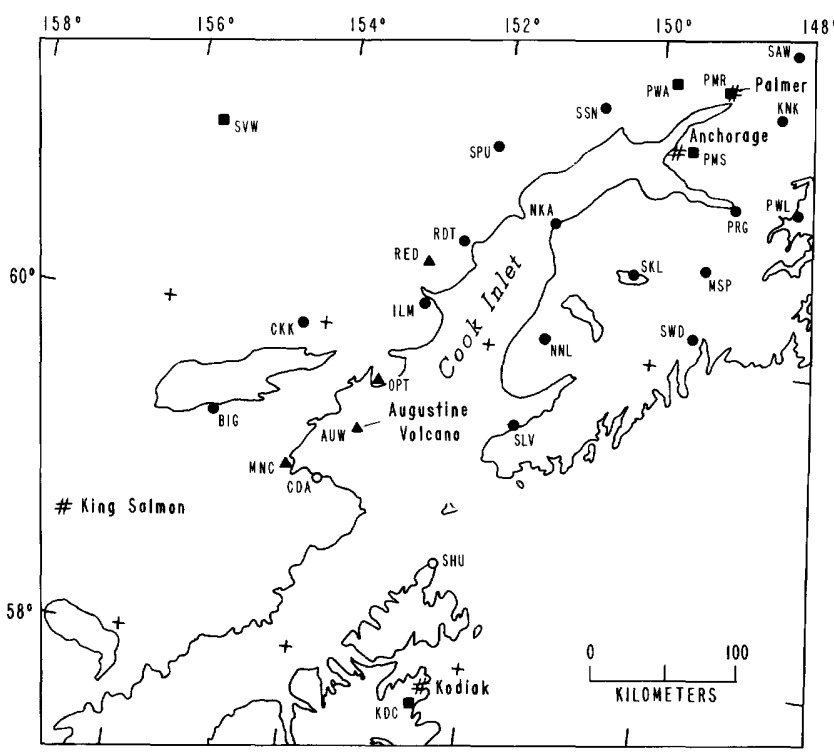

Figure 1. Index map of Cook Inlet region showing seismograph network. Symbols as follows: solid circles, USGS seismic stations; open circles, USGSUniversity of Alaska cooperative seismic stations; triangles, University of Alaska seismic station; squares, NOAA seismograph stations; \#, selected cities and towns.
January eruptive activity. Two of the Augustine Island stations failed on December 4 and 26, respectively, and the other stations on the island failed on January 2 , possibly due to mudflow activity (Kienle and Forbes, 1976) or to bad weather and electronic malfunctions (Johnston, 1978). Nevertheless, the University of Alaska seismograph network, originally established on Augustine Island in 1970, has documented earthquake activity prior to the 1976 eruptions (Mauk and Kienle, 1973; Lalla and Kienle, 1978; D. J. Lalla, oral and written commun., 1978; Lalla and Kienle, 1986). A new seismograph network was installed by the University of Alaska in time to record the April 13-18 volcanic activity. Although the University of Alaska data are being analyzed and published separately, some of the results from their efforts have been used to help interpret the regional USGS and NOAA network recordings of the Augustine eruptive activity.

Data from the USGS and NOAA seismograph stations were telemetered to a central recording point, the NOAA Palmer Observatory. The standard equipment for each USGS station included a vertical seismometer with a natural frequency of $1.0 \mathrm{~Hz}$ (Mark Products, Model L4), an amplifier, and a voltagecontrolled oscillator (USGS, Model J-202). The recording facility, operated by the NOAA Alaska Tsunami Warning Center, utilized a bank of discriminators (Develco, Model 6203), 16-mm film multichannel oscillographs (Geotech develccorder, Model 4000D), a time-code generator (Datatron, Model $3150-209-1$ ), and a radio receiver for WWV time signals (Specific Products, Model SR7R). The multichannel oscillograph photographically recorded 18 different seismic channels along with time marks on a single roll of film. This film was then analyzed by means of a Geotech Model 6585 film viewer. Time was based on universal time (u.t.) for the entire seismograph network. The response characteristics of the entire seismic system from seismometer to film viewer have been described by Lahr and others (1974).

\section{TYPES OF SEISMIC SIGNALS}

Seismic activity in volcanic regions has been classified according to the nature of the seismic signal and to the relationship of such signals to volcanic eruptions. A standard classification discussed by Shimozuru (1971) and Minakami (1974) recognizes:

(1) A-type earthquakes. These have shallow focal depths of between 1 and $10 \mathrm{~km}$, occur within $20 \mathrm{~km}$ of the volcanic vent, and show distinct $P$ and $S$ phases.

(2) B-type earthquakes. These have focal depths of less than $1 \mathrm{~km}$, are concentrated immediately beneath the eruptive crater, and do not show clear $\mathrm{P}$ or $\mathrm{S}$ phases.

(3) Explosion earthquakes. These have no clear $\mathbf{P}$ or $\mathrm{S}$ phases and are associated with explosive activity.

(4) Volcanic tremor. These are similar to B-type or explosion earthquakes, except that they are of long duration and are interpreted as being related to subsurface volcanic magma and (or) gas transport (Aki and Koyanagi, 1981). Such signals can last several minutes to continuous periods of time (Shimozuru and others, 1966; Kubotera, 1974; Koyanagi, 1982). 
A modified version of this well-known classification scheme was proposed by Latter (1981). In Latter's scheme, the term "volcano-tectonic earthquake" was proposed, which includes all earthquakes in the vicinity of a volcano that have the high-frequency appearance of the A-type earthquakes of Shimozuru and Minakami but are not necessarily greater than $1 \mathrm{~km}$ in depth. Latter also used the term "volcanic earthquakes," which includes B-type and explosion earthquakes as well as earthquakes that have the low-frequency appearance of B-type earthquakes but occur at depths greater than $1 \mathrm{~km}$.

Seismogram recordings are influenced by the sensing instrument, the hypocenter distance, the nature of the Earth's crust between the hypocenter and the sensing instrument, and the source mechanism. Unfortunately, in the case of the 1976 Augustine eruptions, the hypocenter distances to the recording stations were large, the nature of the Earth's crust between the hypocenter and the seismograph stations is still poorly understood, and the source mechanism for all practical purposes is still unknown. These factors make it difficult to apply the standard classifications, such as those discussed above, to the Augustine eruptions. A more simplified scheme was therefore used.

The USGS and NOAA seismograph stations recorded the following recognized types of seismic signals during the Augustine eruptions:

(1) Shallow earthquakes. These have fairly sharp onsets with well-defined phases, a frequency range of 3 to $10 \mathrm{~Hz}$ (with the dominant frequency being 4-6 Hz), and hypocenters not more than $40 \mathrm{~km}$ from Augustine volcano (normally within $20 \mathrm{~km}$ of Augustine volcano). This type of earthquake would be similar to Latter's volcano-tectonic earthquakes.

(2) Volcanic tremor. These have emergent onsets, have poorly defined phases where pulsating signals are not unusual, and have a frequency range of 0.4 to $8 \mathrm{~Hz}$ (with the dominant frequency being 2-7 $\mathrm{Hz}$ and the average frequency $4.5-5 \mathrm{~Hz}$ ). These signals can have a short duration like those of shallow earthquakes, and they would include Latter's volcanic earthquakes. They can also be of longer duration, where they would include Shimozuru and Minakami's and (or) Latter's volcanic tremor.

(3) Eruption-induced air-phase signals. These have emergent onsets, an overall equal rate of growth and decay (although pulsating signals are not unusual), a frequency range of 1 to $12 \mathrm{~Hz}$, and a velocity of about $0.3 \mathrm{~km} / \mathrm{s}$.

\section{Shallow Earthquakes}

The USGS seismograph stations CKK and BIG were used for determining the number and magnitude of Augustine Island shallow ear thquakes because the more distant seismograph stations were not as sensitive in detecting this activity. The time-interval range between $P$ and $S$ arrivals at $C K K$ and the time-interval range between $P$ arrivals at $C K K$ and $B I G$ were established from a review of the large earthquake swarm at Augustine Island of January 22 and 23, 1976, which preceded the main January eruption sequence. The $\mathrm{P}$ arrival time at $\mathrm{BIG}$ was found to range from 2.8 to $3.8 \mathrm{~s}$ after the $\mathrm{CKK} \mathrm{P}$ arrival time, and the $\mathrm{S}$ minus $P$ arrival-time interval at $\mathrm{CKK}$ was found to range from 10.0 to $12.0 \mathrm{~s}$. Because hundreds of these earthquakes were recorded during the beginning of the eruption, a fair degree of confidence was established in recognizing Augustine events as based on this criteria. These $\mathrm{P}$ and $\mathrm{S}$ arrival-time differences were used for the rest of the record as the criteria for determining whether or not recorded earthquakes were related to Augustine volcano.

A seismogram of a typical Augustine earthquake of December 21, 1975, is shown in figure 2. This particular event had an $\mathrm{S}$ minus $\mathrm{P}$ arrival-time interval of $11.3 \mathrm{~s}$ at CKK. The $P$ arrival at BIG was $3.3 \mathrm{~s}$ later than the $\mathrm{P}$ arrival at CKK. The frequency of the $\mathrm{P}$ wave at CKK was about $5 \mathrm{~Hz}$, and the maximum peakto-peak amplitude was $18.4 \mathrm{~mm}$. Based on the work of Doug Lalla at the University of Alaska (Lalla and Kienle, 1978; D.J. Lalla, oral and written commun., 1978), the hypocenter of this event was determined to lie beneath the summit of Augustine volcano at a depth of $0.6 \mathrm{~km}$ below sea level. Lalla's detailed results, which covered the October through December 1975 pre-eruption period, show that all of the earthquakes that fit the arrival-time requirements established for BIG and $\mathrm{CKK}$ and that had a P-wave frequency of about $5 \mathrm{~Hz}$ at CKK occurred near the summit of Augustine volcano at depths no greater than $1.1 \mathrm{~km}$ below sea level. A few earthquakes were detected that satisfied the Augustine arrival-time criteria on CKK and BIG and that had CKK frequencies higher than $5 \mathrm{~Hz}$. Lalla found that the hypocenters of such earthquakes were also shallow (that is, less than $1.1 \mathrm{~km}$ below sea level) and were located in the southeast region of the volcano.

During the February eruptions, numerous earthquakes were detected at CKK and BIG that deviated from the typical Augustine events. These earthquakes had a P-phase frequency usually as high as $10 \mathrm{~Hz}$ and an $\mathrm{S}$ minus $\mathrm{P}$ arrival-time interval at $\mathrm{CKK}$ of about $9.8 \mathrm{~s}$. At first, it was believed that they were not Augustine events. Similar events, such as the two shown in figure 3 , were also recognized by Lalla during the pre-eruption period of 1975. The event of December 29, 1975 (fig. 3A) was found by Lalla to have a hypocenter $3.8 \mathrm{~km}$ below sea level and $3 \mathrm{~km}$ northwest of the summit. This event had an $\mathrm{S}$ minus $\mathrm{P}$ arrival-time interval at CKK of $9.76 \mathrm{~s}$, a frequency of about $9 \mathrm{~Hz}$, an unusually large S-phase arrival, and a local magnitude $\mathrm{M}_{\mathrm{H}}$, as based on equation (2) below, of 2.2. The event of November 21, 1975 (fig. 3B), was found by Lalla to have a hypocenter $7.2 \mathrm{~km}$ below sea level and beneath the summit. This event had an $\mathrm{S}$ minus $P$ arrival-time interval at $C K K$ of $9.6 \mathrm{~s}$, a frequency of about $9 \mathrm{~Hz}$, and an $\mathrm{M}_{\mathrm{L}}$ of 1.6. Based on pre-eruption data from the University of Alaska seismograph network, Lalla found that the hypocenters of such events were located under Augustine Island at depths ranging from 1.4 to $16.4 \mathrm{~km}$ below sea level. Based on some of Lalla's more accurately located preeruption shallow earthquakes, a plot was constructed of the $\mathrm{S}$ minus $\mathrm{P}$ arrival-time intervals at $\mathrm{CKK}$ with respect to calculated depths (fig. 4). 
For this paper, the Augustine shallow earthquakes with $S$ minus $P$ arrival-time intervals of between 10.0 and $12.0 \mathrm{~s}$ (that is, probable hypocenter depths less than $1.1 \mathrm{~km}$ below sea level) are referred to as very shallow earthquakes. The Augustine earthquakes having $S$ minus $P$ arrival-time intervals of between 9.4 and $10.0 \mathrm{~s}$ (that is, probable hypocenter depths greater than $1.1 \mathrm{~km}$ but less than $20 \mathrm{~km}$ ) are referred to as moderately shallow earthquakes. Both categories of earthquakes are shallow earthquakes (that is, earthquakes having hypocenters of up to 20 $\mathrm{km}$ below sea level).
The Richter's local magnitude for these shallow earthquakes was calculated using the following formula (Lahr, 1980):

$M_{L}=\log _{10} \frac{(A)}{2 C}-B_{1}+B_{2} \log _{10}\left(D^{2}\right)-R_{k f}$,

where

A = maximum peak-to-peak earthquake amplitude in millimeters;

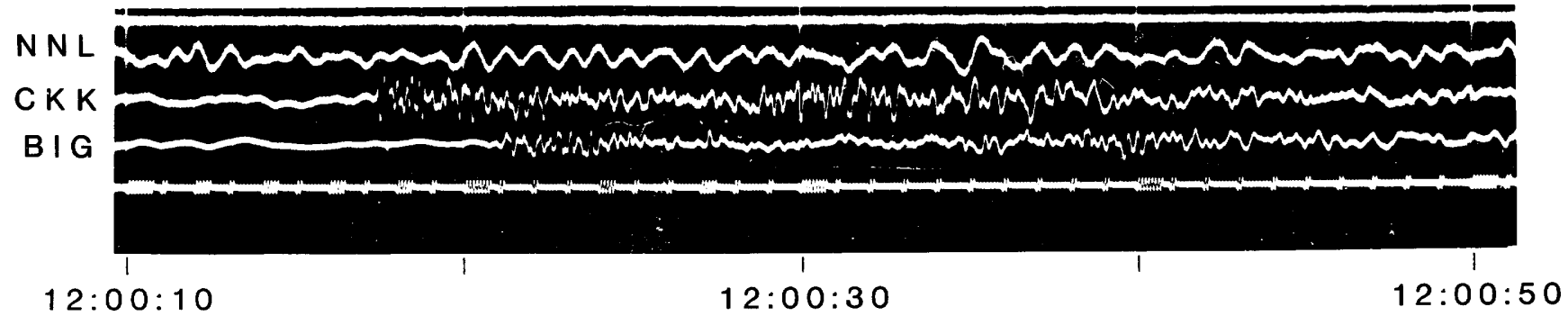

Figure 2. Seismogram of a typical Augustine shallow earthquake with $\mathrm{M}_{\mathrm{L}}=1.6$ as recorded at seismic stations NNL, CKK, and BIG on December 21, 1975. Hours, minutes, and seconds (12:00:30) given in universal time (u.t.).

(A)

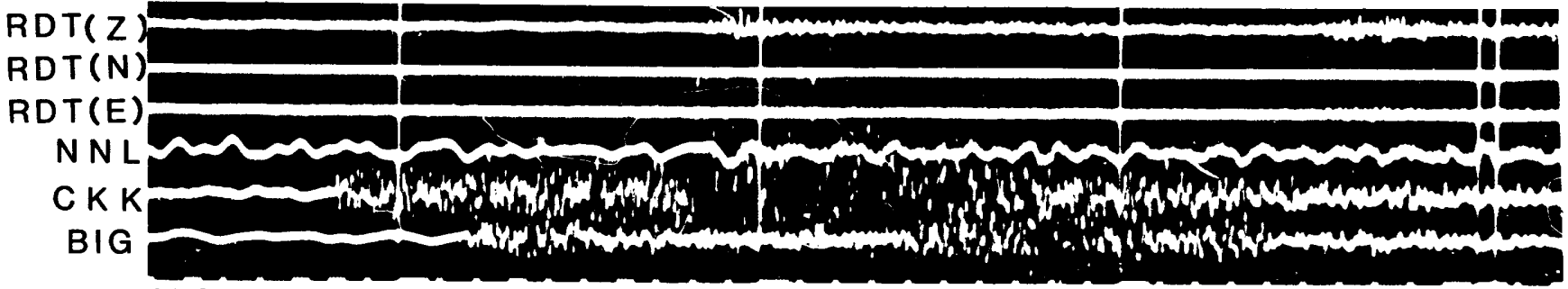

(B)
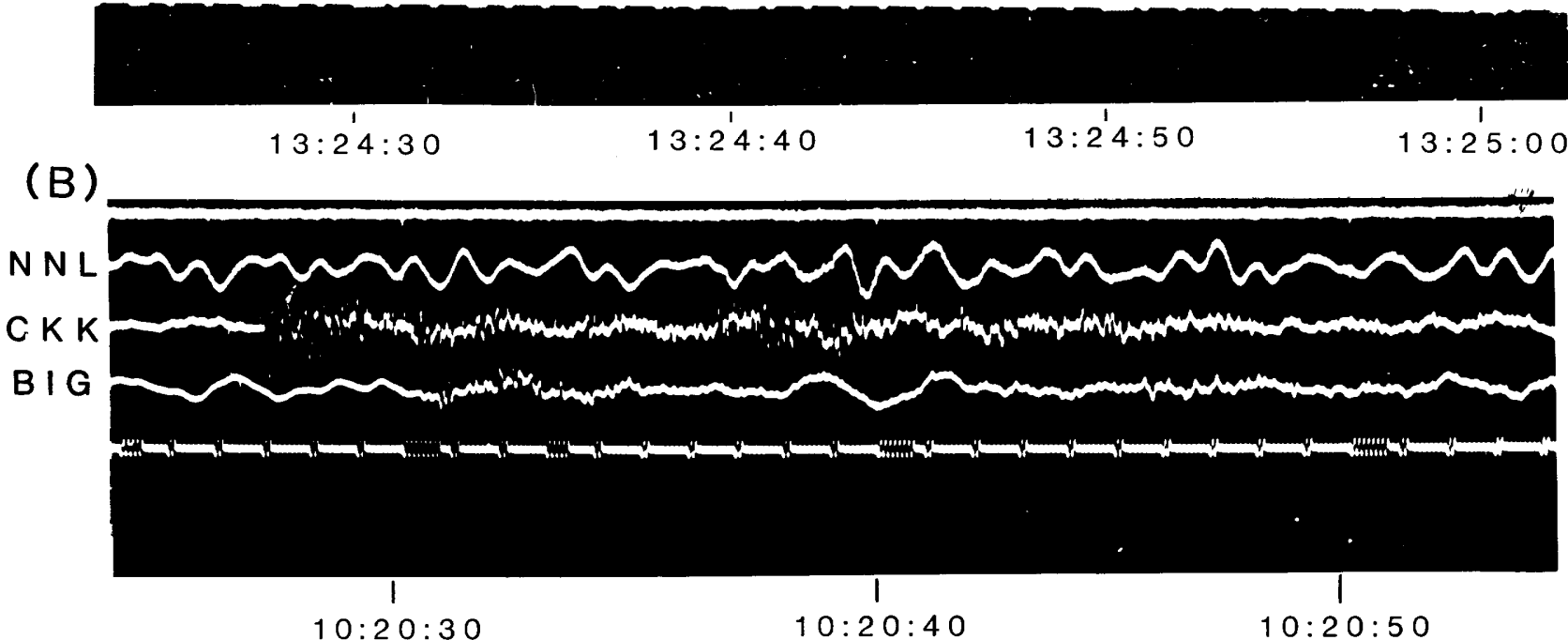

Figure 3. Seismograms of two moderately shallow Augustine earthquakes. A, Earthquake of December 29 , 1975 $\left(M_{L}=2.2\right)$. B, Earthquake of November $21,1975\left(M_{L}=1.6\right)$. Seismic stations denoted at left. 


\section{$\mathrm{C}=$ peak-to-peak amplitude in millimeters for a $10 \mu \mathrm{V} \mathrm{rms}$ (root mean square), $5-\mathrm{Hz}$ test voltage introduced at preamplifier input;}

$B_{1}=0.15$, for $1 \mathrm{~km} \leq \mathrm{D} \leq 200 \mathrm{~km}$;

$\mathrm{B}_{2}=0.80$, for $1 \mathrm{~km} \leq \mathrm{D} \leq 200 \mathrm{~km}$;

$D=\sqrt{X^{2}+z^{2}}$, where $X$ is the epicentral distance (about $82 \mathrm{~km}$ for $\mathrm{CKK}$ ), and $\mathrm{Z}$ is

and the focal depth in kilometers;

$R_{k f}=$ frequency response of system for frequency $f$.

Equation (1) reduces to

$$
M_{L}=\log _{10} \frac{(A)}{18.0}+2.9-1.3
$$

where $\mathrm{Z}$ is assumed to be zero, $R_{k f}$ is equal to 1.3 at a frequency of $5 \mathrm{~Hz}$, and $\mathrm{C}$ equals 9 (D.J. Lalla, oral and written commun., 1978). Based on equation (2), the calculated $M$ value for the December 21, 1975, Augustine ear thquake is $\mathbf{1 . 6}$.

The earthquake-radiated energy $E$ (in ergs) for these shallow earthquakes was calculated using the following empirical relationship (Richter, 1958):

$$
\log _{10} E=9.9+1.9 \mathrm{M}_{\mathrm{L}}-0.024 \mathrm{M}_{\mathrm{L}}{ }^{2} \text {. }
$$

Based on equation (3), the calculated radiated energy for the Decemper 21, 1975, Augustine earthquake is about $7.8 \times 10^{12}$ ergs.

The larger Augustine shallow earthquakes were located using the HYPOELLIPSE computer program as described by Lahr (1980). Initially, the P-wave horizontally layered velocity model developed by Matumoto and Page (1969) for the eastern Kenai Peninsula and the Prince William Sound region was considered for locating these earthquakes. Seismic

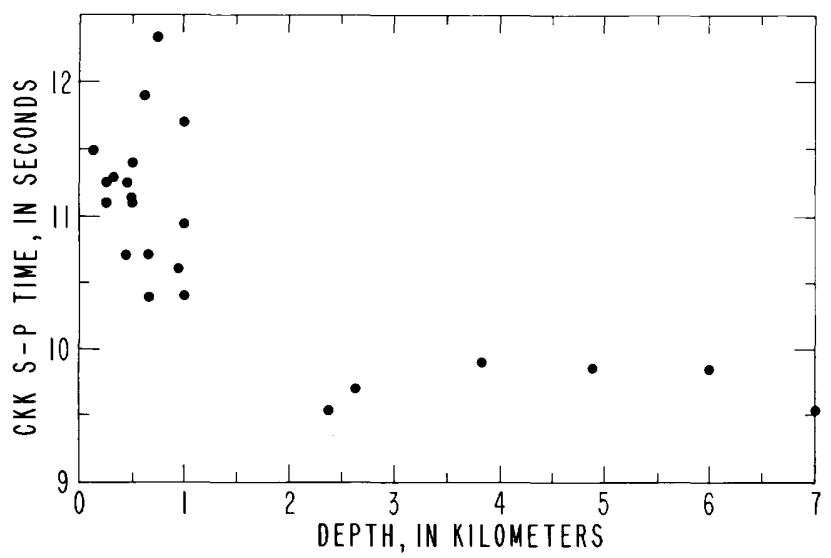

Figure 4. $S$ minus $P$ arrival-time intervals at seismic station CKK versus calculated hypocenter depths for some of the larger 1975-76 pre-eruption shallow Augustine earthquakes (D.J. Lalla, written commun., 1978). refraction work by Pearson and Kienle (1978) suggested a cylindrical model for Augustine that consisted of a $2.25-2.6 \mathrm{~km} / \mathrm{s}$ core flanked by pyroclastic material having velocities as low as 1.2 $\mathrm{km} / \mathrm{s}$. A velocity of $2.7 \mathrm{~km} / \mathrm{s}$ was determined by Pearson and Kienle immediately beneath the volcano to a depth of about $0.9 \mathrm{~km}$ below sea level. The Matumoto and Page regional model is a poor representation of the shallow velocity structure of the Augustine volcano region. For this reason, the model was abandoned and a horizontally layered model developed by the University of Alaska (J. Kienle, oral. commun., 1977) was adopted with modification (table 1). A value of 1.78 for the ratio between $P$ and $S$ velocity was assumed for the entire model. Considering the P-velocity data base, this model represents the best horizontally layered model for the Augustine volcano region. Although any model that is composed of uniform horizontal layers is a poor representation of the actual velocity structure of the immediate Augustine volcano region (Mitronovas and Isacks, 1971; Lahr, 1975; Pearson and Kienle, 1978), such models do have the advantage of simplifying the computation of traveltimes. It was found by using HYPOELLIPSE and the above model that the hypocenter locations for the main earthquake swarm of January were fairly scattered, with most events located northwest of Augustine Island and at depths as great as $60 \mathrm{~km}$.

To better locate Augustine events with the horizontally layered crustal model given in table 1 , station $\mathrm{P}$-wave delays were assigned by using a welllocated earthquake event as a master event. The preeruption Augustine shock of 08:51 November 19, 1975, which was located by the University of Alaska seismograph network, was chosen as the master event. Station delays of $-0.13 \mathrm{~s},+0.56 \mathrm{~s},-0.38 \mathrm{~s},+1.04$ $\mathrm{s},+0.37 \mathrm{~s},+1.36 \mathrm{~s},+0.10 \mathrm{~s}$, and $+0.39 \mathrm{~s}$ were assigned to $\mathrm{CKK}, \mathrm{BIG}$, ILM, NNL, RDT, NKA, SKL, and SPU, respectively, in order to reduce the $\mathrm{P}$-phase residuals for this master event to zero.

The horizontal P-velocity model (table 1), with incorporated station delays, was used with the HYPOELLIPSE computer program to calculate hypocenter locations for the Augustine earthquake events. The calculated hypocenters for the January, February, and April eruption periods are shown in figure 5. The calculated hypocenter locations for the February events were less scattered than those for the January events. This is because three of the University of Alaska seismograph stations on the mainland (that is, OPT, CDA, and $\mathrm{MNC}$ ) were included in determining the February hypocenter locations. The April earthquake hypocenter determinations, which also included readings from one of the University of Alaska seismograph stations located on Augustine Island, showed the least amount of scatter.

The northwest trend in the epicenter locations for the January eruptive period was originally thought to correspond to the principal horizontal tectonic stress orientation, which should be about N. 30, W. for Augustine Island (Nakamura and others, 1977). Because of the poor quality of the epicenter data, a statistical approach was undertaken for a typical very shallow earthquake where the arrival times at every station were allowed to vary randomly with a standard 
Table 1. Crustal model used for determining hypocenter locations for Augustine shallow earthquakes

\begin{tabular}{rcrr}
\hline $\begin{array}{l}\text { Layer } \\
(\mathrm{km})\end{array}$ & $\begin{array}{c}\text { Velocity } \\
(\mathrm{km} / \mathrm{s})\end{array}$ & $\begin{array}{c}\text { Depth } \\
(\mathrm{km})\end{array}$ & $\begin{array}{c}\text { Thickness } \\
(\mathrm{km})\end{array}$ \\
\hline 1 & 3.40 & 0.0 & 0.9 \\
2 & 5.10 & .9 & 5.1 \\
3 & 5.40 & 6.0 & 5.6 \\
4 & 6.60 & 11.6 & 30.0 \\
5 & 8.06 & 41.6 & 18.4 \\
6 & 8.09 & 60.0 & 20.0 \\
7 & 8.11 & 80.0 & 20.0 \\
8 & 8.14 & 100.0 & 50.0 \\
9 & 8.27 & 150.0 & 50.0 \\
10 & 8.41 & 200.0 & 50.0 \\
11 & 8.59 & 250.0 & 50.0 \\
12 & 8.74 & 300.0 & $1,000.0$ \\
\hline
\end{tabular}

deviation of 0.16 s. A 21:26 January 22, 1976, earthquake was chosen for this test, and the results also reveal a northwest orientation in the scatter of these locations (fig. 6). Random errors in reading the arrival times combined with the geographical distribution of the seismograph stations probably caused the observed northwest-trending scatter of earthquake epicenters.

Because the hypocenter locations for the January through April Augustine earthquakes could not be satisfactorily determined, the criteria based on frequency and relative $P$ and $S$ arrival times at $C K K$ and BIG were used to recognize Augustine events and to determine their approximate hypocenter depths.

\section{Volcanic Tremor}

During the 1976 eruptions of Augustine volcano, many signals were recorded that do not have the appearance of shallow earthquakes (that is, Latter's volcano-tectonic earthquakes). These signals have emergent onsets, reach maximum amplitudes usually before the halfway mark of their total duration, and can have longer durations than shallow earthquakes. A high degree of variation exists among these signals, but for classification purposes in this paper they are divided into two groups: small-amplitude and largeamplitude volcanic tremor, or more simply small and large tremor. The large tremors recorded at CKK were defined to have peak-to-peak amplitudes of over $2 \mathrm{~cm}$ as measured on a Geotech Model 6585 film viewer, while the small tremors were defined to have peak-to-peak amplitudes on CKK of less than $2 \mathrm{~cm}$. At the beginning of this study, it was not known if these signals correlated with eruptive events.

Dibble (1974) described "vibrations," that accompanied eruptions of Ruapehu volcano in New Zealand. These "vibrations" accompanied eruptions of mud and ash, occurred of ten with little warning, had durations usually of $1 \mathrm{~min}$, and had roughly equal rates of growth and decay. Larger "vibrations," which accompanied injection of vesicular andesite in the

\section{$153^{\circ} 35^{\prime}$
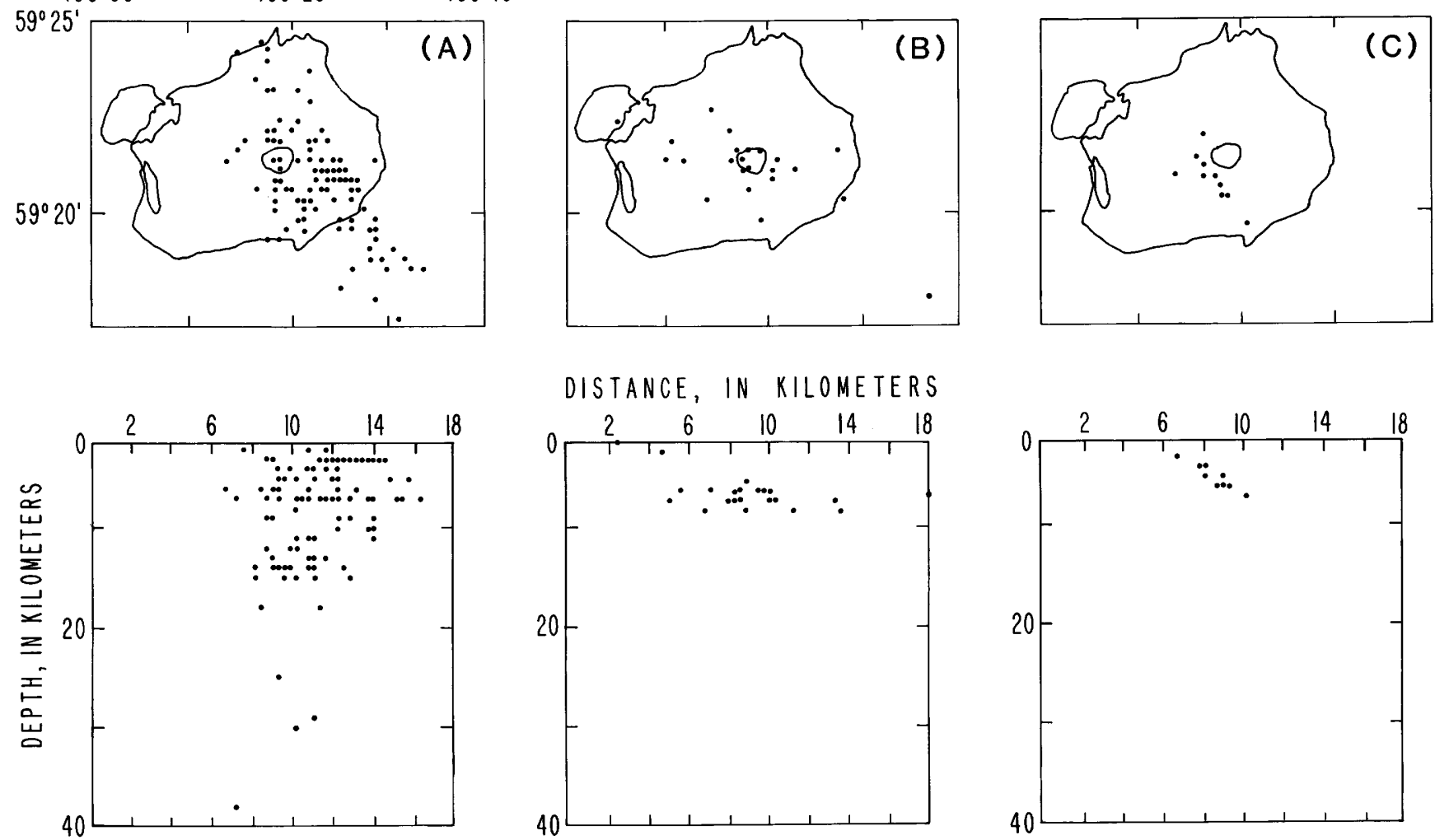

Pigure 5. Hypocenters for some of the larger 1976 very shallow earthquakes of Augustine volcano. A, Earthquake swarm of January 22-25. B, Earthquake swarm of February 6-14. C, Earthquake swarm of April 13-18. 
Crater Lake of Ruapehu volcano, reached maximum amplitudes in about $18 \mathrm{~s}$, had emergent onsets, and decayed slowly for over $3 \mathrm{~min}$. The small and large Augustine volcanic tremors appear to be similar to Dibble's "vibrations," and yet they have some different characteristics. Like Dibble's small "vibrations," the Augustine small tremors are emergent and most have nearly equal rates of growth and decay. However, some of the Augustine small tremors lasted much longer than $1 \mathrm{~min}$. Most of these were found to have a somewhat pulsating amplitude with time, a pattern that deviates from that of equal rates of growth and decay. Most of the Augustine large tremors have emergent onsets similar to Dibble's large "vibrations," but differ in that they usually display a symmetrical growth and decay rate with some amplitude fluctuations superimposed (figs. 21, 23).

\section{Large Tremor (Large-Amplitude Volcanic Tremor)}

At about 18:00 on January 22, 1976, a large pyroclastic eruption occurred at Augustine volcano. This eruption was confirmed by infrasonic signals and ash falls (Kienle and Shaw, 1979). The corresponding signal recorded at CKK (fig. 7) had an emergent onset and built rapidly to a maximum amplitude in about 14 s. This signal decayed over a period of $3.75 \mathrm{~min}$ and is similar to a signal recorded by a Willmore vertical station $9.1 \mathrm{~km}$ from Ruapehu volcano for a steam
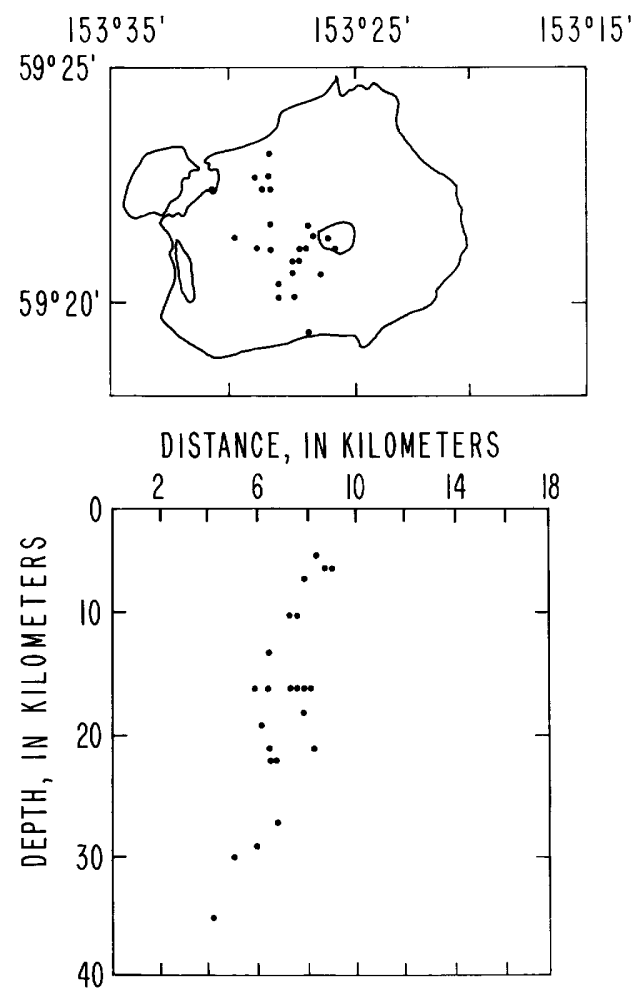

Figure 6. Distribution of hypocenters for the 21:26 u.t. January 22, 1976, very shallow Augustine earthquake due to arrival times at all stations being randomly varied. eruption at that volcano on July 24, 1966 (Dibble, 1974). Originally the Augustine signal was not recognized as representing a major eruptive event because such a rapid rise to maximum amplitude was not typical of the other Augustine eruptive signals (that is, large-amplitude volcanic tremor). The rapid increase in amplitude is now interpreted as being the P-phase arrivals of several very shallow Augustine earthquakes in close succession where each earthquake was larger than the preceding one. At least three very shallow earthquakes are believed to be represented, and the largest of these earthquakes had an approximate local magnitude of 2.3. The P-phase arrivals of these earthquakes are marked by arrows in figure 7. These ear thquake arrivals would have helped obscure the emergent onset of the principal eruptive signal.

The large tremor of 18:00 January 22 is not typical of most Augustine large tremors, which usually have less rapid amplitude growths and thus have more symmetrical signals. For example, the large tremor of 13:55 January 23, 1976 (figs. 8, 21C), started as a small tremor at $13: 46: 22$, reached a 2 -cm peak-to-peak amplitude at about $13: 53: 25$, peaked at about $13: 54: 45$, and finally ended at about 14:05:00. This particular large tremor had a total duration of $18.5 \mathrm{~min}$. Thirteen large tremors were recorded during the January eruptive activity, and three more were recorded during February. All of these in detail had unique amplitude configurations (figs. 21, 23).

All 16 of the Augustine large tremors (figs. 21, 23) have been verified as representing or at least roughly correlating with major eruptive events as indicated by infrasonics (Kienle and Shaw, 1979), by direct observation of some of the eruptions (Kienle and Forbes, 1976; Trapp, 1976; Hobbs and others, 1977; Stith and others, 1978), and by NOAA-4 satellite photographs. One such satellite photograph, taken on January 23, 1976, at 20:05:07, shows several eruptive clouds from events that occurred during the preceding several hours (fig. 9). Other evidence for eruptions included observations of ash falls, damage to flying aircraft by ash clouds, lidar detection, and radar detection of ash clouds (Kienle and Shaw, 1979; Remsberg and others, 1976; Johnston, 1978). In table

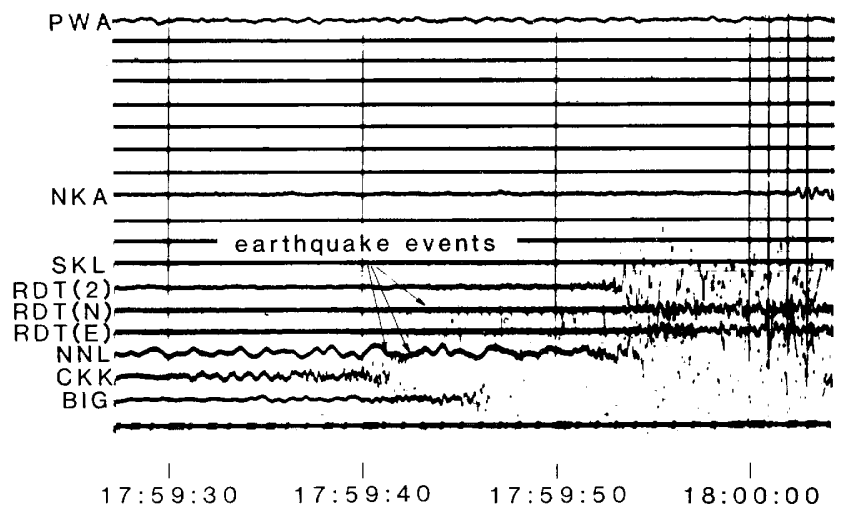

Figure 7. Seismogram of initial part of January 22, 1976, Augustine eruption (large tremor). Seismic stations denoted on left. 
2, the times of the large tremors recorded at CKK are given along with the infrasonic evidence for the times of major eruptive events at Augustine volcano.

Small Tremor (Small-Amplitude Volcanic Tremor)

Small tremors are, as previously defined, emergent Augustine signals at CKK with peak-to-peak amplitudes of less than $2 \mathrm{~cm}$. Hundreds of small tremors were recorded during the Augustine eruptive period. Although most of these small tremors were under $2 \mathrm{~min}$ in duration, the longest had a duration of over $40 \mathrm{~min}$. The typical small tremor of $11: 23$ January 23 (fig. 10) started at about 11:22:14, peaked at about 11:23:20, and ended at about 11:24:00. Although this signal was in general fairly symmetrical, it did pulsate markedly.
A tremor that lasted at least $25 \mathrm{~min}$ and had a large enough amplitude at CKK to be classified as a large tremor for about 4 min occurred on February 9. A seismogram for part of this tremor is shown in figure 11, along with a photograph by Jeff Stith of the University of Washington Cloud and Aerosol Physics Group of the Atmospheric Science Department that shows the eruptive activity of the volcano at 00:04. Unfortunately, the period from 23:59 February 8 to 00:03 February 9 was not seismically recorded as a result of a film change. Therefore, the pyroclastic flow shown in figure $11 \mathrm{C}$ was not seismically recorded. The pulsating nature of small-tremor signals can be easily seen in figure $11 \mathrm{~A}$. Such signals might have, resulted from shallow-earthquake swarms at the summit region of the volcano, where the signals have been highly attenuated as a result of the physical nature of the volcanic pile.
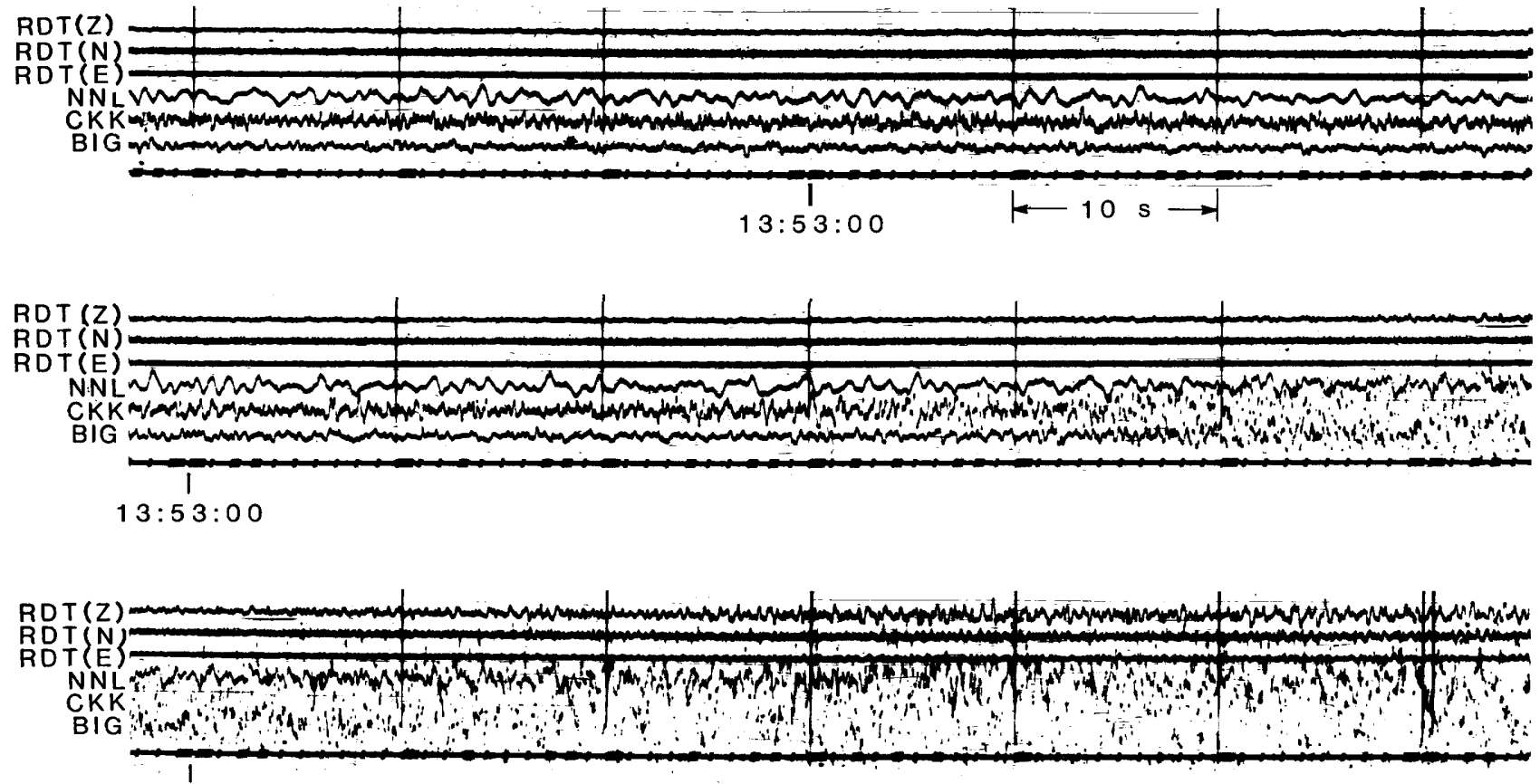

$13: 54: 00$

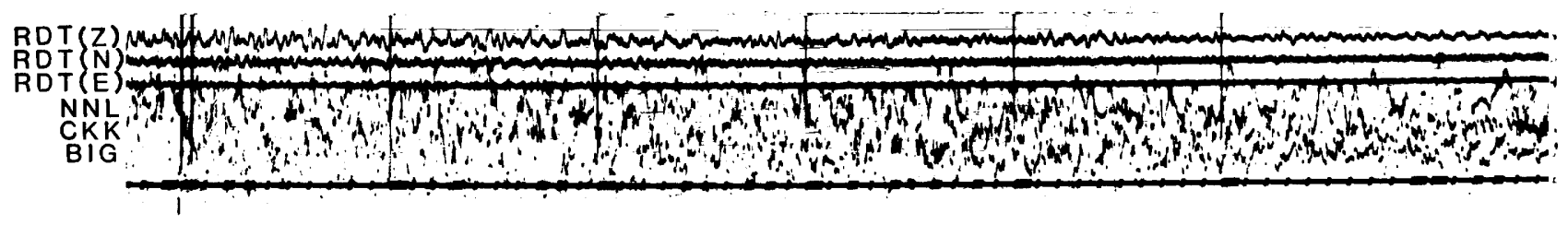

$13: 55: 00$

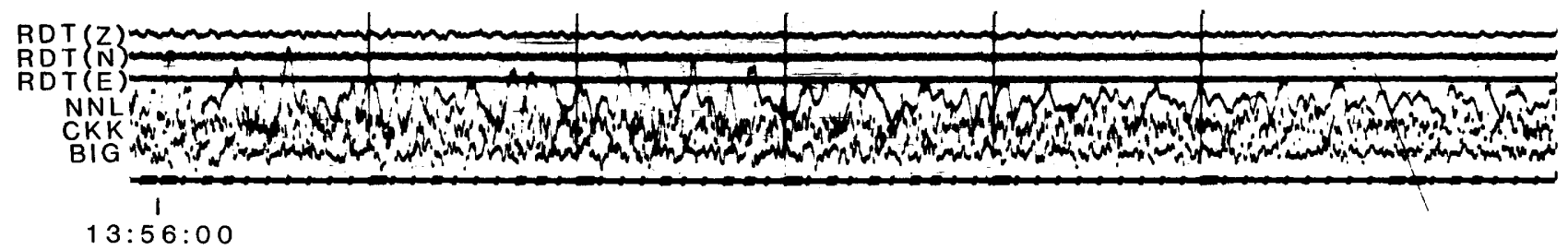

Figure 8. Seismogram of a January 23, 1976, Augustine eruption (large tremor). Seismic stations denoted at left. 
Occasionally, very shallow Augustine earthquakes appear to be related to small tremor. For example, the $\mathrm{M}_{\mathrm{L}}=1.8$ earthquake at $23: 35: 11.5$ on February 13 was followed by a small tremor and an eruptive cloud (fig. 12), as documented by the University of Washington Cloud and Aerosol Physies Group (L.F. Radke and J.L. Stith, oral commun., 1976). This suggests a relationship of very shallow earthquakes to eruptive events and tremor.

Some Correlations and Correlation Problems Between Observed Eruptive Activity and Volcanic Tremor

Between February 8 and February 19, 1976, 10 airborne visits to Augustine volcano were made by the University of Washington Cloud and Aerosol Physies
Group (Stith and others, 1978). Numerous eruptive clouds were observed by this group during their visits. For example, a photograph, which was taken during their approach to Augustine volcano on February 8-9, documented two large eruptive clouds (fig. 13A) that appear to correlate with a 22:27:02 large tremor and a 22:53:44 small tremor. When the University of Washington group arrived at Augustine volcano, they observed signs of a very recent pyroclastic flow (fig. $13 \mathrm{~B})$, which probably corresponds to the 22:27:02 large tremor. The small cloud above the volcano probably corresponds to the detected tremor of $23: 35: 49$. Based on automatic photographs taken during the University of Washington visits to Augustine, 11 eruptive clouds were observed. All eruptive clouds observed by the University of Washington group correlate with tremors. The only tremor for which the group did not

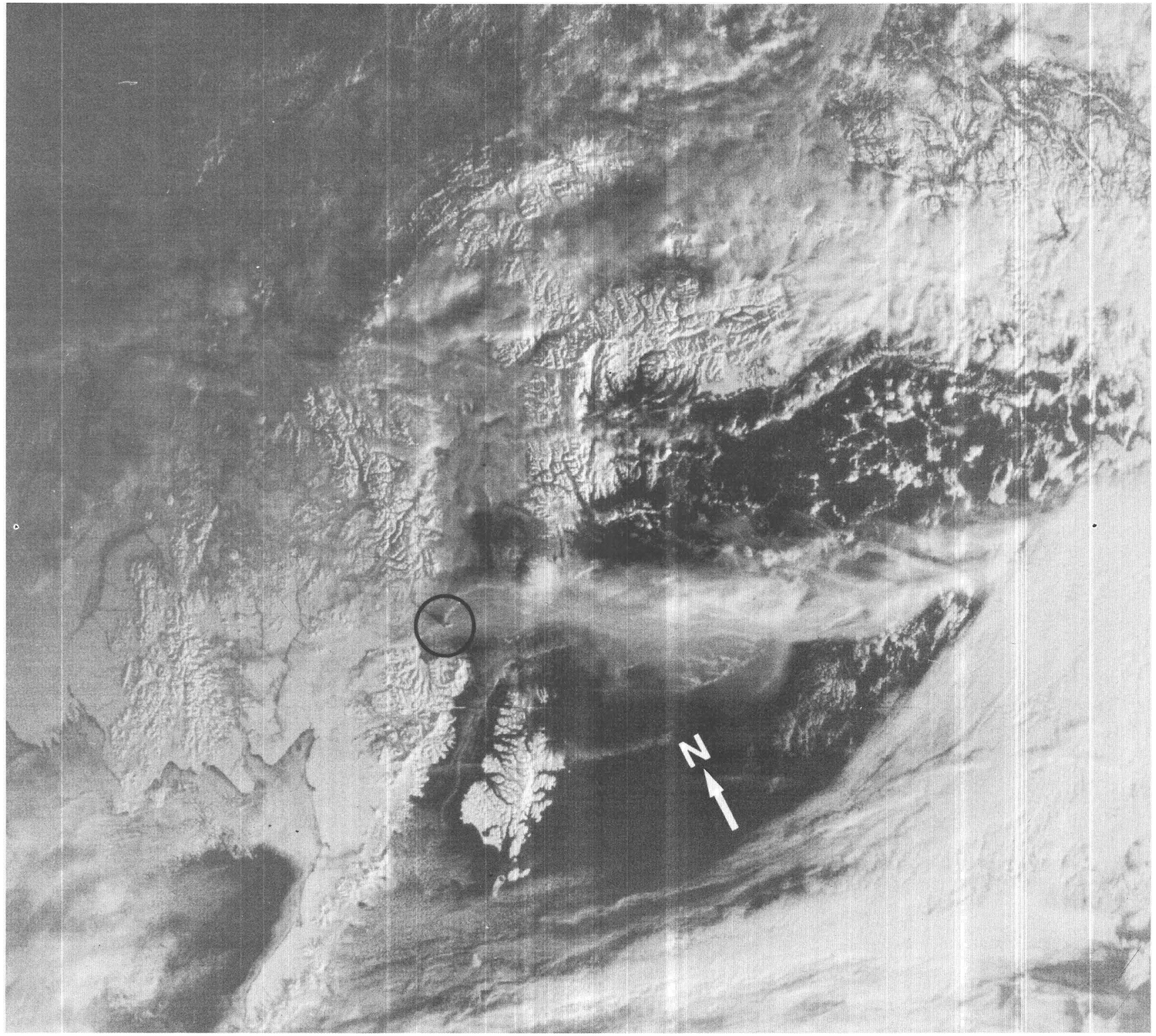

Figure 9. Satellite photograph of Alaska taken at 20:05:07 u.t. on January 23, 1976, by NOAA-4. Circle on photograph indicates location of Augustine volcano. 
observe an eruptive cloud occurred at 00:10:21 on February 10. The failure to observe an eruptive cloud for this tremor might have been due to the poor weather conditions.

Even though the correlation between the observed eruptive clouds and large tremor is good, such a correlation does not necessarily mean that all eruptive signals (that is, small- and large-amplitude volcanic tremors) recorded during the 1976 Augustine eruptive period correlate directly with respect to time with actual eruptions. For example, a period of about 8 min was described by the University of Washington Cloud and Aerosol Physics Group as the duration of the main eruption shown in figure 11, which started at about 00:00:00 February 9. An examination of figure $23 \mathrm{C}$ shows that small tremor was actually recorded from $00: 00: 03$ to $00: 26: 00$, and that a large tremor actually occurred between 00:10:00 and 00:13:47. As previously mentioned, the period from 23:59 February 8 to $00: 03$ February 9 was not seismically recorded as a result of a film change. Because of the size of this eruption (fig. 11), a large tremor is suspected to have occurred during this film change. Yet, the $3.78 \mathrm{~min}$ of the large tremor that started at 00:10:00 actually occurred after the main eruption was reported by the University of Washington group. A careful examination of photographs of this period indicates the continuous emission of ashy "steam" clouds, which were not in the amount expected for the amplitude of the large tremor or of the small tremor recorded at CKK. This 00:10:00 large tremor was the only recorded large tremor that does not correlate directly with respect to time with a large explosive eruption of Augustine volcano.

Another observation of eruptive activity by the University of Washington Cloud and Aerosol Physics Group is shown in figure 14. During this activity, base surges blanketed at least the upper one third of Augustine volcano, with at least one pyroclastic flow reaching halfway down the volcano (fig. 14). The seismic signal, which corresponded to this eruptive activity, started as a small tremor at about 00:30:49.5 February 13, 1976, and was followed by a shallow earthquake at $00: 30: 50.8$. Although the photograph is timed at 00:34:00 and indicates continued movement of the pyroclastic flow, the actual seismic signal preceded it by several minutes. Photographic evidence suggests that the pyroclastic flow was in progress as early as 00:32:34 and that downslope movement had stopped by $00: 41: 20$. The seismic signal preceded the pyroclastic flow and may have preceded the start of the summit eruption.

Most likely, considerable eruptive activity occurred at Augustine Island that was not recorded by the CKK and BIG seismograph stations. A vertical view of the summit and northeast flank of Augustine volcano is shown in figure 15. This NASA photograph was taken at $03: 22$ on April 13, 1976. At this time, shallow-earthquake swarms with no tremor were being recorded by the CKK seismograph station. The photograph indicates eruptive activity by the dark clouds of ash and steam at the summit and by

Table 2. Arrival times, durations, and amplitudes of Augustine volcanic tremors at CKK during January 1976 , including arrival times of eruption-induced infrasonics at Fairbanks, Alaska

\begin{tabular}{|c|c|c|c|c|c|c|}
\hline $\begin{array}{c}\text { Arrival } \\
\text { of small } \\
\text { at C } \\
1976 \\
\end{array}$ & $\begin{array}{l}\text { I time } \\
\text { tremors } \\
\text { CKK } \\
(u, t) \\
\end{array}$ & $\begin{array}{c}\text { Arrival time of } \\
\text { large tremors } \\
\text { at CKK } \\
\text { (u.t.) }\end{array}$ & $\begin{array}{l}\text { Duration of } \\
\text { large tremor } \\
\text { at CKK } \\
\text { (min) }\end{array}$ & $\begin{array}{l}\text { Total duration } \\
\text { of tremor } \\
\text { at CKK } \\
\text { (min) }\end{array}$ & $\begin{array}{l}\text { Peak-to-peak } \\
\text { maximum amplitude } \\
\text { of tremor at CKK } \\
(\mathrm{cm})\end{array}$ & $\begin{array}{c}\text { Arrival time } \\
\text { of infrasonics } \\
\text { at Fairbanks } \\
\text { (Kienle and Shaw, 1979) } \\
\text { (u.t.) }\end{array}$ \\
\hline Jan. 22 & $17: 59: 31$ & $17: 59: 42$ & 2.96 & 4.09 & 13.40 & $18: 38$ \\
\hline Jan. 23 & $08: 08: 43$ & - & - & 2.28 & .70 & - \\
\hline Jan. 23 & $08: 11: 27$ & -- & -- & .72 & .60 & - \\
\hline Jan. 23 & $08: 14: 30$ & - & -- & .75 & .60 & -- \\
\hline Jan. 23 & $08: 16: 25$ & -- & -- & 1.08 & .70 & - \\
\hline Jan. 23 & $08: 18: 54.5$ & -- & - & 40.09 & 1.70 & - \\
\hline Jan. 23 & $09: 08: 00$ & -- & -- & 4.62 & .66 & - \\
\hline Jan. 23 & $10: 29: 55$ & - & -- & 1.23 & .80 & - \\
\hline Jan. 23 & $10: 50: 11$ & - & - & 2.72 & 1.32 & - \\
\hline Jan. 23 & $11: 05: 09.5$ & - & - & 1.17 & .80 & - \\
\hline Jan. 23 & $11: 16: 25 \cdot 7$ & - & - & 1.73 & .64 & - \\
\hline Jan. 23 & $11: 22: 14$ & - & - & 1.67 & .82 & - \\
\hline Jan. 23 & $11: 26: 22$ & - & -- & 3.35 & 1.10 & - \\
\hline Jan. 23 & $13: 41: 57.5$ & - & - & .82 & .98 & -- \\
\hline Jan. 23 & $13: 46: 22$ & $13: 53: 25$ & 4.24 & 18.46 & 13.40 & $14: 32$ \\
\hline Jan. 23 & $15: 00: 42.5$ & $15: 00: 42.5$ & 3.79 & 7.29 & 8.20 & $15: 40$ \\
\hline Jan. 23 & $16: 07: 40$ & -- & - & .33 & 1.00 & - \\
\hline Jan. 23 & $16: 10: 33$ & $16: 10: 33$ & 3.01 & 12.35 & 4.60 & $16: 55$ \\
\hline Jan. 23 & $16: 32: 22.5$ & - & - & 1.12 & .94 & - \\
\hline Jan. 23 & $16: 52: 44$ & $16: 58: 19$ & 3.10 & 13.93 & 8.60 & $17: 37$ \\
\hline Jan. 23 & $17: 15: 40$ & -- & - & 1.08 & .38 & - \\
\hline Jan. 23 & $17: 19: 10.5$ & - & - & .58 & .56 & - \\
\hline Jan. 23 & $17: 33: 53$ & -- & -- & .51 & .60 & - \\
\hline Jan. 23 & $17: 37: 30$ & - & -- & 2.03 & 1.50 & -- \\
\hline Jan. 23 & $17: 41: 42$ & $17: 41: 55$ & 2.75 & 5.03 & 6.20 & $18: 19$ \\
\hline Jan. 23 & $20: 09: 43$ & $20: 09: 43$ & 3.78 & 7.65 & 5.20 & $20: 47$ \\
\hline Jan. 24 & $02: 07: 30$ & - & - & .98 & 1.20 & - \\
\hline Jan. 24 & $02: 17: 00$ & $02: 21: 50$ & 2.84 & 18.83 & 2.30 & $02: 57$ \\
\hline Jan. 24 & $05: 59: 00$ & $05: 59: 00$ & 6.16 & 6.16 & 4.20 & $06: 38$ \\
\hline Jan. 24 & $08: 42: 37.7$ & - & - & .70 & .98 & - \\
\hline Jan. 24 & $11: 20: 01$ & $11: 23: 45$ & 5.75 & 13.20 & 2.50 & $12: 01$ \\
\hline Jan. 24 & $14: 39: 39.7$ & $14: 40: 15$ & 6.75 & 13.34 & 3.80 & $15: 20$ \\
\hline Jan. 24 & $18: 39: 58$ & $18: 40: 55$ & 2.58 & 5.70 & 11.20 & $19: 17$ \\
\hline Jan. 24 & $18: 54: 18$ & - & - & .48 & .82 & -- \\
\hline Jan. 25 & $14: 57: 04$ & $14: 57: 10$ & 11.83 & 18.93 & 4.40 & $15: 35$ \\
\hline
\end{tabular}


cloud trails from the paths of recent small pyroclastic flows that had gone through the northeastern crater breach of the volcano.

\section{Eruption-Induced Air-Phase Signals}

During part of the January 1976 eruptive period, very pronounced disturbances, which followed a good number of the major eruptions, were recorded by seismograph stations in the Cook Inlet region. Oneminute windows of the seismogram that recorded such a disturbance along with the preceding 05:59:00 large tremor of January 24, 1976, are shown in figure 16. The NNL seismograph station initially detected the disturbance, which had a frequency range of 1.0 to 12 $\mathrm{Hz}$ and a maximum amplitude of $3.6 \mathrm{~cm}$. NKA then recorded the disturbance, with a frequency range of 1.0 to $9 \mathrm{~Hz}$ and a maximum amplitude of $12.0 \mathrm{~cm}$, followed by SKL with a frequency range of 1.0 to $9 \mathrm{~Hz}$ and a maximum amplitude of $2.1 \mathrm{~cm}$. The disturbance was then recorded about $321 \mathrm{~km}$ northeast of Augustine volcano by the PWA seismograph station; the signal recorded there had a frequency range of 2.1 to $4.0 \mathrm{~Hz}$ and a maximum amplitude of $7.6 \mathrm{~cm}$.

These seismic disturbances are similar to largeamplitude volcanic tremor because they have indistinct first arrivals and, in general, equal rates of growth and decay. The seismic disturbances were pronounced enough to be originally used instead of the large tremors on CKK to recognize major eruptive events. The disturbances, except for those on PWA, were confined between 20:09:43 January 23 and 15:25:00 January 25 and have velocities of about 0.33 $\mathrm{km} / \mathrm{s}$, based on a correlation with the corresponding large tremors. The relationship of the duration of these signals to the duration of the corresponding large tremors and to the time from the start of these corresponding large tremors is illustrated in figure 17.

The speeds of these disturbances are approximately the same as the $0.313 \mathrm{~km} / \mathrm{s}$ speed for lower-channel infrasonic waves from the Trident and Redoubt explosive eruptions that were detected by microbarometers (Wilson and Forbes, 1969), which is approximately the speed of sound at this latitude in winter (Diamond, 1963). The speed of sound for motionless air can be approximated (Hardy and others, 1942) by the following relation:

$$
\mathrm{C}=20.1 \sqrt{\mathrm{T}} \text {, }
$$

where

$\mathrm{C}$ is the speed of sound measured in meters per second; and

$\mathrm{T}$ is temperature in Kelvins.

The approximate temperature of the first kilometer of atmosphere in the Cook Inlet region on January 24, 1976 (fig. 29B), was $-10{ }^{\circ} \mathrm{C}\left(263{ }^{\circ} \mathrm{K}\right)$. At such a temperature, the speed of sound as given by equation (4) would be about $0.326 \mathrm{~km} / \mathrm{s}$. These disturbances appear to be atmospheric pressure disturbances that were generated by eruptions of Augustine volcano. Such signals are henceforth called eruption-induced air-phase signals.
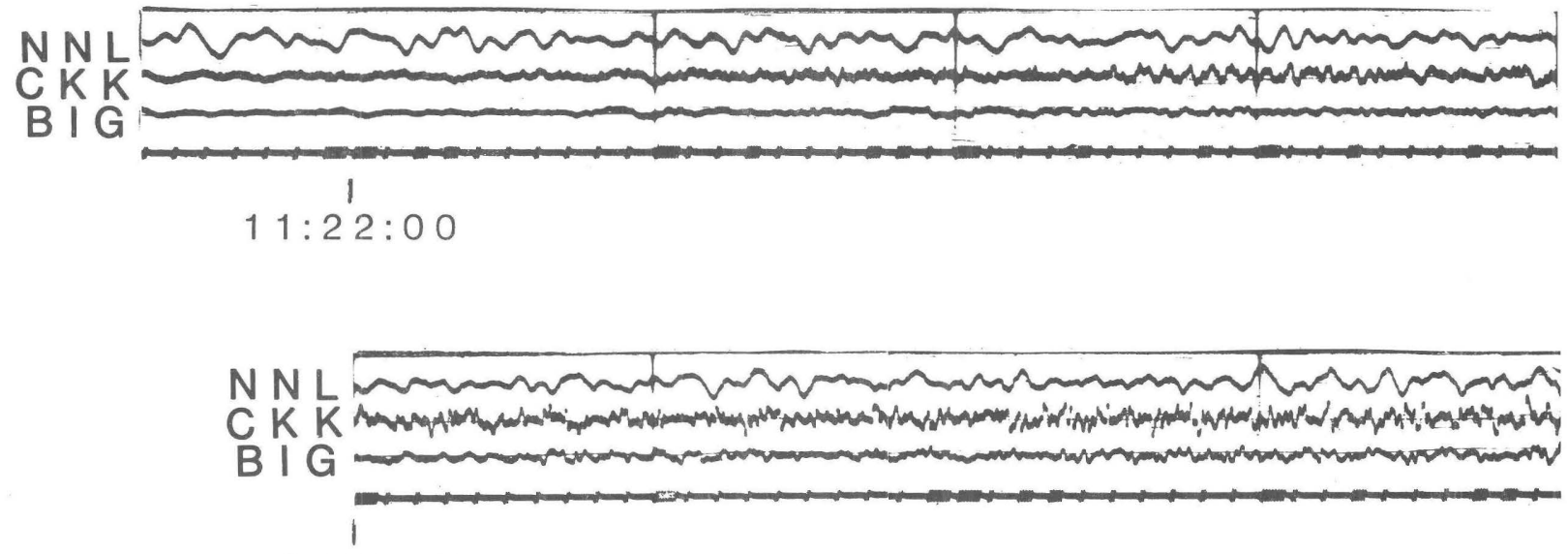

$11: 22: 40$

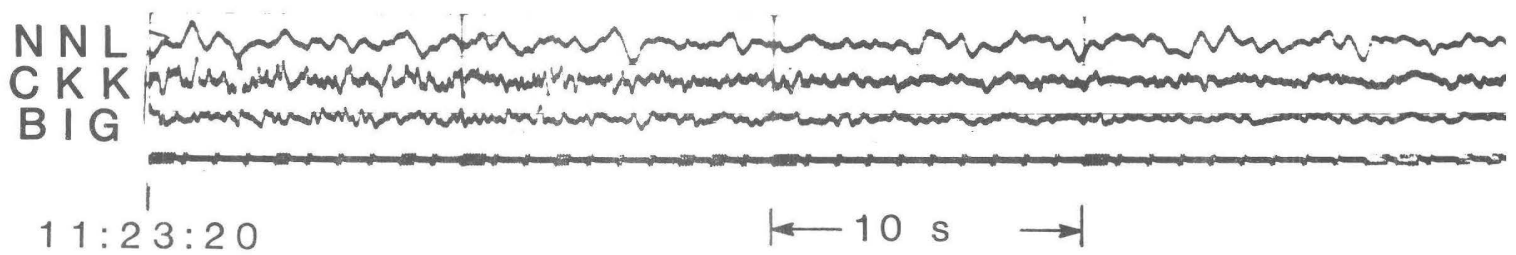

Figure 10. Seismogram of January 23, 1976, Augustine eruption (small tremor). 


\section{SEISMIC TIME SEQUENCE}

The complete sequence of Augustine events as detected by the seismograph station CKK is shown in figure 18 for the time period from November 1, 1975, to April 30, 1976. Included in this summary are (A) the daily count of very shallow Augustine earthquakes $(<1.1$ $\mathrm{km}$ below sea level as based on the criteria for $\mathrm{P}$ and $\mathrm{S}$ arrival times at CKK and BIG); (B) the daily count of very shallow earthquakes for the period of November through December 1975 as based on University of Alaska seismic data (D.J. Lalla, oral and written
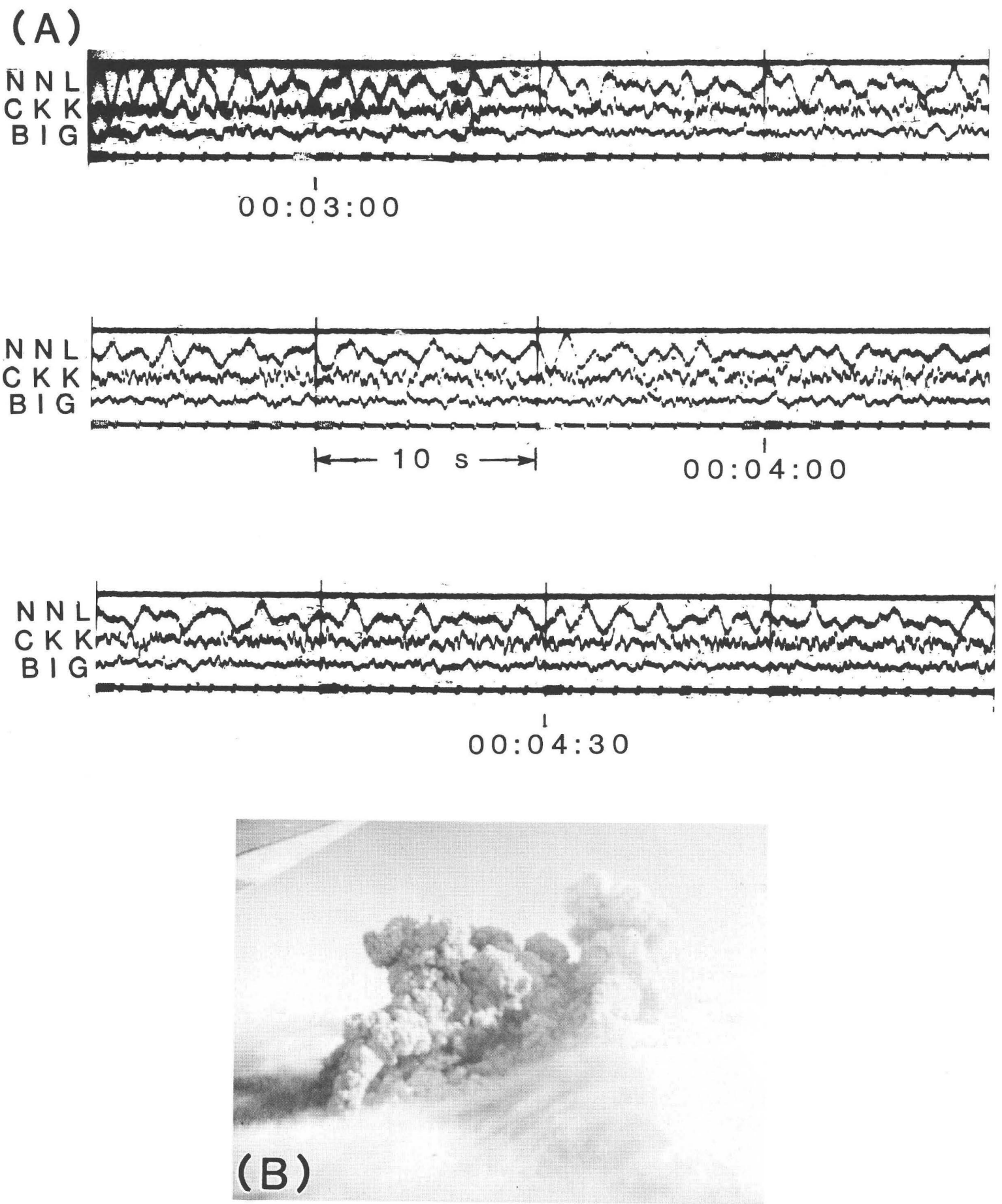

Figure 11. Seismogram and photographs related to February 8-9, 1976, eruptive activity of Augustine volcano. A, Seismogram of small tremor, which is part of long tremor of February 8-9. B, Photograph of 00:04:00 u.t. February 9 showing corresponding eruptive activity. C, Photograph of 00:02:40 u.t. February 9. Photographs taken by the University of Washington Cloud and Aerosol Physies Group. 
commun., 1978); (C) the daily count of moderately shallow Augustine earthquakes $(>1.1 \mathrm{~km}$ but $<20 \mathrm{~km}$ below sea level as based on the criteria for relative $\mathrm{P}$ and $\mathrm{S}$ arrival times and frequencies at CKK and BIG); (D) the daily count of small tremor recorded by the CKK seismograph station; $(\mathrm{E})$ the daily total duration in minutes of small tremor; $(F)$ the daily count of large tremor recorded by the CKK seismograph station; and (G) the daily total duration in minutes of large tremor.

A good part of the smaller seismic activity probably would have been missed by the CKK and BIG seismograph stations, since these stations are located 82 and $103 \mathrm{~km}$, respectively, from the summit of Augustine Island. Of the 452 very shallow earthquakes detected during November and December 1975 by the University of Alaska seismograph network, only 176 were detected by the CKK and BIG seismograph stations (figs. 18A, B). Based on equations (2) and (3), the total radiated energy from all shallow Augustine earthquakes detected by CKK during this period was $1.2 \times 10^{15}$ ergs (fig. 19). This compares to about $1.9 \times$ $10^{15}$ ergs as detected by the University of Alaska seismograph network. Even though the CKK and BIG seismograph stations failed to detect some of the smaller Augustine seismic activity, the data from these stations were selected for examination because they were the closest continuously operating stations during the 1976 Augustine eruptions.

Extensive precursor activity in the form of shallow earthquakes occurred before the onset of the initial eruption of Augustine volcano on January 22, 1976 (fig. 18). Such activity began as early as May 1975 (Kienle and Shaw, 1979; Lalla and Kienle, 1978). The largest precursor swarm occurred on November $18-19,1975$, and consisted of 90 very shallow earthquakes. These earthquakes had a total of $0.65 \mathrm{x}$ $10^{15}$ ergs of radiated energy. The largest event of the swarm had a local magnitude of about 2.3. Very shallow precursor earthquake swarms also occurred on December 1-2, 13-14, 21-22, 24, 26-29, and December 31-January 2.

Of special interest are the moderately shallow earthquakes. Such events occurred on November 12, 21, 26, December 2, 28, 29, January 4, 15-18, and 21 (fig. 18). The January 15-18 swarm, the largest moderately shallow precursor swarm before the January 22 eruption, consisted of nine earthquakes. These earthquakes had a total of $0.13 \times 10^{15}$ ergs of radiated energy and had $M_{L}$ values of up to 2.0. The moderately shallow event of January 21, which had a local magnitude of 1.7 , occurred just $24.66 \mathrm{~h}$ before the first Augustine explosive eruption of $17: 59: 29.9$ January 22. No moderately shallow Augustine events were detected during the January or April eruptive periods, but such events were fairly common during the February eruptions. In fact, the February earthquake swarms consisted of 43 moderately shallow earthquakes. This was the largest concentration of moderately shallow earthquakes to occur between November 1975 and April 1976.

A total of 1,064 very shallow earthquakes

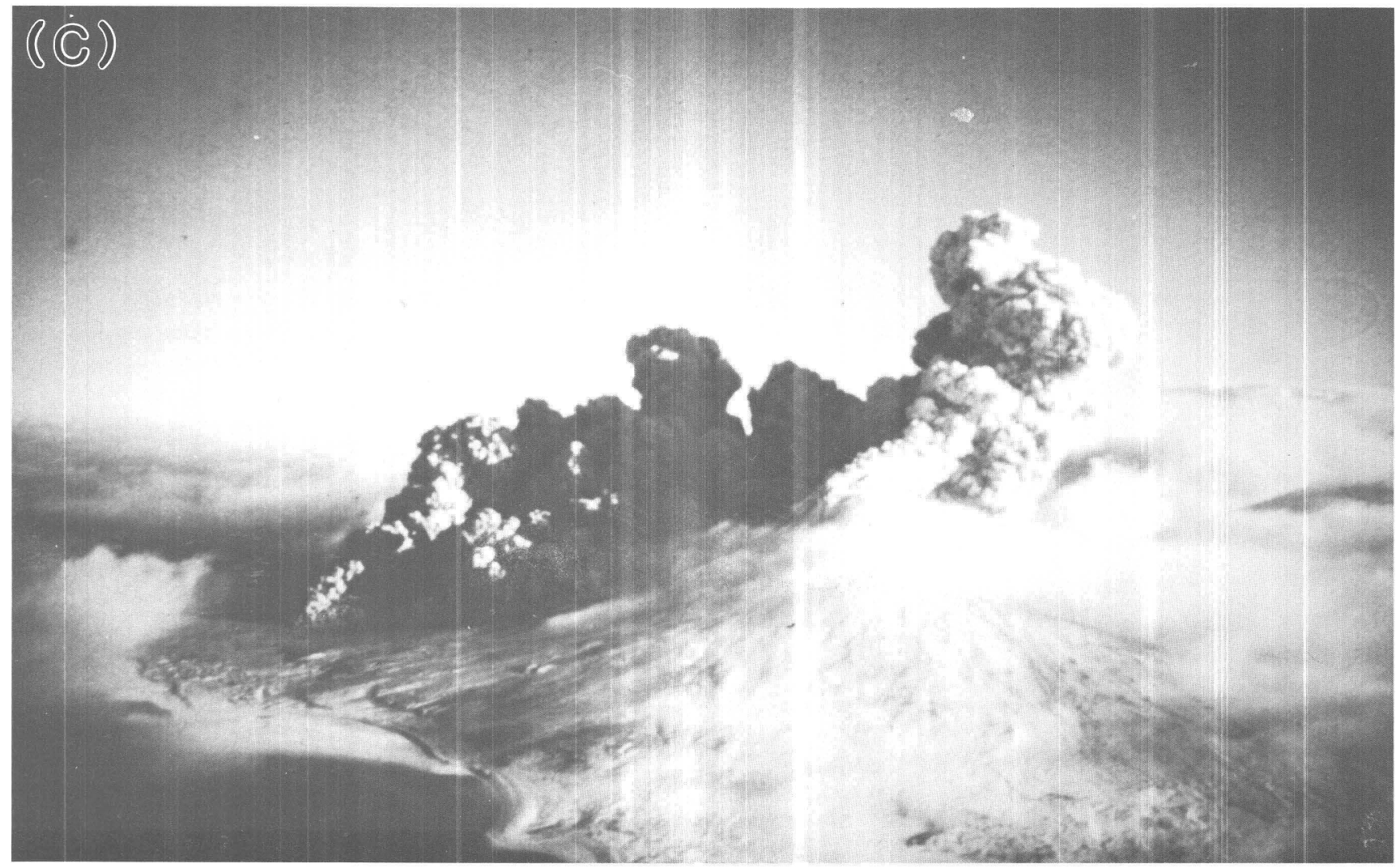

Figure 11. Continued. 
accompanied the eruptive activity that began on January 22. These earthquakes radiated a total of 31.0 $\mathrm{x} 10^{15}$ ergs of energy. During this eruptive period, 13 major eruptive events (that is, large tremors) and at least 22 smaller eruptive events (that is, small tremors) occurred as based on the seismic record (table 2). Very few earthquakes occurred in the 11 days following this first eruptive sequence.

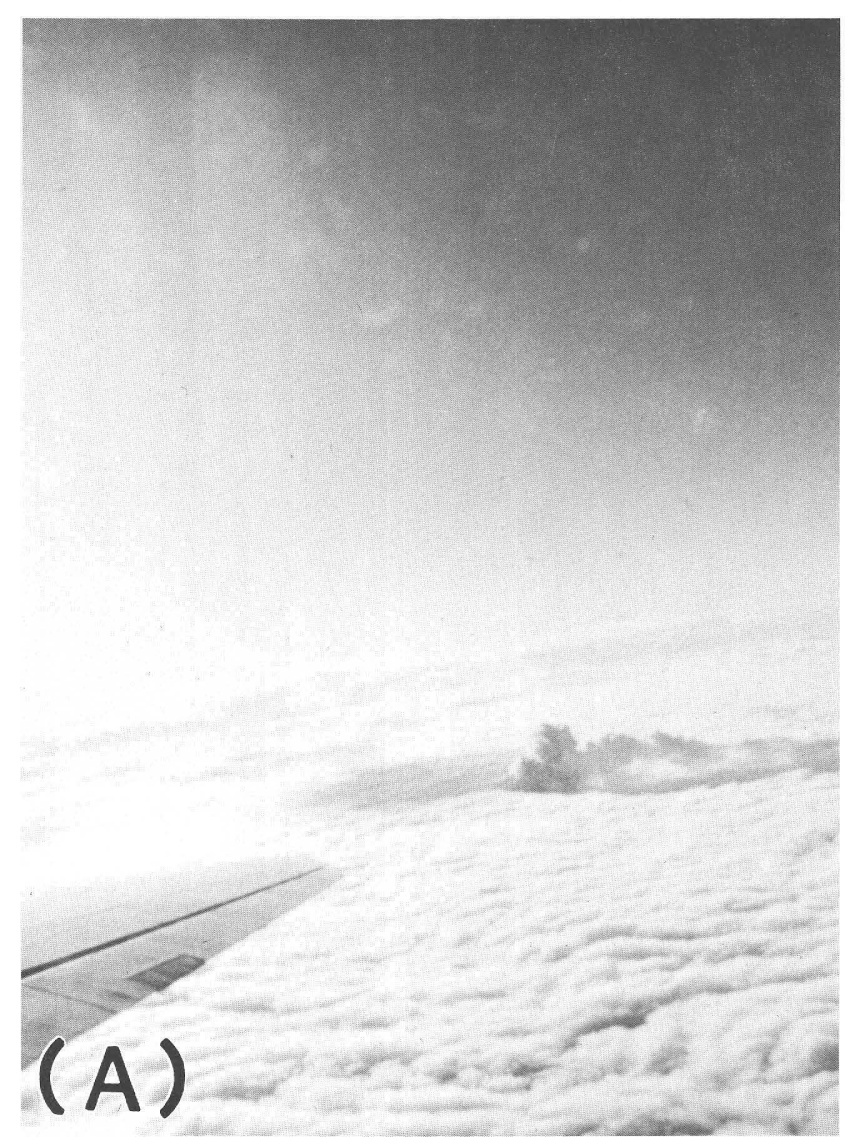

\section{(B)}
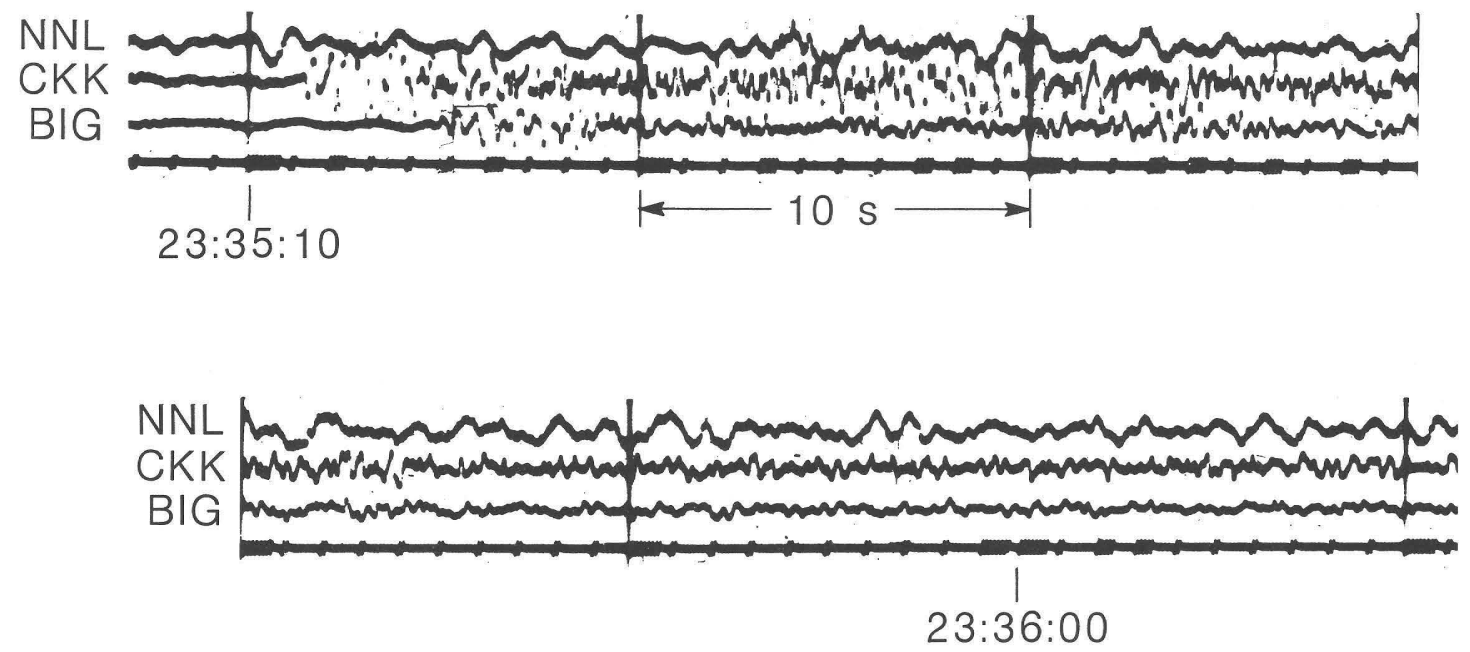

Figure 12. Seismogram and photograph related to a February 13, 1976, very shallow Augustine earthquake, which was followed by small tremor and an eruptive cloud. A, View at 23:39:16 u.t. Photograph taken by University of Washington Cloud and Aerosol Physics Group. B, Seismogram showing $23: 35: 10$ u.t. tremor. 
Eruptive activity commenced again on February 6. A total of 321 very shallow and 43 moderately shallow earthquakes, which collectively represented a total of $0.94 \times 10^{15}$ ergs of radiated earthquake energy, occurred during this second eruptive period. This eruptive period included 3 major eruptive events (large tremors) and at least 125 smaller eruptive events (small tremors) as based on the seismic record.

The third eruptive sequence commenced on April 13 after 53 days of few earthquakes. Initially, this eruptive sequence was represented by a very shallow

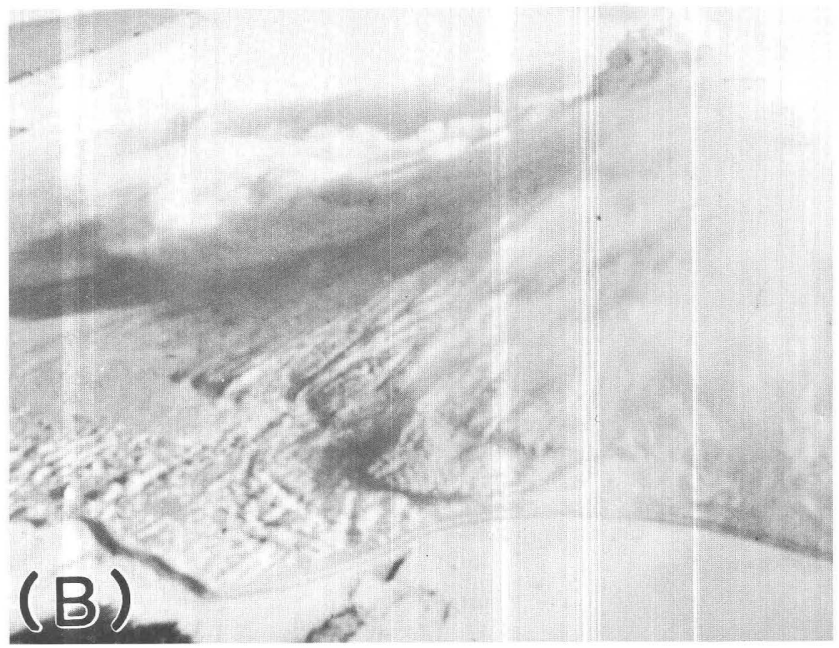

Figure 13. Photographs of Augustine volcano taken by the University of Washington Cloud and Aerosol Physics Group on February 8, 1976. A, View at 23:05:06 u.t. showing two eruptive clouds, which correlate with the 22:27:02 u.t. large tremor and the 22:53:44 u.t. small tremor of that date. B, View at 23:54:08 u.t. showing signs of a recent pyroclastic flow.

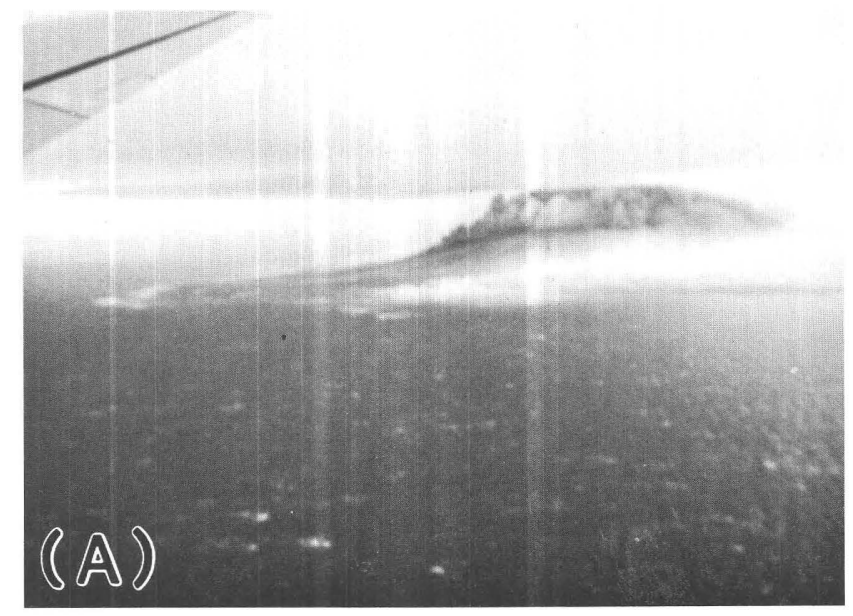

\section{(B)}

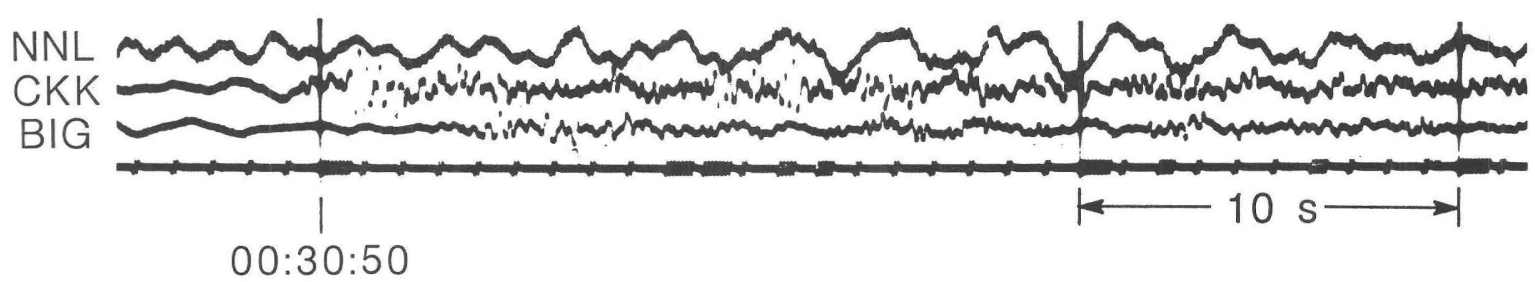

Figure 14. Photograph and seismogram related to February 13, 1976, eruptive activity at Augustine volcano. A, View at $00: 34: 00$ u.t. of eruptive activity. Photograph taken by University of Washington Cloud and Aerosol Physies Group. B, Seismogram showing the 00:30:49.5 u.t. small tremor and the 00:30:50.8 u.t. earthquake on that date. Seismic stations denoted at left. 
earthquake swarm and with possible seismically undetected small eruptions. This swarm ended on April 14, but very shallow earthquake swarming and numerous small tremors occurred again during April 16-18. Forty-five small eruptive events (small tremors) were detected during the period of April 16 through 18. Between April 13 and 18, a total of 81 very shallow earthquakes occurred, which represented approximately $0.076 \times 10^{15}$ ergs of radiated energy.

\section{The January Eruptive Sequence}

The January eruptive sequence is summarized in figure 20. This summary on an hourly basis includes (A) the count of very shallow earthquakes; (B) the count of small tremor; (C) the total duration in minutes of small tremor; (D) the count of large tremor; and (E) the total duration in minutes of large tremor.
The eruptive sequence began with no obvious warning at approximately 17:59:42 on January 22 as a large tremor (figs. 7, 21A). This eruptive event might have started as early as $17: 59: 29.9$ as a very weak small tremor. As previously described, this seismic signal had an emergent onset and built rapidly to a 17:59:45 maximum peak. Three very shallow Augustine earthquakes occurred in close succession during this rapid build up, at $17: 59: 41.4,17: 59: 42.3$, and $17: 59: 43.2$. Their local magnitudes are estimated to be at least 1.6 , greater than 1.6 but less than 2.3 , and 2.3, respectively. Very shallow Augustine earthquakes also occurred during the eruption, at 18:02:19.8 and 18:02:46.6 with $M=1.5$ and $M_{L}=1.7$, respectively. The only very shallow Augustine earthquakes to occur within the $72 \mathrm{~h}$ preceding this eruption were an $\mathrm{M}_{\mathrm{L}}=0.64$ earthquake at $17: 39: 51$, an $\mathrm{M}_{\mathrm{L}}=0.82$ earthquake at $04: 16: 24$, and an $\mathrm{M}_{\mathrm{L}}=1.5$ earthquake at $02: 55: 48.5$. Two moderately shallow

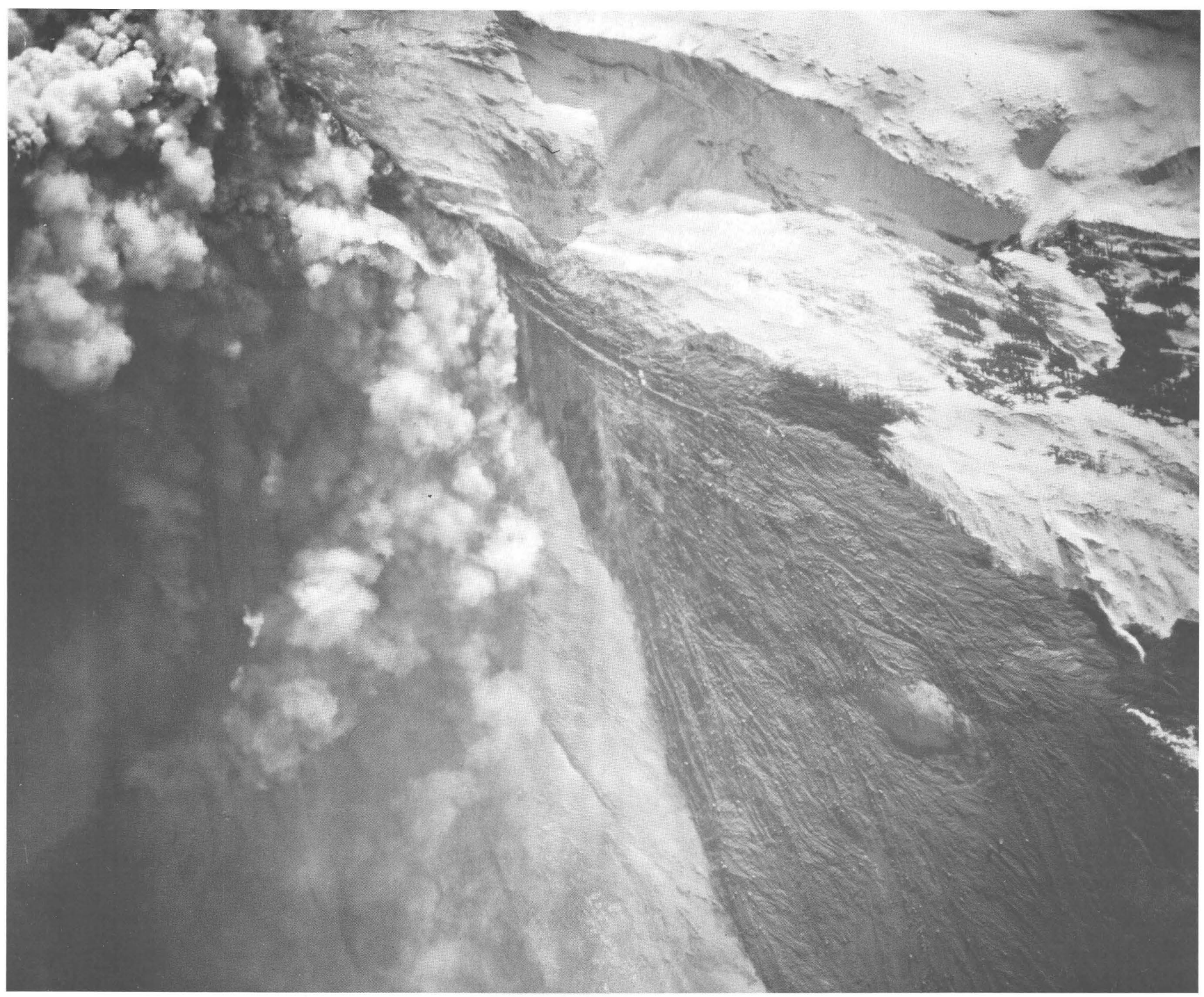

Figure 15. A vertical photograph of summit and northeast flank of Augustine volcano taken by NASA at 03:22 u.t. on April 13, 1976. 
events occurred during the preceding $72 \mathrm{~h}$. These were an $\mathrm{M}_{\mathrm{L}}=1.6$ earthquake at $17: 19: 06.5$ on January 21 and an $\mathrm{M}_{\mathrm{L}}=0.64$ earthquake at $07: 00: 31$ on January 20 .

Following the initial large tremor, an $\mathrm{M}_{\mathrm{L}}=1.2$ earthquake occurred at 18:32:25.6 (fig. 21A), which marked the onset of the largest of the shallowearthquake swarms (fig. 20A). Initially the earthquakes in this swarm, all being very shallow, occurred at a rate of about 43 events per hour. By 03:00 on January 23, the earthquake rate reached_its peak of 90 recognizable events per hour. The largest earthquake occurred at 2:16:01 January 23 with an $\mathrm{M}_{\mathrm{L}}$ of 2.5. By 07:00 the rate had dropped to 33 events per hour, and for all practical purposes the swarm ended at 08:08:43. During this swarm period, pver 667 earthquakes occurred and about $27 \times 10^{15}$ ergs of earthquake energy was radiated. This 13.5-h

\section{(A)}

P W A M

NKA

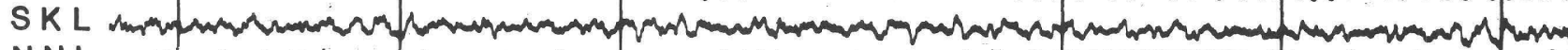

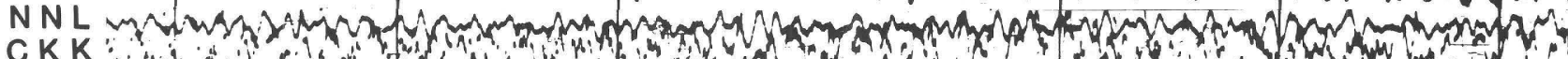

B IG K

$06: 02: 00$

(B)

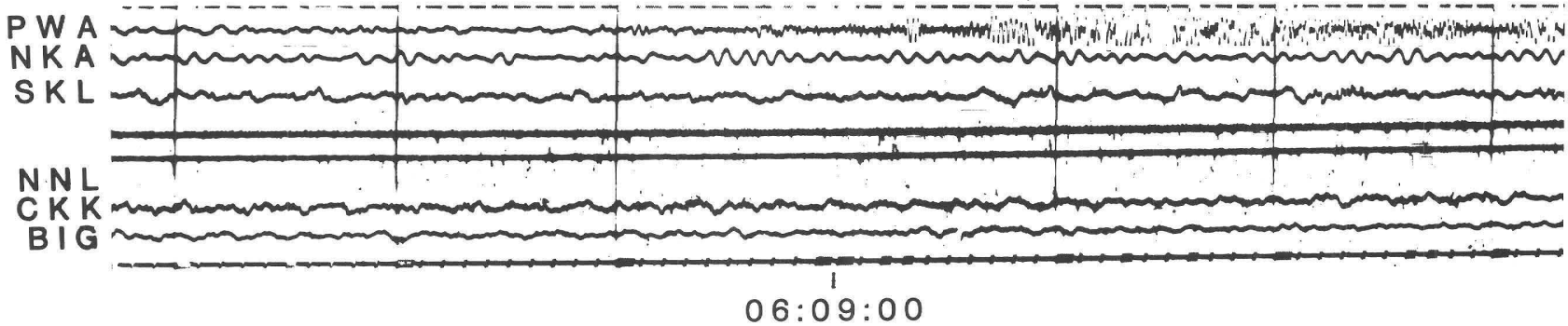

(C)

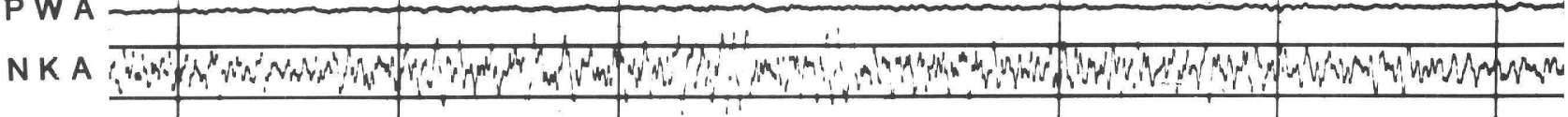

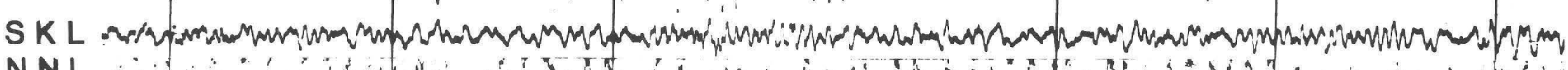

CNL

$B$ IG

$06: 12: 00$

(D)

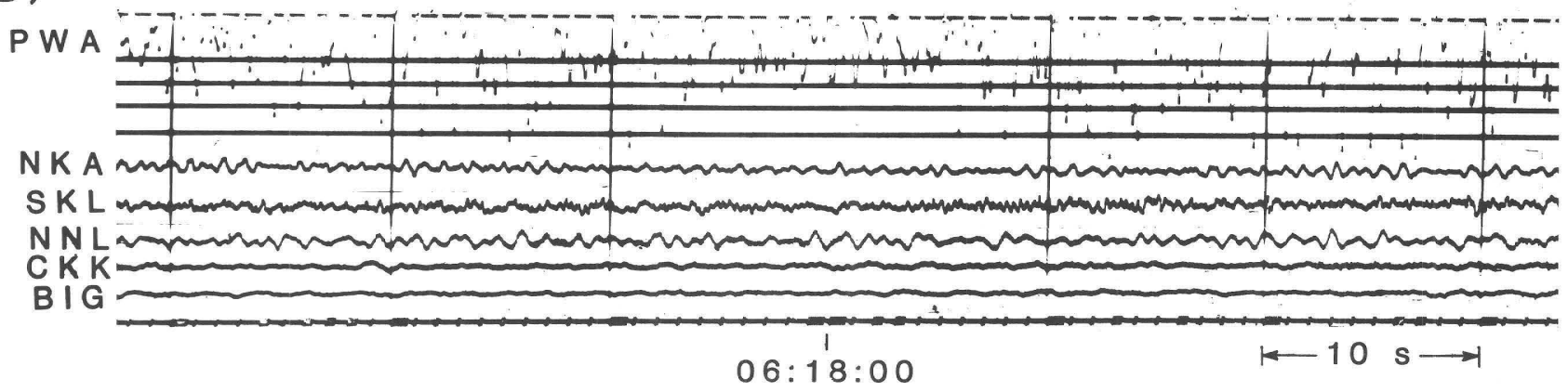

Figure 16. One-minute windows of the seismogram recording seismic activity of January 24, 1976. A, Large tremor beginning at 05:59:00 u.t. B, Eruption-induced air-phase signal at seismic station NNL. C, Air-phase signal at seismic stations NKA and SKL. D, Air-phase signal at seismic station PWA. 


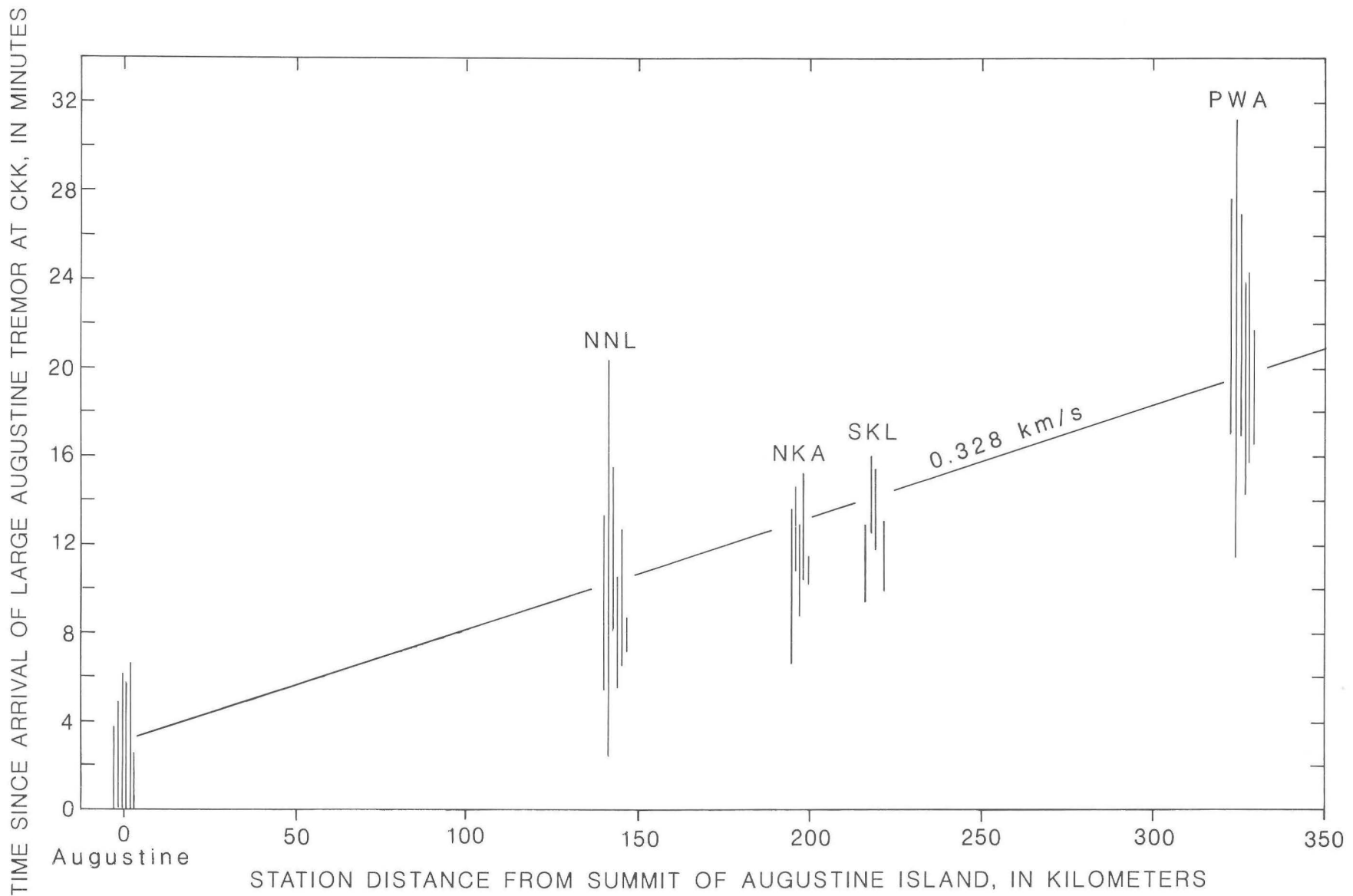

Figure 17. Commencement, duration, and approximate traveltime of Augustine eruption-induced air-phase disturbances as recorded at seismic stations NNL, NKA, SKL, and PWA from 20:00 u.t. January 23 through January 24, 1976, with respect to large tremors at Augustine volcano as recorded at seismic station CKK (tables $2,3)$.

earthquake swarm radiated about 82 percent of the total Augustine shallow-earthquake energy of $34 \mathrm{x}$ $10^{15}$ ergs (fig. 19) for the period of November through April.

Between 08:08 and 13:45 on January 23, a series of 13 small tremors occurred (table 2) along with some very shallow earthquake swarms. Although most of these small tremors lasted for less than $2 \mathrm{~min}$, one small tremor at $08: 18: 54.5$ actually lasted $40 \mathrm{~min}$, which represents the longest recorded duration of a small tremor.

Between $13: 53$ on January 23 and 15:09 on January 25, a series of 12 large tremors occurred (table 2; fig. 20) along with some very shallow earthquake swarms and small tremor. The peak-topeak amplitudes of these large tremors at 5-s intervals as measured on a Geotech Model 6585 film viewer are shown on figure 21 , as are the $\mathrm{M}_{\mathrm{L}}$ values and times for very shallow earthquakes during these large tremors. Some of these large tremors displayed a fairly symmetrical distribution of amplitudes over time (fig. $21 \mathrm{~F}, \mathrm{H}, \mathrm{J}, \mathrm{K}, \mathrm{L})$. Others were characterized by more of an asymmetrical distribution, with the rate of increase in amplitude greatly exceeding the rate of decay (fig. 21D, G, M). None were as extreme as the asymmetrical distribution of amplitudes over time of the 18:00 January 22 event (fig. 21A). One large tremor displayed an asymmetrical distribution of amplitudes with two major peaks (fig. 21E), which most likely represents two overlapping tremors. In detail, each large tremor had its own unique amplitude configuration.

Most of the Augustine earthquake swarms that occurred during the January eruptive sequence preceded and were possibly linked to large tremors, even though very few earthquakes occurred during or immediately following the large tremors. For example, shallow-earthquake swarms immediately preceded the large tremors of $13: 53$ and $16: 58$ on January 23, and of $11: 23$ and $14: 40$ on January 24 (fig. $21 \mathrm{C}, \mathrm{F}, \mathrm{K}, \mathrm{L}$ ), but no earthquakes occurred during or immediately following these large tremors. The same is true for the large tremor of 15:00 January 23, except for a small earthquake swarm that followed the large tremor after a lapse of about $15 \mathrm{~min}$ (fig. 21D). In the case of the 16:10 January 23 large tremor (fig. $21 \mathrm{E})$, the earthquake swarm extended into the first

Figure 18. Sequence of Augustine events between November 1, 1975, and April 30, 1976. 

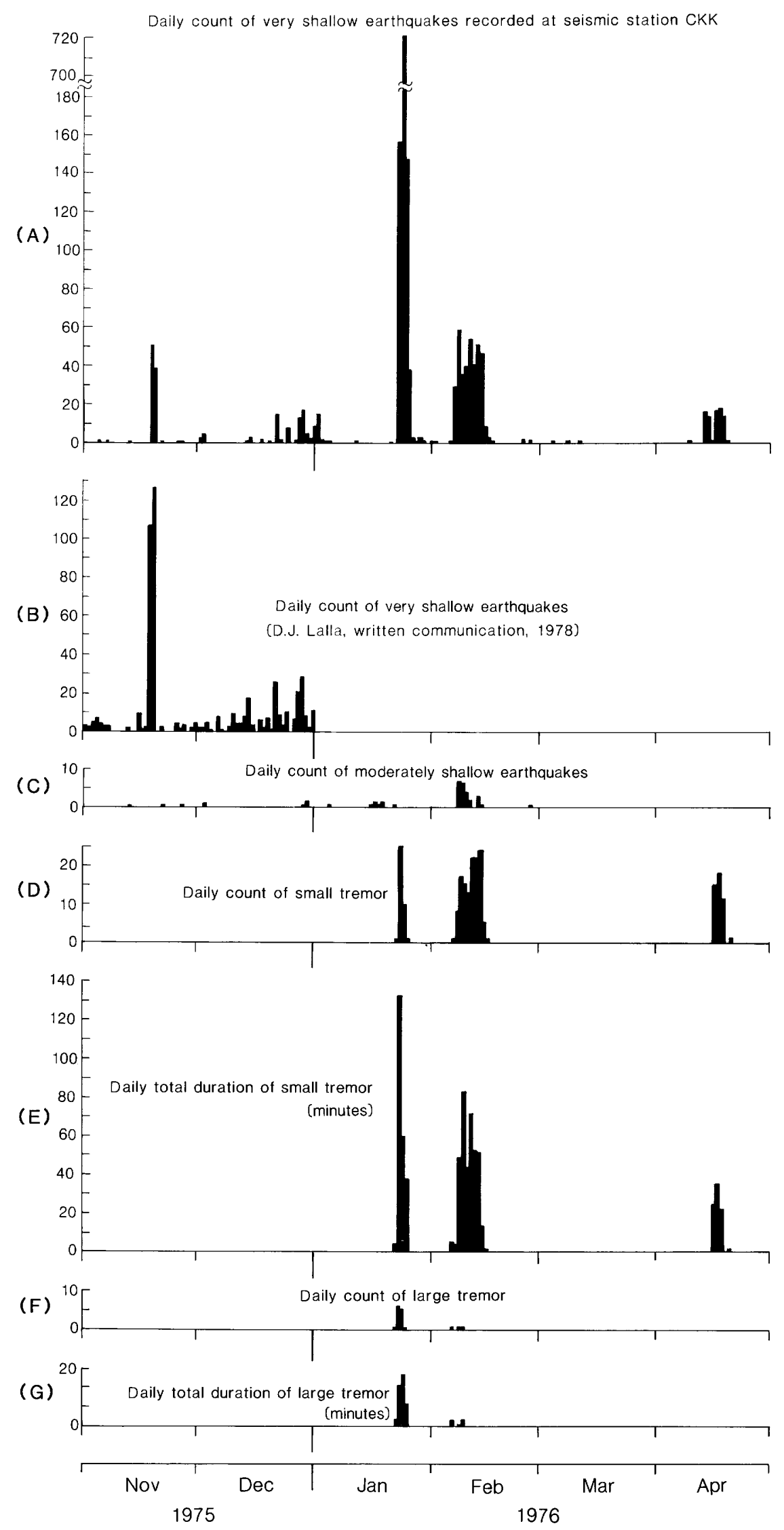
peak of the large tremor but not into the second. This may indicate that the two peaks represent two overlapping large tremors. A somewhat different pattern is shown for the large tremors of 17:41 January 23, 18:40 January 24, and 14:57 January 25 (fig. 21G, M, N), since they were preceded by only one or two earthquakes. Again, no earthquakes occurred during or after these large tremors.

Earthquakes occurred before, during, and after the large tremors of 20:09 January 23 and 05:59 January 24 (fig. $21 \mathrm{H}, \mathrm{J}$ ). This deviation from the sequence described above suggests that some of these shallow earthquakes might have occurred independently of the 20:09 and 05:59 large tremors.

Eruption-induced air-phase disturbances were detected northeast of Augustine volcano in the Cook
Inlet region during the January eruptions by seismograph stations. The arrival times and durations of the air-phase seismic signals for the January large tremors have been listed in table 3 for the NNL, NKA, SKL, and PWA seismograph stations. In addition, the maximum peak-to-peak amplitudes of signals at PWA are given. PWA recorded these disturbances for every large-tremor event during the January eruptive period except for those of 17:59 January 22 and 16:10 January 23. These air-phase signals were confined between 20:09 January 23 and 15:25 January 25 at NNL, between 02:21 January 24 and 15:25 January 25 at NKA, and between 02:21 January 24 and 19:02 January 24 at SKL. The reason for the air-phase time confinement is probably due to the nature of the eruptions and (or) to atmospheric conditions.

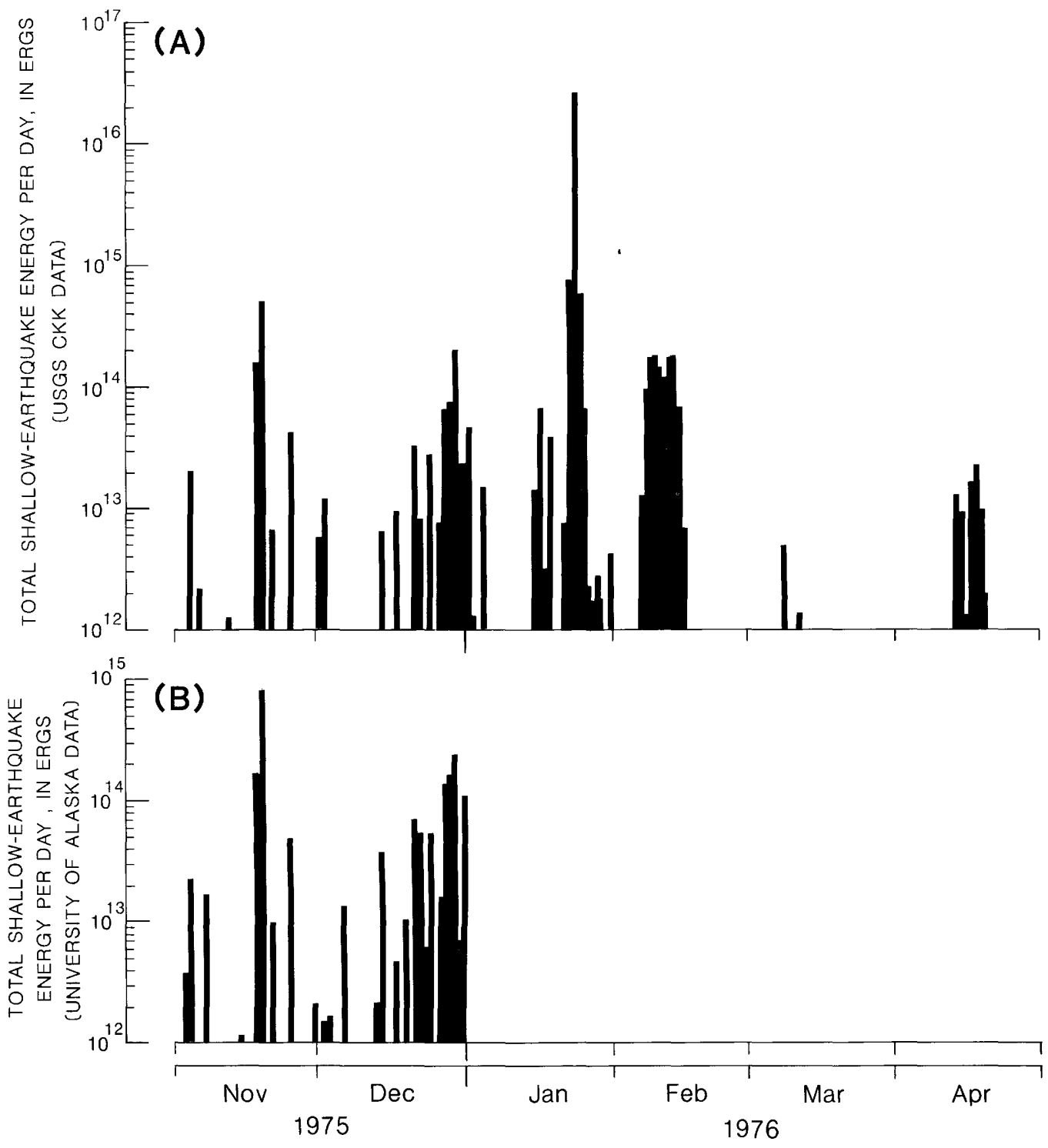

Figure 19. Daily shallow-earthquake radiated energy for Augustine volcano between November 1, 1975, and April 30, 1976. A, Energy determined by equation 3 in text using CKK seismograph shallow-earthquake data. B, Energy determined by equation 3 using University of Alaska shallow-earthquake data (after D.J. Lalla, written commun., 1978). 


\section{The February Eruptive Sequence}

The February eruptive sequence is summarized in figure 22. This summary on an hourly basis includes (A) the count of very shallow earthquakes, (B) the count of moderately shallow earthquakes, (C) the count of small tremor, (D) the total duration in minutes of small tremor, (E) the count of large tremor, and $(F)$ the total duration in minutes of large tremor.

Without obvious warning the February eruptive sequence began at about 14:44:14 on February 6 as small tremor, increased to large tremor, and then decayed with a fairly symmetrical distribution of amplitudes over time (fig. 23A). Two other large tremors have been recognized during this February eruptive period. One started at about 22:27:02 February 8 and the other at about 00:10 February 9 . Unlike most of the January large tremors, the February ones were not preceded by very shallow earthquake swarms. In fact, these large tremors appear to have little relationship to the Augustine shallow ear thquakes.

The February eruptive sequence consisted of numerous very shallow earthquake swarms, moderately shallow earthquake swarms, and small tremors. A total of 321 very shallow Augustine earthquakes
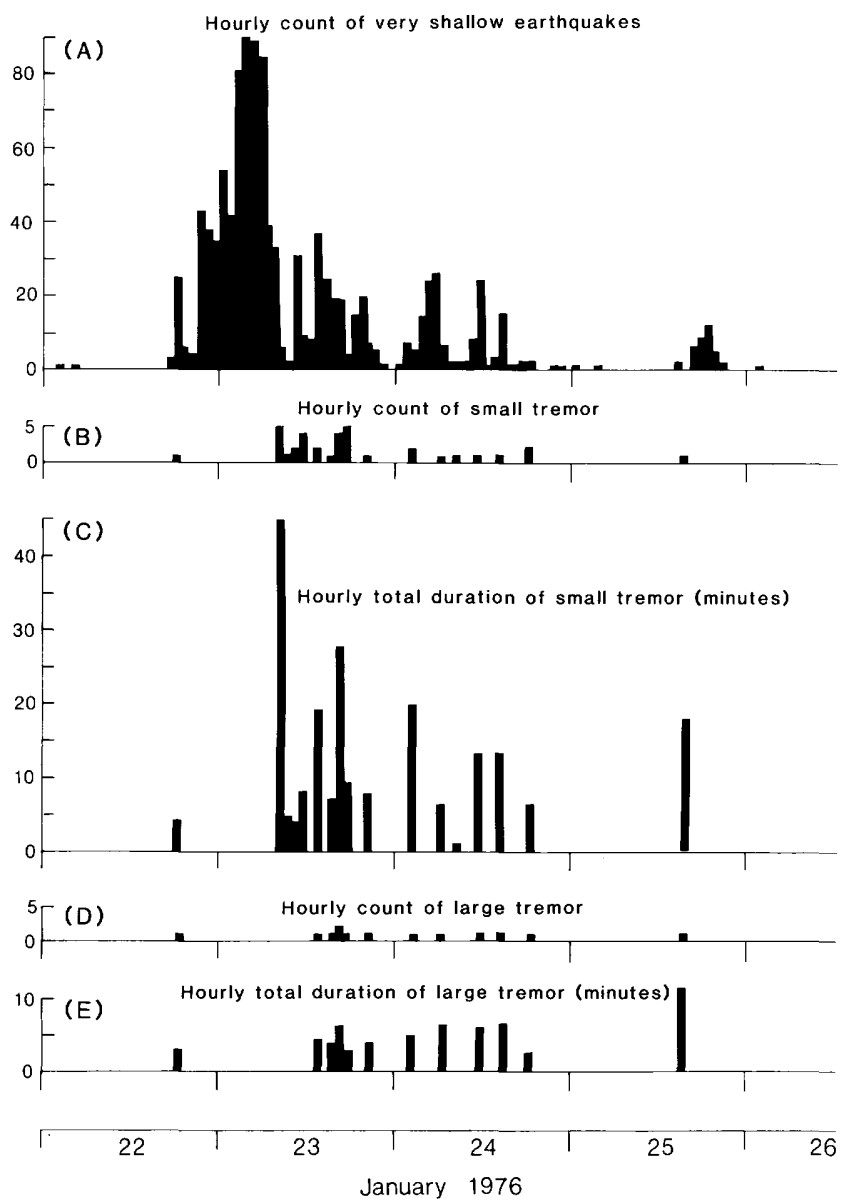

Figure 20. Sequence of Augustine events between 00:00 u.t. January 22 and 12:00 u.t. January 26, 1976. occurred. These were fairly evenly distributed over the eruptive period. A total of 43 moderately shallow earthquakes occurred of which 32 were between 6:00 February 7 and 10:00 February 9. In contrast, 231 of the 255 February small tremors occurred between 13:00 February 8 and 9:00 February 14 .

Many of the February small tremors appear to correspond to some of the very shallow earthquakes. In some cases small tremors may have been "triggered" by shallow earthquakes, as indicated in figure 12, where a 23:35:11.5 February 13 earthquake immediately preceded small tremor and an observed eruptive cloud.

The energy radiated by the moderately shallow earthquakes during the February eruptions was about $0.26 \times 10^{15}$ ergs as based on equation (3). This is about 46 percent of the total energy radiated between November 1, 1975, and April 30,1976, by all of the moderately shallow Augustine earthquakes. Most of the rest ( 52 percent) of the radiated energy from moderately shallow earthquakes occurred during the $\mathbf{1 5}$ days prior to the initial January 22 eruption.

\section{The April Eruptive Sequence}

The April seismic eruptive sequence is shown in figure 24. This summary on an hourly basis includes (A) the count of very shallow earthquakes, (B) the count of small tremor, and (C) the total duration in minutes of small tremor. No moderately shallow earthquakes and no large tremors were detected during this period of eruption.

The April eruptive sequence consisted of 81 very shallow earthquakes. This sequence also included 45 small tremors, ranging from 0.40 to $2.10 \mathrm{~min}$ in duration with an average duration of $0.94 \mathrm{~min}$. This eruptive sequence began with an earthquake swarm at $00: 25: 23$ on April 13. The swarm consisted of 29 very shallow Augustine earthquakes, which lasted until 09:56 on April 14. Following 42 hours of quiescence, a second phase of the April eruptive sequence began at 04:14 on April 16 as a series of small tremors. Shallow earthquake swarming did not occur until 07:28 on April 16 .

\section{SEISMIC DATA INTERPRETATIONS}

\section{Source Mechanisms for the Eruptions}

One of the major problems in seismology is understanding the source mechanisms of seismic signals from volcanoes. With respect to volcanic tremor, similar signals have been generated by pyroclastic flows, lava avalanches (Shimozuru and others, 1969), rockfalls (Tilling and others, 1975), and geysers (Rinehart, 1965; Kieffer and Ihnen, 1977). It is believed that explosive seismic signals are caused by the vibration of a spherical magma chamber (Kobotera, 1974) or of a cylindrical chamber and (or) conduit (Shimozuru, 1961; St. Lawrence and Qamar, 1979). It has been argued that such vibrations are due to magma movements, due to the "implosion of vapor bubbles" (Kieffer and Ihnen, 1977), and due to the transition from subsonic speeds to supersonic speeds of 
moving gases (Steinberg and Steinberg, 1975) that were possibly caused by the "sudden release of pressure in the gas by the mechanical failure of a capping retaining medium" (Self and others, 1979). Explosive seismic signals might also be caused by vibration of a magma-filled crack that is being extended by magmatic pressure, or by vibration of a chain of cracks separated by barriers that yield to magma pressures in a "jerkily" fashion (Aki and others, 1977).

Because of the large distances between Augustine volcano and the seismograph stations and because of the complex crust of this region, the volcanic tremor may have been caused by shallowearthquake (that is, Latter's volcano-tectonic earthquake) swarms in the summit region of Augustine, where the seismic signals have been highly attenuated. Such attenuated signals have been observed by MacDonald and Eaton (1964, their fig. 36) in Hawaii for shallow earthquakes recorded at distances greater than $15 \mathrm{~km}$ from their epicenters. In addition, if the shallow earthquakes occurred at a very high rate, the earthquake signals would overlap and possibly result in the volcanic tremor that was observed. For example, Malone and Qamar (1984) observed signals during the 1984 eruptions of Mount St. Helens that graded from distinct earthquakes to volcanic tremor and then back to distinct earthquakes. Malone and Qamar interpreted this volcanic tremor as at least partially due to a high frequency of similar-sized earthquakes. The Augustine earthquake swarms could be related to the "mechanical failure...of the retaining medium" in the
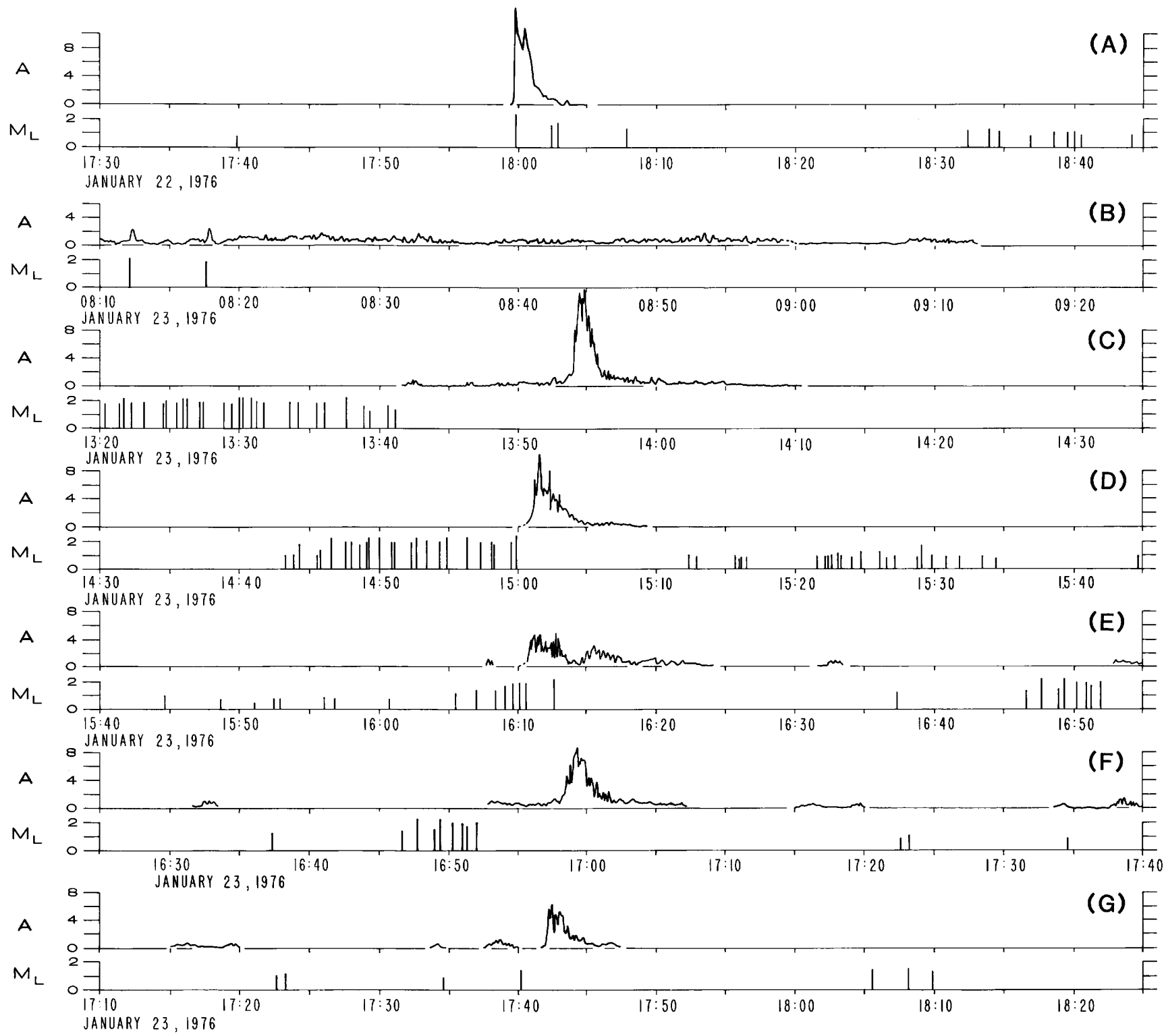

Figure 21. Augustine peak-to-peak amplitudes $(A)$, in centimeters, of large tremor and local magnitudes $\left(M_{L}\right)$ of very shallow earthquakes during January 22-25, 1976. Amplitudes were recorded at seismic station CKK. 
conduit. If this interpretation is correct, not all tremor necessarily corresponds to eruptions. However, the direct observations during some of the February eruptions do suggest such a one-to-one correspondence.

\section{Earthquake Frequency-to-Magnitude Relationships}

The frequency distribution of magnitudes of the Augustine shallow earthquakes is shown in figure 25 . Both the interval distribution (the number of events within the interval $M_{L}$ to $M_{L}+0.05$ ) and the cumulative distribution (the number of events greater than or equal to $\mathrm{M}_{\mathrm{L}}$ ) are shown for the following groups of events: ${ }^{L}$ (A) the January 22-23 main earthquake swarm; (B) the January 23-25 eruptive period; (C) the February 5-16 eruptive period, excluding events more than $1.1 \mathrm{~km}$ below sea level (that is, the moderately shallow earthquakes); (D) the April 13-20 eruptive period; (E) the December 21, 1975 , to January 3, 1976, period, excluding the moderately shallow earthquakes; and $(F)$ the November 1,1975 , to April 30,1976 , period of moderately shallow earthquakes. Each of the cumulative distribution plots may be fitted by two straight-line segments having the form (Gutenberg and Richter, 1949)

$$
\log _{10} N=a-b M_{L}
$$

where $\mathrm{N}$ is the total number of earthquakes having a magnitude greater than or equal to $\mathrm{M}_{\mathrm{L}}$

The parameters $a$ and $b$ satisfying equation (5) for each of the cumulative distribution plots have been determined by fitting straight-line segments by eye and are given in figure 25. Parallel lines have also been fitted by eye to the interval distribution data.
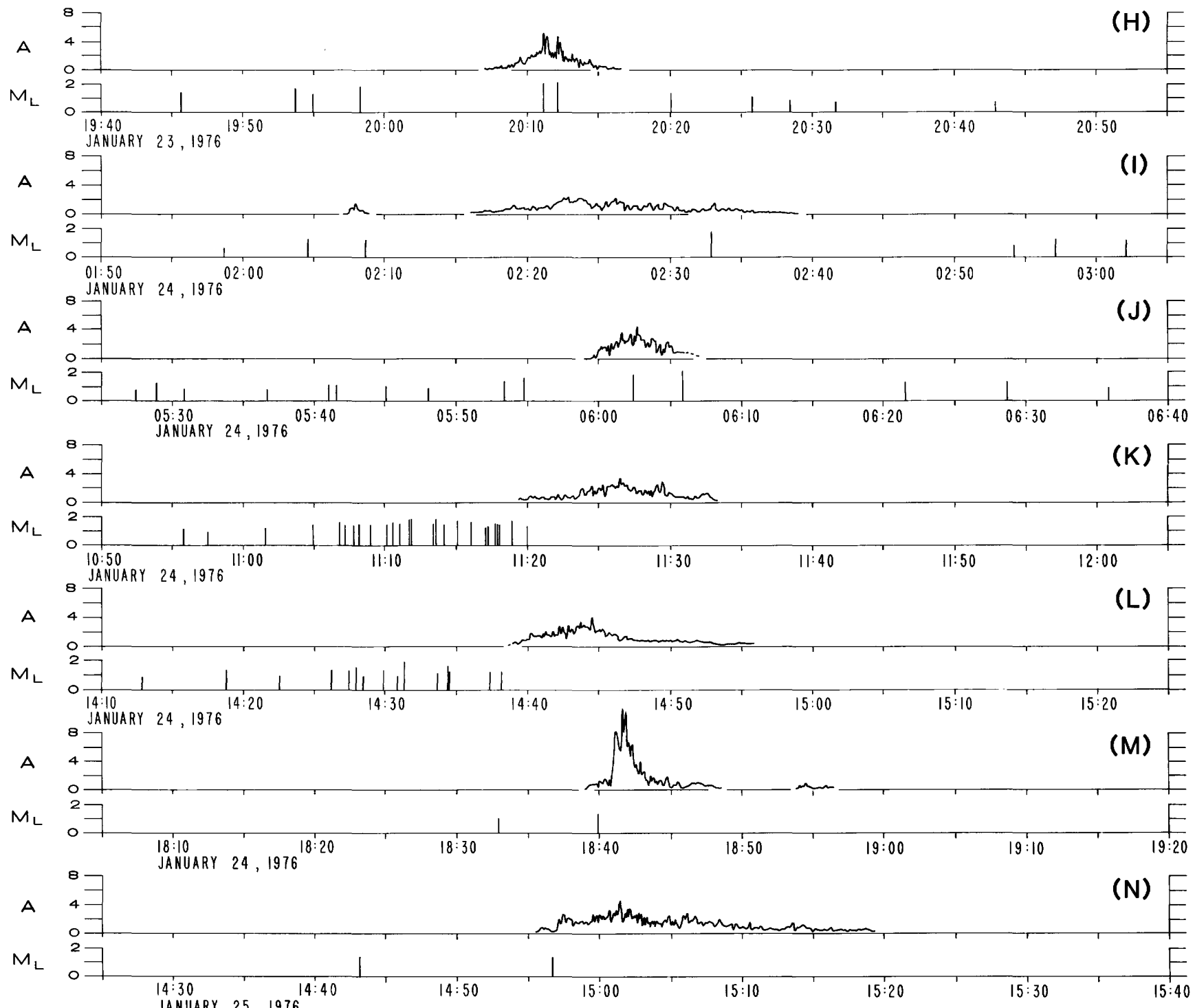

Figure 21. Continued. 
Table 3. Arrival times and durations of Augustine eruption-induced air-phase seismic signals at NNL, NKA, SKL, and PWA, including maximum amplitudes of the air-phase seismic signals at PW A

\begin{tabular}{|c|c|c|c|c|c|c|c|c|c|}
\hline $\begin{array}{l}\text { Arrival time } \\
\text { of large } \\
\text { tremors at } \\
\text { CKK } \\
1976 \text { (min) }\end{array}$ & $\begin{array}{l}\text { Arrival time } \\
\text { of air-phase } \\
\text { seismic } \\
\text { signals at } \\
\text { NNL (u.t.) }\end{array}$ & $\begin{array}{l}\text { Duration of } \\
\text { air-phase } \\
\text { seismic } \\
\text { signals at } \\
\text { NNL (min) } \\
\end{array}$ & $\begin{array}{l}\text { Arrival time } \\
\text { of air-phase } \\
\text { seismic } \\
\text { signals at } \\
\text { NKA (u.t.) }\end{array}$ & $\begin{array}{l}\text { Duration of } \\
\text { air-phase } \\
\text { seismic } \\
\text { signals at } \\
\text { NKA (min) } \\
\end{array}$ & $\begin{array}{l}\text { Arrival time } \\
\text { of air-phase } \\
\text { seismic } \\
\text { signals at } \\
\text { SKL (u.t.) }\end{array}$ & $\begin{array}{l}\text { Duration of } \\
\text { air-phase } \\
\text { seismic } \\
\text { signals at } \\
\text { SKL (min) } \\
\end{array}$ & $\begin{array}{c}\text { Arrival time } \\
\text { of air-phase } \\
\text { seismic } \\
\text { signals at } \\
\text { PWA (u.t.) } \\
\end{array}$ & $\begin{array}{l}\text { Duration of } \\
\text { air-phase } \\
\text { seismic } \\
\text { signals at } \\
\text { PWA (min) } \\
\end{array}$ & $\begin{array}{c}\text { Peak-to-peak } \\
\text { maximum amplitude } \\
\text { of air-phase } \\
\text { seismic signals at } \\
\text { PWA (cm) }\end{array}$ \\
\hline \multicolumn{10}{|l|}{ Jan. 22} \\
\hline $17: 59: 42$ & -- & -- & -- & - & - & -- & -- & - & - \\
\hline \multicolumn{10}{|l|}{ Jan. 23} \\
\hline $13: 53: 25$ & -- & -- & - & -- & - & -- & $14: 13: 30$ & 2.83 & 1.60 \\
\hline $15: 00: 42.5$ & -- & - & -- & -- & -- & -- & $15: 19: 17$ & 3.72 & 1.42 \\
\hline $16: 10: 33$ & -- & -- & - & -- & - & -- & & & \\
\hline $16: 58: 19$ & - & -- & -- & - & - & -- & $17: 16: 40$ & 8.83 & 12.00 \\
\hline $17: 41: 55$ & -- & -- & -- & - & -- & -- & $17: 59: 40$ & 4.17 & 2.40 \\
\hline $20: 09: 43$ & $20: 15: 14$ & 7.77 & - & - & - & - & $20: 26: 00$ & 10.53 & 2.60 \\
\hline \multicolumn{10}{|l|}{ Jan. 24} \\
\hline $02: 21: 50$ & $02: 24: 30$ & 17.67 & $02: 28: 15$ & 6.75 & Peak 02:32:00 & Poor signal & $02: 33: 20$ & 19.67 & 16.40 \\
\hline $05: 59: 00$ & $06: 07: 10$ & 7.33 & $06: 10: 10$ & 3.83 & $06: 11: 30$ & 3.5 & $06: 16: 00$ & 10.00 & 7.60 \\
\hline $11: 23: 45$ & $11: 29: 20$ & 5.00 & $11: 32: 30$ & 3.50 & Poor signal & Poor signal & $11: 38: 20$ & 9.67 & 8.80 \\
\hline $14: 40: 15$ & $14: 46: 50$ & 6.17 & $14: 50: 00$ & 5.17 & Poor signal & Poor signal & $14: 56: 20$ & 8.67 & 15.60 \\
\hline $18: 40: 55$ & $18: 48: 10$ & 1.50 & $18: 51: 11$ & 1.23 & Peak 18:52:00 & Poor signal & $18: 57: 40$ & 5.10 & 2.00 \\
\hline \multicolumn{10}{|l|}{ Jan. 25} \\
\hline $14: 57: 10$ & $15: 08: 40$ & 2.66 & Peak 15:07:36 & Poor signal & & & $15: 13: 52$ & 12.13 & 2.40 \\
\hline
\end{tabular}

At initial glance, the lines may appear to fit the cumulative distributions fairly well. Unfortunately, many of the groups of events are small, resulting in substantial uncertainty in the estimated parameters. The scatter of the data is shown most clearly in the interval distributions. As an example, for the December 21 to January 3 very shallow earthquake swarm (fig. 25E), the b-value fit to the earthquake frequency per 0.05-magnitude interval could easily range from 0.04 (that is, a nearly horizontal line) to 3.5 for the $\mathrm{M}_{\mathrm{L}}=0.9$ to $\mathrm{M}_{\mathrm{L}}=1.4$ interval. Clearly, variations in the distributions must be used with caution.

Nevertheless, despite these complications, some very interesting frequency-to-magnitude relationships exist. For example, the earthquake frequency per 0.05-M interval for the January 22-23 main earthquake swarm (fig. 25A) ranges from about 24 earthquakes at $\mathrm{M}_{\mathrm{L}}=0.8$ to about 15 earthquakes at $\mathrm{M}_{\mathrm{L}}=1.7$. The frequency of earthquakes over this $\mathrm{M}_{\mathrm{L}}$ range is nearly constant. Then, at $\mathrm{M}_{\mathrm{L}}=1.75$, the frequency jumps up to 21 earthquakes per $0.05 \mathrm{M}_{\mathrm{L}}$.

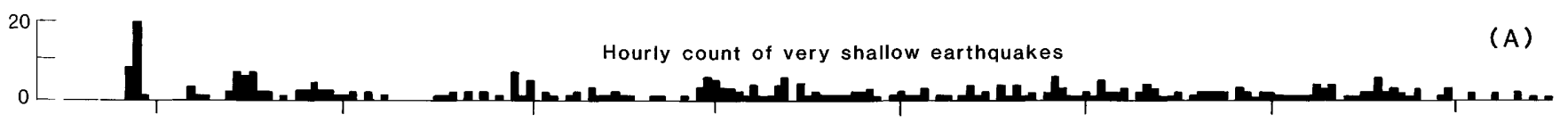

10 Hourly count of moderately shallow earthquakes

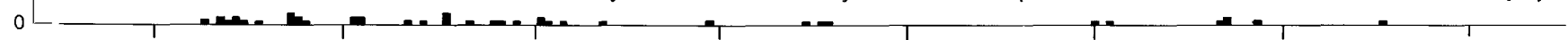

${ }^{10}[-$
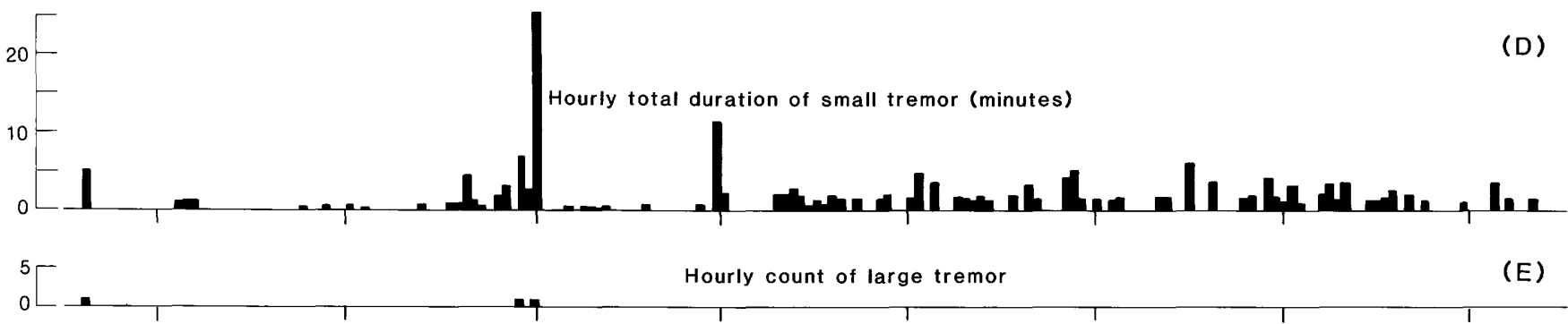

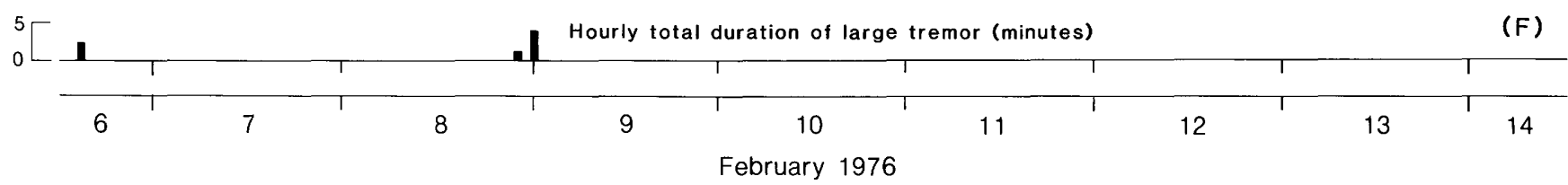

Figure 22. Sequence of Augustine events between 12:00 u.t. February 6 and 13:00 u.t. February 14, 1976 . 
This frequency also stays nearly constant until $\mathrm{M}_{L}=$ 1.95. A large frequency jump occurs at this point, with the rate becoming as high as 52 earthquakes per $0.05 \mathrm{M}_{\mathrm{L}}$, and then the frequency decreases rapidly. This second frequency jump at $\mathrm{M}_{\mathrm{L}}=1.95$ corresponds with the intersection of the two line fits to the cumulative distribution. Although no other $\mathrm{M}_{\mathrm{L}}=1.95$ earthquake frequency jumps have been recognized in the rest of the data, $\mathrm{M}_{\mathrm{L}}=1.75$ jumps appear to occur for the January 23-25 eruptive sequence and for the February 5-16 sequence (fig. 25B, C). For January 2325 , the frequency jumps at $M_{L}=1.75$ from an expected 7 earthquakes per $0.05 \mathrm{M}$ to 14 earthquakes per $0.05 \mathrm{M}$. For February 5-16, the frequency jumps at $M_{L}=1.75$ from an expected 3 earthquakes per 0.05 $\mathrm{M}_{\mathrm{L}}$ to 6 earthquakes per $0.05 \mathrm{M}_{\mathrm{L}}$ In addition, an earthquake frequency jump from an expected 3.5 earthquakes per $0.05 \mathrm{M}_{\mathrm{L}}$ to 8 earthquakes per $0.05 \mathrm{M}$ occurs at $\mathrm{M}_{\mathrm{L}}=1.4$ for the December 21-January 3 earthquake swarm. Upon close examination of the February 5-16 earthquake swarm, an increased earthquake frequency jump also occurs at $\mathrm{M}_{\mathrm{L}}=1.4$.
The breaks of slope in figure 25 are believed to be real because the detection threshold of the operating network was about $\mathrm{M}_{\mathrm{L}}=0.8$ to $\mathrm{M}_{1}=\mathbf{1 . 0}$. Also, such breaks have been observed elsewhere for Atype and B-type volcanic earthquakes (Filson and others, 1973; Guerra and others, 1976; Tanaka, 1967), as well as for fracture experiments performed in the laboratory (Mogi, 1962; Scholz, 1968; Warren and Latham, 1970). The high $b$ values (as high as 6.0) observed for Augustine volcano are comparable to the high $b$ values determined for A-type and B-type volcanic earthquakes elsewhere (Suzuki, 1959; Shimozuru, 1971).

The jump increase in the earthquake frequency at some upper $M_{L}$ value, and the break in the slope of the line fit to the interval and cumulative earthquake frequency distributions, might reflect an upper size restriction for faulting due to some physical and (or) chemical boundary condition in the crust. For example, the size of the largest earthquakes may be restricted to the dimensions of one very large cell or chamber. Such a large cell might contain most of the

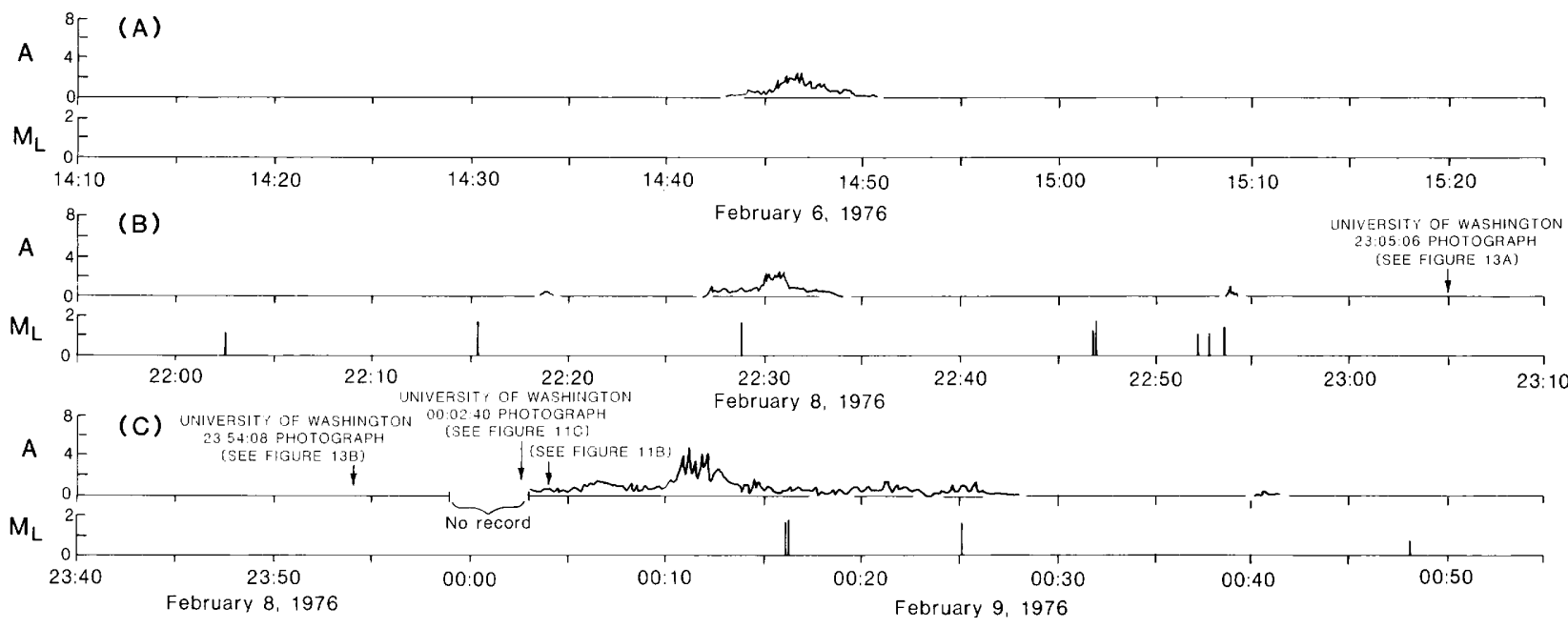

Figure 23. Augustine peak-to-peak amplitudes (A), in centimeters, of large tremor and local magnitudes ( $\mathrm{M}_{\mathrm{L}}$ ) of shallow earthquakes during February 6-9, 1976.
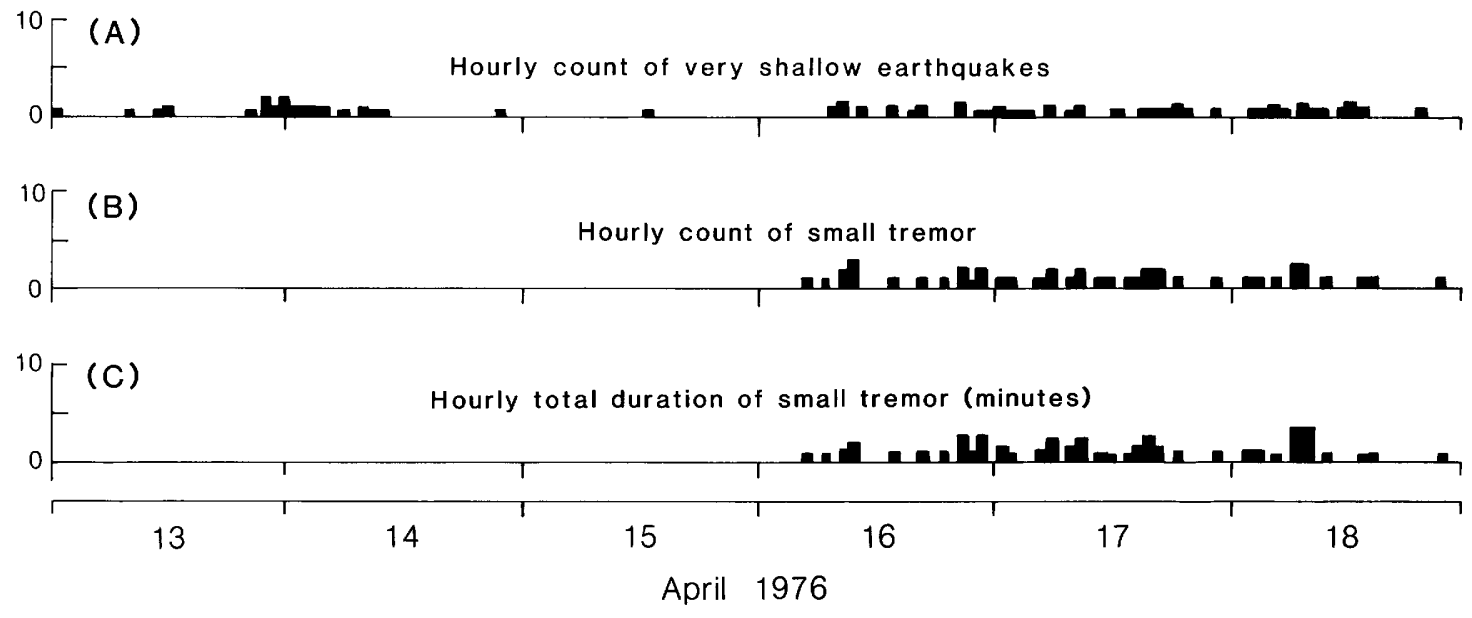

Figure 24. Sequence of Augustine events between 00:00 u.t. April 13 and 00:00 u.t. April 19, 1976 . 
hypocenters for the smaller earthquakes. It was found from seismic observations by Filson and others (1973) of a volcanic eruption in the Galapagos Islands that the caldera collapse of a cylindrical plug resulted in an increased $b$ value in the cumulative earthquake distribution for a surface wave magnitude $\left(M_{S}\right)$ greater than 4.5. This may have resulted from the finite dimensions of the collapse, which did not produce any earthquakes larger than $\mathrm{M}_{\mathrm{S}}=5.1$. At Augustine volcano, the dimensions of the active conduit and (or) active magma body might have restricted the size of the larger earthquakes. In fact, the dimensions of the active conduit and (or) active magma body might have even concentrated the occurrences of the larger earthquakes to some upper $\mathrm{M}_{\mathrm{L}}$ value. This might explain the existence of the Augustine earthquake frequency jumps.

Another change in the cumulative distributions with time was the position of the "knee," the magnitude above which the cumulative distribution steepens (fig. 25). The knee is located at about $\mathrm{M}_{\mathrm{L}}=$ 1.95 for January 22-23 and January 23-25, and at $\mathrm{M}_{\mathrm{L}} \mathrm{L}^{\mathrm{L}}=$ 1.8 for February 5-16. For April 13-20, the knee is estimated to be about $M_{L}=1.1$. This change appears to correlate with the earthquake frequency jumps as well. The movement of both the knee and the highest $\mathrm{M}_{\mathrm{I}}$ earthquake frequency jump to smaller magnitudes with respect to time could reflect a reduction in the dimensions of the region of high stress, which would also reflect a reduction in the dimensions of the seismically active conduit and (or) active magma system. In fact, the position of the knee and of the earthquake frequency jump $\left(M_{L}=1.1\right)$ for the April 1320 period is so small that it probably reflects a restriction of the eruptive activity to just the im mediate summit region.

In addition, the variation in the $b$ values with time for the smaller earthquakes can be partially understood by considering the arguments presented by Warren and Latham (1970). In laboratory experiments
JAN 22-23, 1976 MAIN EARTHQUAKE SWARM VERY SHALLOW EARTHQUAKES

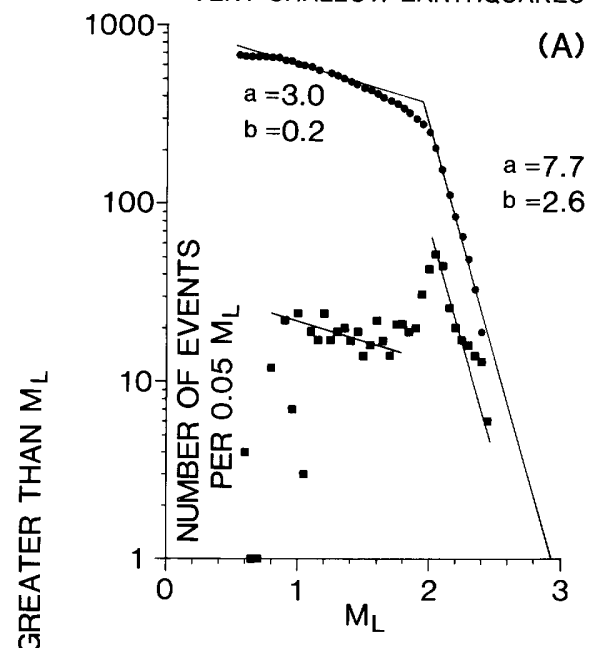

APR 13-20, 1976 ERUPTION PERIOD VERY SHALLOW EARTHQUAKES

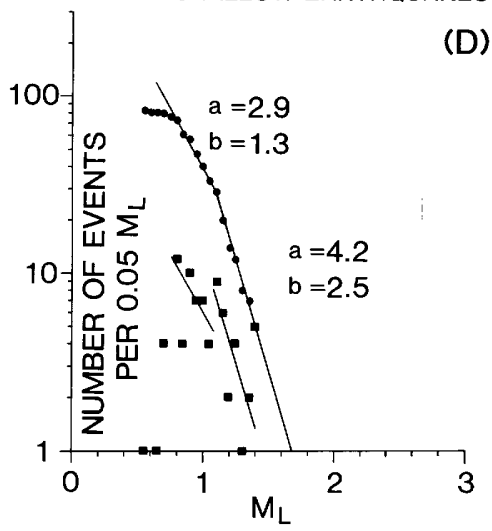

JAN 23-25, 1976 ERUPTION PERIOD VERY SHALLOW EARTHQUAKES

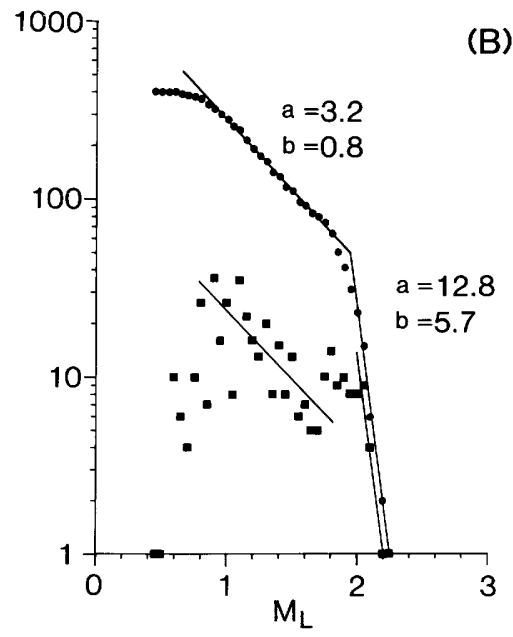

DEC 21, 1975-JAN 3, 1976 VERY SHALLOW EARTHQUAKES

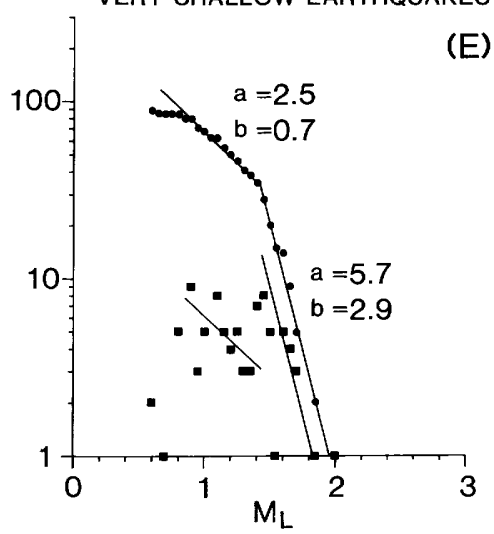

FEB 5-16, 1976 ERUPTION PERIOD VERY SHALLOW EARTHQUAKES

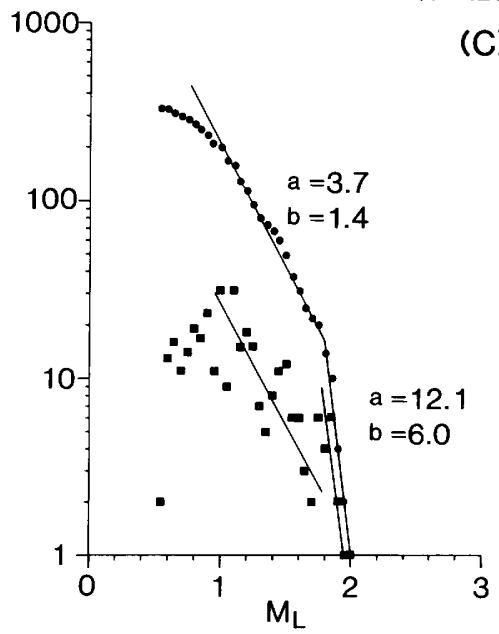

NOV 1, 1975-APR 30, 1976 MODERATELY SHALLOW EARTHQUAKES

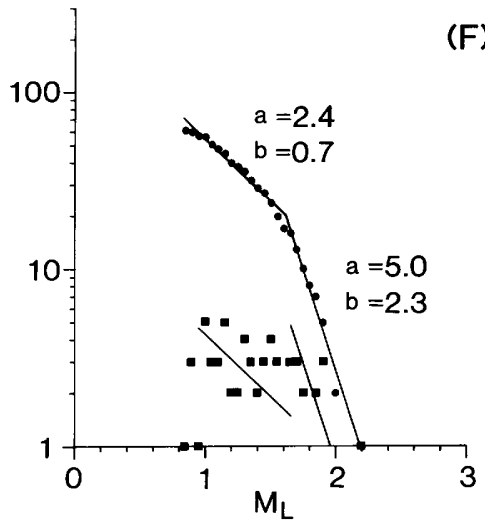

Figure 25. Interval distribution (squares) and cumulative-frequency distribution (circles) of magnitudes for the Augustine 1975-1976 shallow earthquakes. Parameters a and $b$ are from equation 5 in text and have been determined by fitting the straight-line segments shown. 
in which samples were subjected to thermal gradients, Warren and Latham found relatively high b-values, from 1.2 to 2.7, which they attributed to the nonuniformity of the thermally induced stress. They noted that tension fractures growing into high-stress regions will tend to propagate orthogonally into other cracks, resulting in a cellular crack pattern. As time continues, the cellular fracture pattern would become finer, and a larger proportion of small earthquakes would occur, increasing the $b$ value. It can be speculated that the increase of the $b$ value with time for the smaller shallow Augustine earthquakes (January 22-23, 0.2; January 23-25, 0.8; February 5-16, 1.4; and April 13-20,1.3) might be due to a decrease in the size of the cellular fracture pattern in the upper part of a magma chamber and its immediate surroundings--that is, the volcanic conduit and (or) magma body region down to a depth of $1.1 \mathrm{~km}$ below sea level.

\section{Correlations Between Shallow Earthquakes and Explosive Activity}

Correlations of deep $(>40 \mathrm{~km})$ and (or) large $(>5.5$ $M_{S}$ ) earthquakes with volcanic activity have been found (Yamashina and Nakamura, 1978; Carr and Stoiber, 1973; Latter, 1971; Tilling and others, 1976; Yokoyama, 1971; Eaton, 1962). Shallow-earthquake swarms have been documented as occurring before and during eruptive activity in the Hawaiian Islands (Eaton, 1962), in the Mediterranean (Guerra and others, 1976), in the Galapagos Islands (Filson and others, 1973), and in the Orient (Minakami, 1960, 1974; Shimozuru, 1971). Shallow-earthquake events and swarms have been observed to precede the January eruptions and to occur during February eruptions of Augustine volcano.

Because very shallow earthquake swarms immediately precede (by up to $0.5 \mathrm{~h}$ ) and possibly relate to most of the large tremors occurring during January (fig. 21) and because very shallow earthquake swarms occur during tremors in February, the earthquake-radiated energy sequence was compared with the small-and large-tremor sequence by means of crosscorrelation statistical techniques (Davis, 1973). In this correlation technique, a temporal sequence of radiated earthquake energy events is compared with itself (autocorrelation) or with another temporal sequence of events (crosscorrelation). This is done by linear correlation between the earthquake energy sequence and the same sequence at later intervals of time (autocorrelation) or between the earthquake energy sequence and another time sequence at later intervals of time (crosscorrelation). This simple statistical investigation was undertaken to determine if there was any statistical support for the observed correlations.

Such a comparison is shown for the 08:30 January 23 through 03:30 January 24 eruptive period in figure 26 , where very shallow (less than $1.1 \mathrm{~km}$ below sea level) earthquake radiated energy and small- and large-tremor duration were determined for 15-min intervals. The 15-min interval was selected because very shallow earthquake swarms appeared to occur within $15 \mathrm{~min}$ of the large January volcanic tremors.
Although the correlation is not as good as originally suspected, the comparison does suggest that very shallow earthquakes, which precede eruption events, correlate with such events and that the peak of radiated energy from such swarms usually precede the seismic peak of the eruption by about 15 to $30 \mathrm{~min}$ (fig. 26A).

For the February 7 through February 14 eruptive period, similar correlation comparisons were undertaken for very shallow earthquake radiated energy and the duration of small and large tremor (fig. $27 \mathrm{~A}, \mathrm{D})$, for moderately shallow earthquake radiated energy and the duration of small and large tremor (fig. $27 \mathrm{E}, \mathrm{F})$, and for moderately shallow earthquake radiated energy and very shallow earthquake radiated energy (fig. $27 \mathrm{G}, \mathrm{H}$ ). There appears to be a direct correlation between very shallow earthquake radiated energy and small- and large-tremor duration, which confirms the observed increase in earthquake activity during tremors. But no obvious correlation for moderately shallow activity with very shallow activity or with eruptive activity was found (fig. 27E-H). Possibly the time-lag delay observed for the January eruptions with respect to shallow ear thquakes was due to obstructions in the upper part of the conduit. Such obstructions were then cleared by the time of the February eruptions.

A similar correlation comparison was made for the April eruptive period, and no correlations were found between very shallow earthquakes and small tremors (fig. 28). This suggests, as previously indicated by the earthquake $b$ values, that the dimensions of the conduit had been reduced. It is possible that the conduit was no longer transporting magma, and thus the source of the small April eruptions could have been from the immediate summit region.
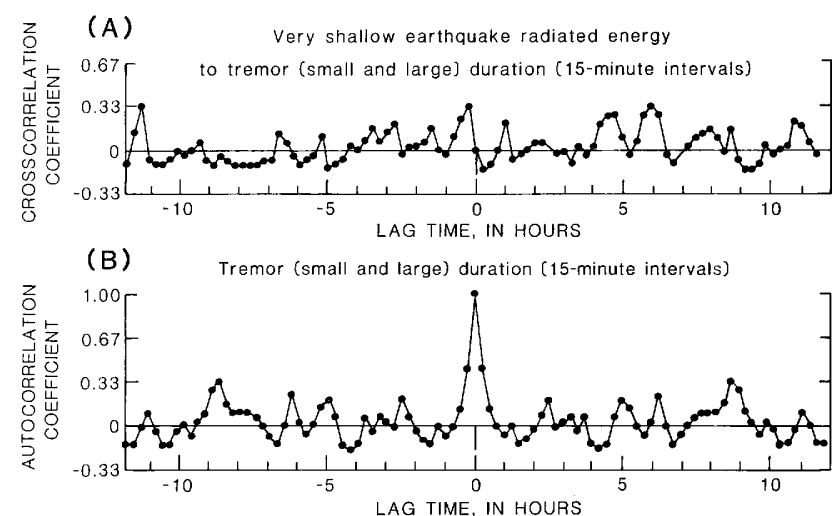

(C)

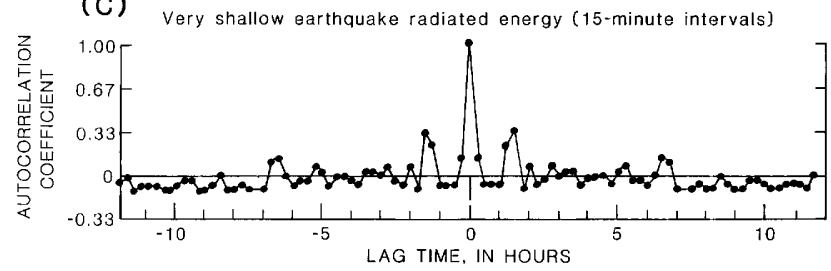

Figure 26. Correlations between radiated energy of very shallow earthquakes and volcanic tremor duration between 08:30 u.t. January 23 and 03:30 u.t. January $24,1976$. 

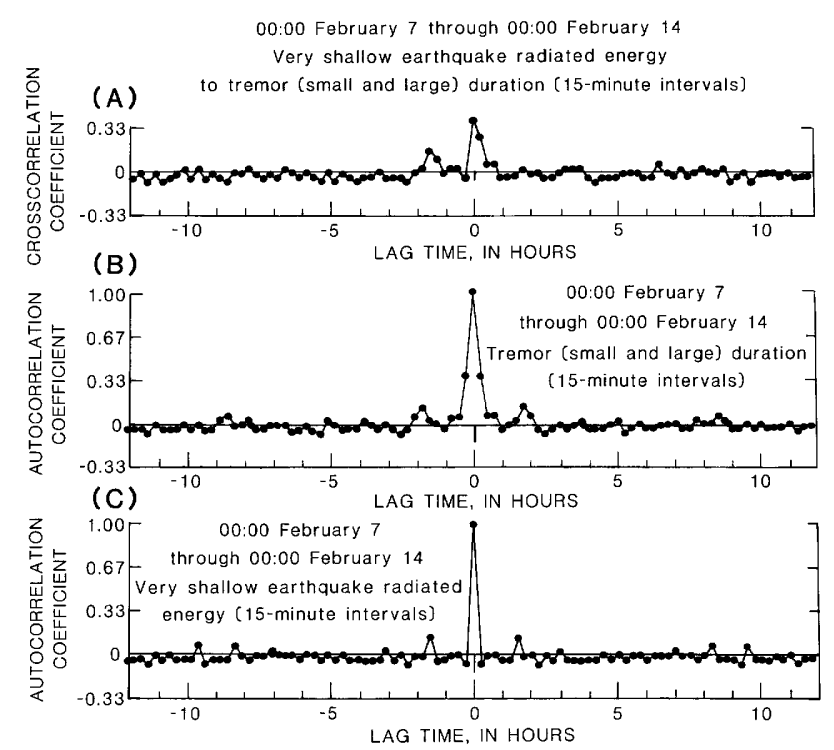

00:00 February 7 through 06:00 February 13
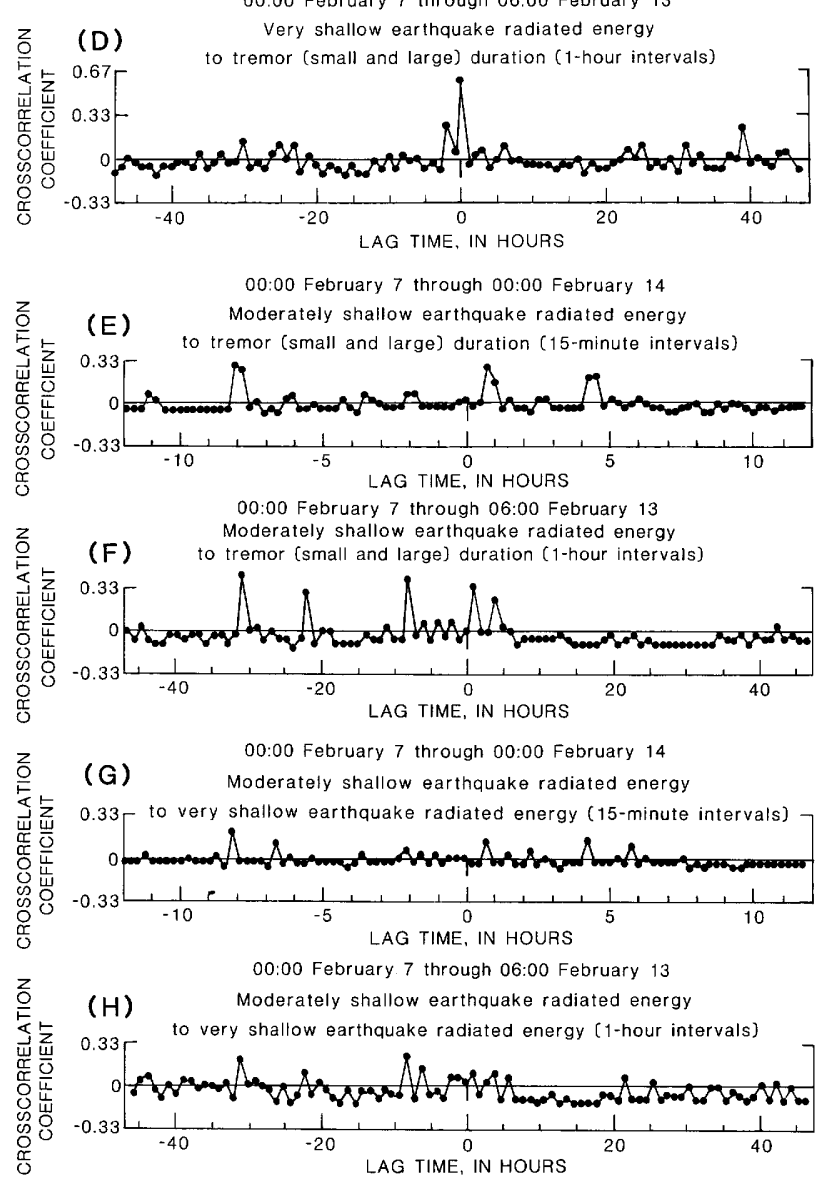

Figure 27. Correlations between very shallow Augustine earthquake radiated energy, moderately shallow Augustine earthquake radiated energy, and Augustine volcanic tremor duration between 00:00 u.t. February 7 and 00:00 u.t. February 14, 1976.

\section{The Air-Phase Mechanism}

Eruption-induced air-phase signals from Augustine volcano were detected by seismograph stations located northeast of Augustine Island to distances of up to $321 \mathrm{~km}$ (figs. 16, 17; table 3). Airphase disturbances were noted in 1955 at distances of $65 \mathrm{~km}$ northeast of Bezymianny volcano during its eruption (Gorshkov, 1959), and seismometers near other erupting volcanoes have detected atmospheric pressure disturbances coupling to the ground (Yoshidome and Seino, 1968; Minakami, 1974; Nairn and others, 1976). More recently, air-wave disturbances from the 1980 eruption of Mount St. Helens have been detected by seismograph stations to distances of $11,300 \mathrm{~km}$ (Donn and Balachandran, 1981; Sawada and others, 1982). Such air-to-ground coupling has been documented for meteors (Donn and Balachandran, 1974; Nagasawa, 1978), for large unidentified bodies from space (most likely large meteors) that have hit the Earth (Ben-Menahem, 1975), and for aircraft sonic booms (McDonald and Goforth, 1969). Conversely, ground disturbances due to earthquakes have coupled to the atmosphere, resulting in sound disturbances (Hill and others, 1976). During the 1883 Krakatoa eruption, some air-phase disturbances coupled to the ocean surface (Harkrider and Press, 1967).

It is not completely understood why air-phase disturbances occurred in the Cook Inlet region during the period between 14:13 January 23 to 15:25 January 25 (table 3). As previously mentioned, seismic recordings are influenced by the type of sensing instrument, the hypocenter distance, the nature of the energy-transporting media between the hypocenter and the sensing instrument, and the source mechanism. All of the seismograph stations detecting the air-phase
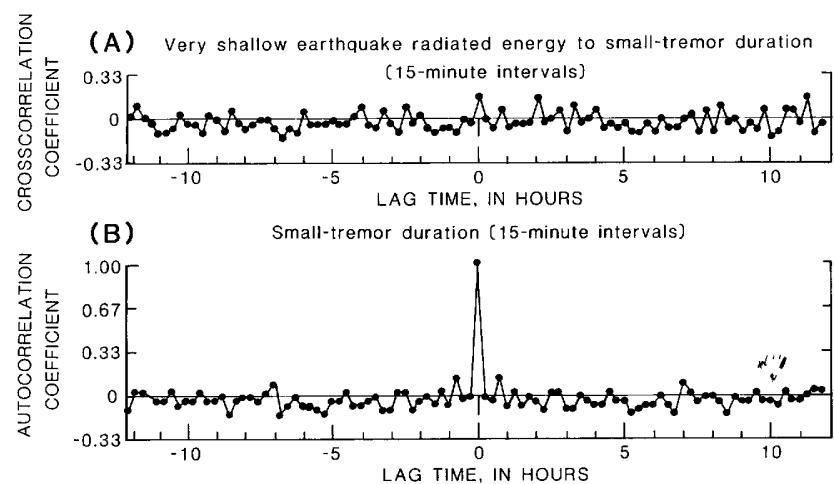

(C) Very shallow earthquake radiated energy (15-minute intervals)

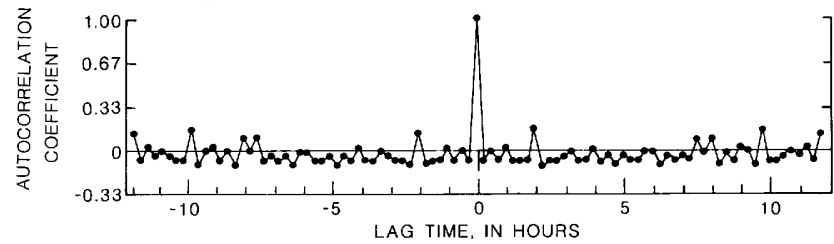

Figure 28. Correlations between very shallow Augustine earthquake radiated energy and Augustine small-tremor duration between 08:00 April 16 and 16:00 April 18, 1976. 
disturbances except SKL were located on unconsolidated deposits, which is a medium better suited than bedrock for air-to-ground seismic coupling. The only factors that might have influenced the air phase with respect to time would have been the atmospheric conditions (energy-transporting media) and the explosive mechanism at the volcano (source mechanism).

During the January 23-25 period of the air-phase eruptive detections in the Cook Inlet region, the atmospheric conditions were favorable for transmitting air-phase disturbances from Augustine Island up the Cook Inlet. As described by PridmoreBrown (1962), air-disturbance rays from a source are bent "downwards on the downwind side," and such downward bending is accentuated by positive temperature gradients (inversions). For the first 0.5 $\mathrm{km}$ of the atmosphere during this time, the wind shifted from being a northeast wind (blowing toward the southwest) to a west wind, to a southwest wind, and then finally to a south wind (National Weather Service; fig. 29). Temperature inversions also occurred (fig. 29).

A crater formed during the January eruptions, and by the end of this first eruptive period it had a depth of $200 \mathrm{~m}$. It was breached sometime during the January eruptions on its nor thern side. More extensive pyroclastic flow deposits were found on the northern flank of the mountain than elsewhere (Johnston, 1978). Such deposits probably resulted from several directed blasts from the crater break. North- or nor theast-directed blasts at the summit of the volcano could have triggered the atmospheric pressure disturbances, which then traveled northeast up the Cook Inlet during the January 23-25 eruptions.

\section{Seismic-Geologic Correlation}

Although the limited amount of direct observations indicate a correlation of small and large tremors with volcanic eruptions, the relationship of tremors to the stratigraphy of the 1976 eruption deposits is not obvious. For example, Johnston (1978) reported the following deposits for the January eruptive period (bottom to top): (a) a discontinuous tan ash; (b) a gray ash present nearly everywhere, which possibly represented two distinct deposit layers; (c) an olive ash layer in the northeastern quadrant of the island; (d) three pumiceous pyroclastic flow deposits; and (e) pyroclastic flow deposits on all flanks of the mountain. The relationship of these observed deposits to the 13 detected large tremors and the 22 small tremors can only be speculated. Considering the number of seismic eruptive events, it is suspected that other erupted horizons might be found, especially on the upper slopes of the volcano.

Johnston (1978) reported for the February and April eruptions two fairly large pyroclastic flow deposits on all flanks of the volcano, and then about 70 to 100 smaller pyroclastic flow deposits on the nor theast flank of the volcano. Possibly the two initial pyroclastic deposits correspond to the first large tremor and the following small-tremor cluster of 14:45 on February 6 and of $02: 17$ to $04: 38$ on February 7, respectively. The other 70-100 smaller pyroclastic flow deposits might correspond to the other 116 small tremors and the other 2 large tremors of February (fig. 22) and to the 45 small tremors of April (fig. 24). Perhaps not all of the February and April small tremors represented eruptions. It is more likely, however, that not all of the erupted horizons have been found or that some of the horizons were possibly destroyed by overriding pyroclastic flows.

A dome began to grow sometime between February 6 and 12 within in crater of Augustine volcano and continued to grow during the rest of the February and April eruptions (Johnston, 1978). It is suspected, partly as a result of the blocky nature of most of the pyroclastic flow deposits, that most of the tremors were related to eruptions associated with the growth of this new dome, whereas most of the tremors observed during the $08: 00$ to $13: 45$ eruptive period on

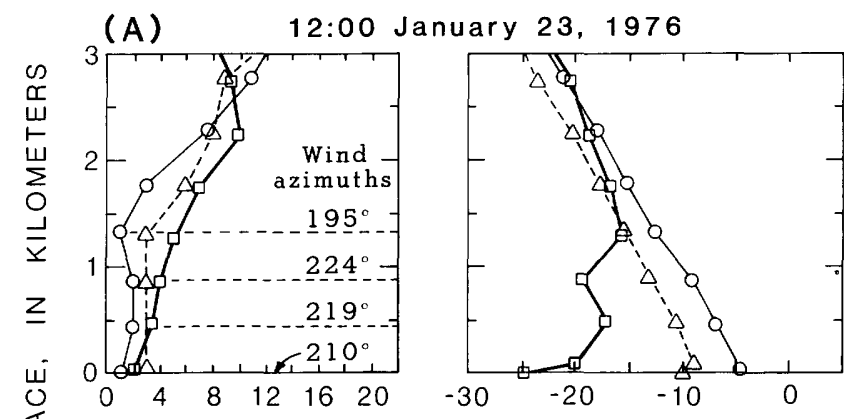

(B) 00:00 January 24, 1976
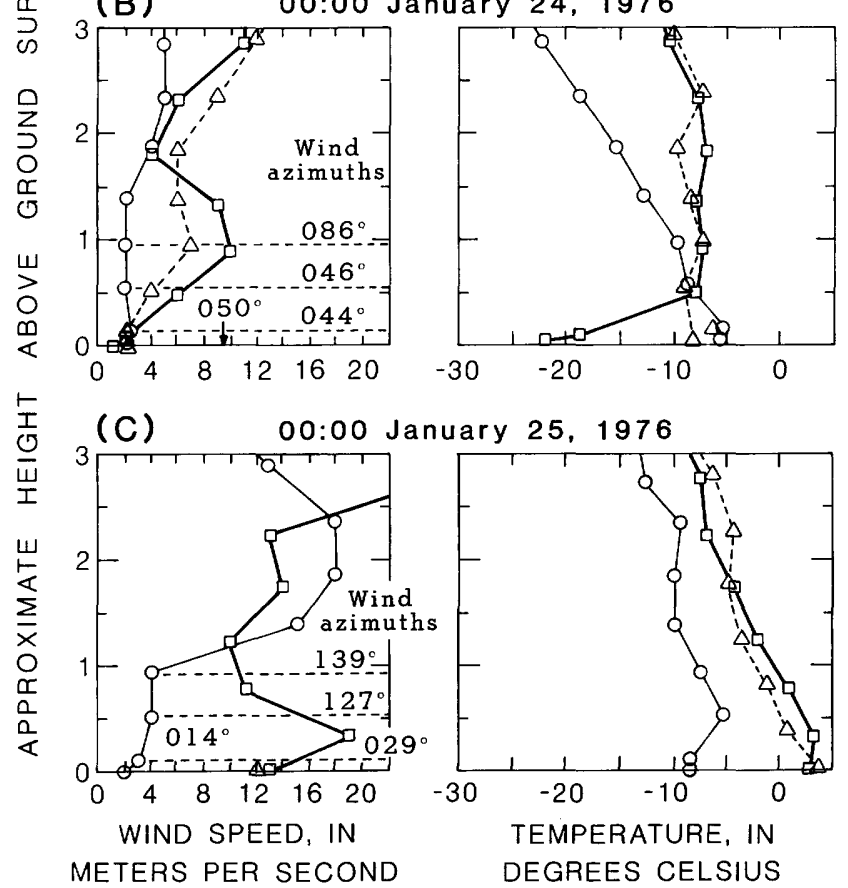

Figure 29. Radio soundings of the atmosphere at Kodiak (triangles), King Salmon (squares), and Anchorage (circles), (NOAA, National Weather Service). Wind azimuths are given just for Anchorage. A, Sounding for 12:00 January 23, 1976. B, Sounding for 00:00 January 24. C, Sounding for 00:00 January 25. 
January 23 were related to eruptions occurring while the old 1963-64 dome still existed. This old dome probably was destroyed by the large tremor of 13:46 January 23.

In order to account for the plagioclase microphenocryst observed in the erupted deposits, Johnston (1978) concluded that roughly 13 to 80 days of mixing of basalt and dacite at a depth of about 2-10 $\mathrm{km}$ would have been required before the first eruption. Interestingly enough, this time period roughly correlates with the time span of the moderately shallow earthquakes that occurred before the January eruptions at depths between 1.1 and $20 \mathrm{~km}$ below sea level. (These earthquakes preceded the January eruptions by up to 71 days, as shown in figure 18C-E.)

\section{CONCLUSIONS}

Shallow earthquakes, volcanic tremor, and eruption-induced air-phase signals were recognized as seismic signals related to the Augustine 1976 eruptive activity. These seismic events, including their seismic time sequence, revealed information about (a) the source mechanisms of the eruptions, (b) the earthquake frequency-to-magnitude relationships, (c) the relationships between shallow earthquakes and volcanic tremor, (d) the eruption-induced air-phase mechanism, and (e) the seismic-geologic relationships.

The volcanic tremor in general appears as gradually increasing and then decreasing seismic signals, which in detail actually pulsate. These signals are believed to possibly result from tremor caused by the transport of gases, magma, and (or) rock through the conduit during volcanic eruptions. Because of the large distances between Augustine volcano and the seismograph stations and because of the complex crustal structure at the volcano, the tremors might have also been caused by highly at tenuated earthquake swarms consisting of a high frequency of similar-sized events in the summit region of the volcano. Such swarms could be related to the mechanical failure of any retaining medium in the conduit region and could account for the pulsating nature of the tremor signals.

The frequency distribution of magnitudes for Augustine shallow earthquakes varies with respect to both time and earthquake size, and it appears to reflect different stages and aspects of the volcanic eruptive process. Even though a fair amount of scatter exists in the magnitude distribution data, these data have been roughly fitted by two straight-line segments, each having the form of the Gutenberg and Richter (1949) relationship. In these frequency-tomagnitude plots, the line segment for the larger earthquakes is always the steeper of the two. This larger slope for larger earthquake magnitudes is believed to be caused by the restriction of the size of the largest earthquakes to the boundaries of the Augustine shallow magma body and (or) conduit. The steepening of the slope for the smaller shallow earthquakes with time during the 1976 eruptive period might be due to the decrease in size of the cellular fracture pattern in the upper part of the Augustine magma body and (or) conduit region.
Although the first January eruption began with no obvious warning, shallow-earthquake swarms preceded by up to $30 \mathrm{~min}$ many of the January eruptions; in contrast, during February, swarms occurred during but did not precede the eruptions. It is suspected that the time-lag delay observed for the January eruptions with respect to shallow-earthquake swarms was due to obstructions in the upper part of the conduit that were cleared by the time of the February eruptions. No correlation appears to exist between shallow earthquakes and small tremor for the April eruptive period. Such a lack of correlation suggests that the conduit between the magma at depth and the summit of the volcano was no longer transporting gases, magma, and (or) rock.

During the period of the air-phase eruptive disturbances in the Cook Inlet region (14:13 January 23 to 15:25 January 25), the atmospheric conditions were favorable for transmitting such disturbances up Cook Inlet. Not only did temperature inversions exist during at least part of this time, but the winds were also out of the southwest for part of this time period. In addition, north- to northeast-directed eruptive blasts were believed to have occurred, which would have been ideal for triggering any northeastward-traveling atmospheric pressure disturbances.

Although the limited observations of Augustine eruptions indicate a correlation between seismic tremor and volcanic eruptions, the relationship between tremor and the stratigraphy of the 1976 erupted deposits is not obvious. Considering the number of tremors, it is suspected that more 1976 erupted horizons might still be found on Augustine Island.

\section{REF ERENCES CITED}

Aki, Keiiti, Fehler, Mike, and Das, Shamita, 1977, Source mechanism of volcanic tremor: fluid-driven crack models and their applications to the 1963 Kilauea eruption: Journal of Volcanology and Geothermal Research, v. 2, p. 259-287.

Aki, Keiiti, and Koyanagi, Robert, 1981, Deep volcanic tremor and magma ascent mechanism under Kilauea, Hawaii: Journal of Geophysical Research, v. 86, no. B-8, p. 7095-7109.

Ben-Menahem, Ari, 1975, Source parameters of the Siberian explosion of June 30, 1908, from analysis and synthesis of seismic signals at four stations: Physics of the Earth and Planetary Interiors, v. 11, p. 1-35.

Carr, M.J., and Stoiber, R.E., 1973, Intermediate depth earthquakes and volcanic eruptions in Central America, 1961-1972: Bulletin Volcanologique, v. 37, no. 3 , p. 326-337.

Davis, J.C., 1973, Statistics and data analysis in geology: New York, John Wiley, $550 \mathrm{p}$.

Diamond, Marvin, 1963, Sound channels in the at mosphere: Journal of Geophysical Research, v. 68, no. 11 , p. 3459-3464.

Dibble, R.R., 1974, Volcanic seismology and accompanying activity of Ruapehu volcano, New Zealand, in Civetta, L., Gasparini, P., Luongo, G., and Rapolla, A., eds., Physical Volcanology: Amsterdam, Elsevier, p. 49-85. 
Donn, W.L., and Balachandran, N.K., 1974, Meteorgenerated infrasound: Science, v. 189, p. 707. 1981, Mount St. Helens eruption of 18 May 1980: air waves and explosive yield: Science, v. 213, p. 539-541.

Eaton, J.P., 1962, Crustal structure and volcanism in Hawaii, in MacDonald, G.A., and Kuno, H., eds., The crust of the Pacific Basin: Geophysical Monograph No. 6, Washington, American Geophysical Union, p. 13-29.

Filson, J.R., Simkin, Tom, and Leu, Lei-kuang, 1973, Seismicity of a caldera collapse: Galapagos Islands 1968: Journal of Geophysical Research, v. 78, no. 35, p. 8591-8622.

Gorshkov, G.S., 1959, Gigantic eruption of the volcano Bezymianny: Bulletin Volcanologique, v. 20, no. 2 , p. 1-77.

Guerra, I., Lo Bascio, A., Luongo, G., and Scarpa, R., 1976, Seismic activity accompanying the 1974 eruption of Mt. Etna: Journal of Volcanology and Geothermal Research, v. 1, no. 4, p. 347-362.

Gutenberg, Beno, and Richter, C.F., 1949, Seismicity of the Earth: Princeton, N.J., Princeton University Press, 273 p.

Hardy, H.C., Telfair, David, and Peilemeier, W.H., 1942, The velocity of sound in air: The Journal of the Acoustical Society of America, v. 13, p. 226233.

Harkrider, David, and Press, Frank, 1967, The Krakatoa air-sea waves: an example of pulse propagation in coupled systems: The Geophysical Journal of the Royal Astronomical Society, v. 13, p. 149-159.

Hill, D.P., Fischer, F.G., Lahr, K.M., and Coakley, J.M., 1976, Earthquake sounds generated by bodywave ground motion: Bulletin of the Seismological Society of America, v. 66, no. 4, p. 1159-1172.

Hobbs, P.V., Radke, L.F., and Stith, J.L., 1977, Eruptions of the St. Augustine volcano: airborne measurements and observations: Science, v. 195, p. 871-873.

Johnston, D.A., 1978, Volatiles, magma mixing, and the mechanism of eruption of Augustine volcano, Alaska: Seattle, University of Washington, Ph.D. thesis, $177 \mathrm{p}$.

Kieffer, S.W., and Ihnen, Steve, 1977, Seismic and aseismic geyser eruptions: Eos (American Geophysical Union, Transactions), v. 58, no. 12, p. 1187.

Kienle, Juergen, Davies, J.N., Miller, T.P., and Yount, M. E., 1986, 1986 eruption of Augustine volcano: public safety response by Alaskan volcanologists: Eos (American Geophysical Union, Transactions), v. 67 , no. 29 , p. 580-582.

Kienle, Juergen, and Forbes, R.B., 1976, Augustine-evolution of a volcano: in Annual Report of the Geophysical Institute, 1975/76: Fairbanks, University of Alaska, p. 26-48.

Kienle, Juergen, and Shaw, G.E., 1979, Plume dynamics, thermal energy and long distance transport of volcanic eruption clouds from Augustine volcano, Alaska: Journal of Volcanology and Geothermal Research, v. 6, p. 139-164.

Koyanagi, R.Y., 1982, Procedures for routine analyses and classification of seismic events at the Hawailan Volcano Observatory, Part I: U.S.
Geological Survey Open-File Report 82-1036, 32 p.

Kubotera, Akira, 1974, Volcanic tremors at Aso volcano, in Civetta, L., Gasparini, P., Luongo, G., and Rapolla, A., eds., Physical Volcanology: Amsterdam, Elsevier, p. 29-48.

Lahr, J.C., 1975, Detailed seismic investigation of Pacific-North America plate interaction in southern Alaska: New York, Columbia University, Ph.D. thesis, 141 p.

1980, HYPOELLIPSE/MULTICS: a computer program for determining local earthquake hypocentral parameters, magnitude, and firstmotion pattern: U.S. Geological Survey open-file report 80-59, $59 \mathrm{p}$.

Lahr, J.C., Page, R.A., and Thomas, J.A., 1974, Catalog of earthquakes in south central Alaska, April-June 1972, U.S. Geological Survey open-file report, 74-1060, $35 \mathrm{p}$.

Lalla, D.J., and Kienle, Juergen, 1978, Evolution of seismicity at Augustine volcano, 1970 to 1976 eruption [abs.]: Geological Society of America Abstracts with Programs, v. 10, no. 3, p. 113.

1986, Seismic and thermal precursors to the 1976 eruption of Augustine volcano, Alaska [abs]: International Volcanological Congress, Proceedings, Feb.1-9, 1986, New Zealand, p. 251.

Latter, J.H., 1971, The interdependence of seis mic and volcanic phenomena: some space-time relationships in seismicity and volcanism: Bulletin Volcanologique, v. 35, p. 127-142.

1981, Volcanic earthquakes and their relationship to eruptions at Ruapehu and Ngauruhoe volcanoes: Journal of Volcanology and Geothermal Research, v. 9, p. 293-309.

Macdonald, G.A., and Eaton, J.P., 1964, Hawaiian volcanoes during 1955: U.S. Geological Survey Bulletin 1171, $170 \mathrm{p}$.

Malone, S.D., and Qamar, A.I., 1984, Repetitive microearthquakes as the source for volcanic tremor at Mount St. Helens: Eos (American Geophysical Union, Transactions), v. 65 , no. 45 , p. 1001.

Matumoto, Tosi, and Page, R.A., 1969, Microaftershocks following the Alaska earthquake of March 28, 1964: determination of hypocenters and crustal velocities in the Kenai Peninsula-Prince William Sound area, in The Prince William Sound, Alaska, Earthquake of 1964 and Aftershocks, v. 2B and $C$ of U.S. Coast and Geodetic Survey Publication 10-3: Washington, U.S. Government Printing Office, p. 157-173.

Mauk, F. J., and Kienle, Juergen, 1973, Microearthquakes at St. Augustine volcano, Alaska, triggered by earth tides: Science, v. 182, p. 386-389.

McDonald, J.A., and Goforth, T.T., 1969, Seismic effects of sonic booms: empirical results: Journal of Geophysical Research, v. 74 , no. 10 , p. 26372647.

Minakami, Takeshi, 1960, Fundamental research for predicting volcanic eruptions (Part I), Earthquakes and crustal deformation originating from volcanic activities: Bulletin of the Earthquake Research Institute, v. 38, p. 497-544.

1974, Seismology of volcanoes in Japan, in Civetta, L., Gasparini, P., Luongo, G., and Rapolla, 
A., eds., Physical Volcanology: Amsterdam, Elsevier, p. 1-25.

Mitronovas, Walter, and Isacks, B.L., 1971, Seismic velocity anomalies in the upper mantle beneath the Tonga-Kermadec Island arc: Journal of Geophysical Research, v. 76, p. 7154-7180.

Mogi, Kiyoo, 1962, The fracture of a semi-infinite body caused by an inner stress origin and its relation to earthquake phenomena, 1: Bulletin of the Earthquake Research Institute, v. 40, p. 815829.

Nagasawa, Ko, 1978, An analysis of sonic boom from a great fireball on May 10, 1977, recorded on seismographs of volcano observatories: Bulletin of the Earthquake Research Institute, v. 53, no. 1, p. 270-280.

Nairn, I.A., Hewson, C.A.Y., Latter, J.H., and Wood, C.P., 1976, Pyroclastic eruptions of Ngauruhoe volcano, central North Island, New Zealand, 1974, January-March, in Johnson, R.W., ed., Volcanism in Australia: Amsterdam, Elsevier, p. 385-405.

Nakamura, Kazuaki, Jacob, K.H., and Davis, J.N., 1977, Volcanoes as possible indicators of tectonic stress orientation - Aleutian and Alaska: Pure and Applied Geophysics (PAGEOPH), v. 115, nos. 1-2, p. 87-112.

Pearson, C.F., and Kienle, Juergen, 1978, A seismic refraction study of Augustine volcano, Alaska: Eos (American Geophysical Union, Transactions), v. 59, no. 4, p. 311 .

Pridmore-Brown, D.C., 1962, Sound propagation in a temperature and wind-stratified medium: The Journal of the Acoustical Society of America, v. 34, no. 4, p. 438-443.

Remsberg, E.E., Browell, E.V., and Northam, G.B., 1976, Lidar measurement of stratospheric dust from St. Augustine volcano: Bulletin of the American Meteorological Society, v. 57, no. 9, p. 1152-1153.

Richter, C.F., 1958, Elementary seismology: San Francisco, W.H. Freeman, 768 p.

Rinehart, J.S., 1965, Earth tremors generated by Old Faithful Geyser: Science, v. 150, p. 494-496.

St. Lawrence, William, and Qamar, A.I., 1979, Hydraulic transients: a seismic source in volcanoes and glaciers: Science, v. 203, p. 654-656.

Sawada, Yoshihiro, Wakui, Senichiro, and Komiya, Manabu, 1982, Atmospheric pressure waves generated by the May 18, 1980 eruption of Mount St. Helens: Bulletin of the Volcanological Society of Japan, v. 27, no. 3, p. 195-202.

Scholz, C. H., 1968, The frequency-magnitude relation of microfracturing in rock and its relation to earthquakes: Bulletin of the Seismological Society of America, v. 58, p. 399-415.

Self, Stephen, Wilson, Lionel, and Nairn, I.A., 1979, Vulcanian eruption mechanisms: Nature, v. 277, p. 440-443.

Shimozuru, Daisuke, 1961, Volcanic micro-seisms-discussion on the origin: Bulletin of the Volcanological Society of Japan, v. 5, p. 154-162. 1971, A seismological approach to the prediction of volcanic eruptions, in The surveillance and prediction of volcanic activity: Paris, UNESCO, p. 19-45.

Shimozuru, Daisuke, Kamo, Kosuke, and Kinoshita, W.T., 1966, Volcanic tremor of Kilauea volcano, Hawaii, during July-December 1963: Bulletin of the Earthquake Research Institute, v. 44, p. 10931133.

Shimozuru, Daisuke, Miyazaki, Tsutomu, Gyoda, Noriya, and Matahelumual, Johannes, 1969, Volcanological survey of Indonesian volcanoes. Part 2. Seismic observation at Merapi volcano: Bulletin of the Earthquake Research Institute, v. 47, p. 969990.

Steinberg, G.S., and Steinberg, A.S., 1975, On possible causes of volcanic tremor: Journal of Geophysical Research, v. 80, no. 11, p. 1600-1604.

Stith, J.L., Hobbs, P.V., and Radke, L.F., 1978, Airborne particle and gas measurements in the emissions from six volcanoes: Journal of Geophysical Research, v. 83, no. C8, p. 4009-4017.

Suzuki, Ziro, 1959, A statistical study on the occurrence of small earthquakes (fourth paper): The science reports of the Tohoku University, Fifth series, Geophy sics, v. 11, 54p.

Tanaka, Yasahiro, 1967, On the explosion-earthquake at the volcano Sakurazima: Bulletin of the Volcanological Society of Japan: v. 12, no. 1, p. 26-40.

Tilling, R.I., Koyanagi, R.Y., and Holcomb, R.T., 1975, Rockfall seismicity-correlation with field observations, Makaapuki Crater, Kilauea volcano, Hawaii: U.S. Geological Survey Journal of Research, v. 3, no. 3, p. 345-361.

Tilling, R.I., Koyanagi, R.Y., Lipman, P.W., Lock wood, J.P., Moore, J.G., and Swanson, D.A., 1976, Earthquake and related catastrophic events, island of Hawaii, November 29, 1975: a preliminary report: U.S. Geological Survey Circular 740, 38 p.

Trapp, G.H., 1976, A look at some unusual convective activity associated with volcanic eruption: National Weather Digest, v. 1, no. 1, p. 25-29.

Warren, N.W., and Latham, G.V., 1970, An experimental study of thermally induced microfracturing and its relation to volcanic seismicity: Journal of Geophysical Research, v. 75, no. 23 , p. 4455-4464.

Wilson, C.R., and Forbes, R.B., 1969, Infrasonic waves from Alaska volcanic eruptions: Journal of Geophysical Research, v. 74, no. 18, p. 4511-4522.

Yamashina, K.I., and Nakamura, Kazuaki, 1978, Correlations between tectonic earthquakes and volcanic activity of Izu-Oshima volcano, Japan: Journal of Volcanology and Geothermal Research, v. 4, p. 233-250.

Yokoyama, Izumi, 1971, Volcanic eruptions triggered by tectonic earthquakes: Geophysical Bulletin of the Hokkaido University, v. 25, p. 129-139.

Yoshidome, Michiya, and Seino, Masaaki, 1968, A study on air vibration caused by volcanic explosion: Bulletin of the Volcanological Society of Japan, v. 13, no. 3, p. 141-149. 
